

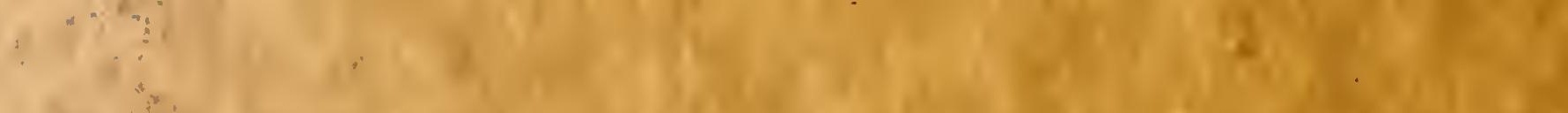

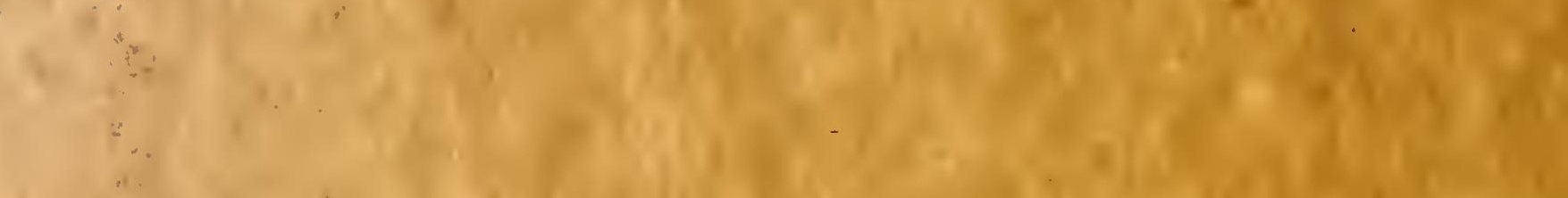

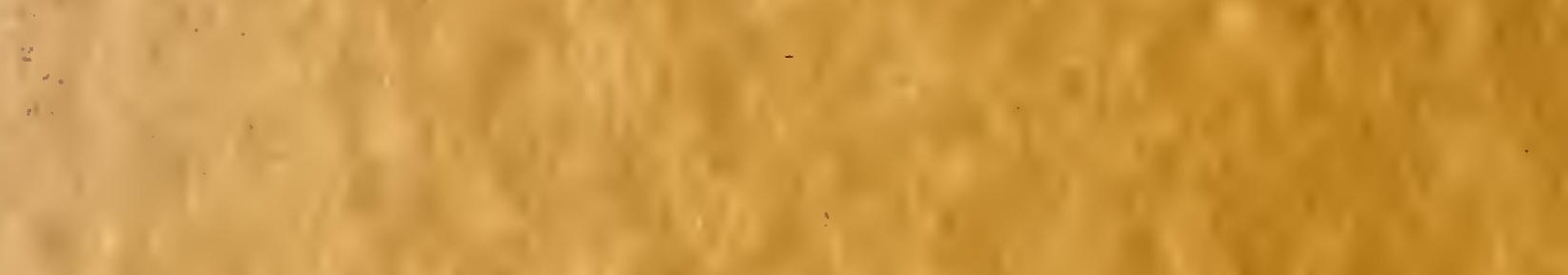

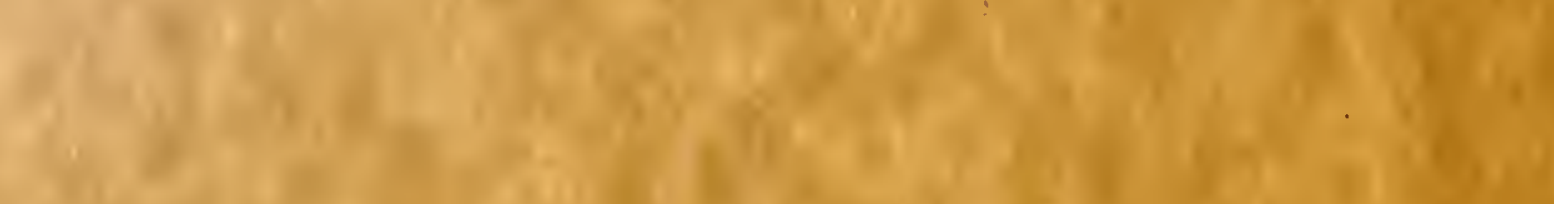

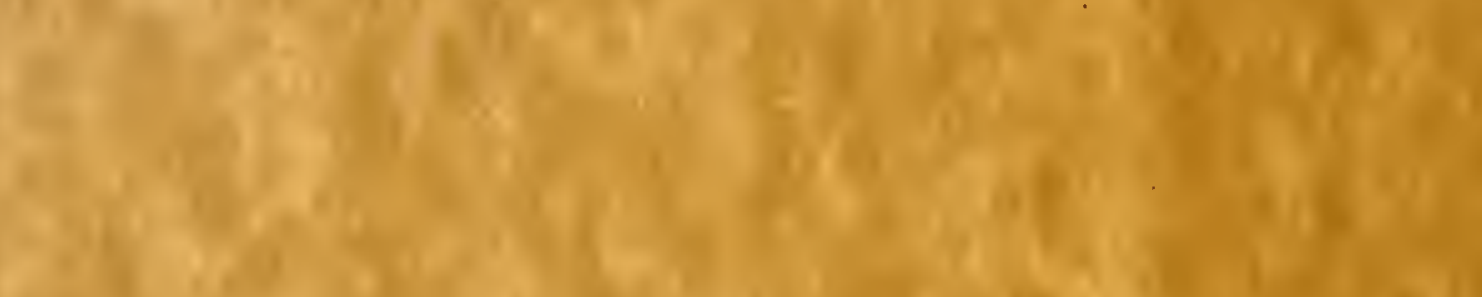

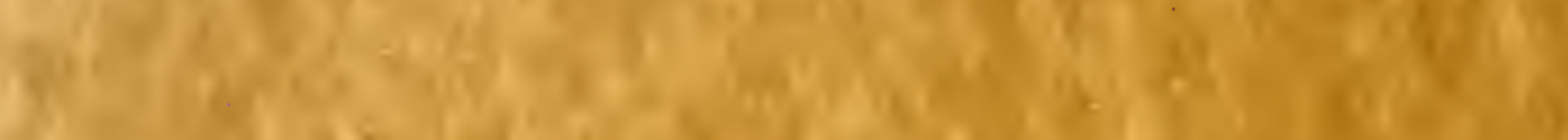

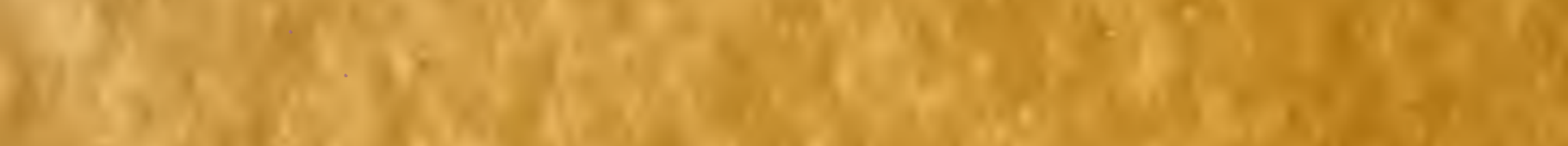
(2)

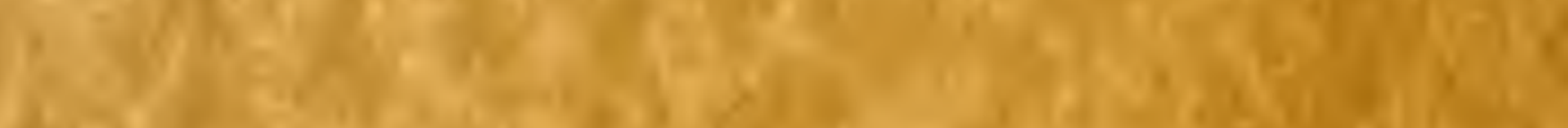

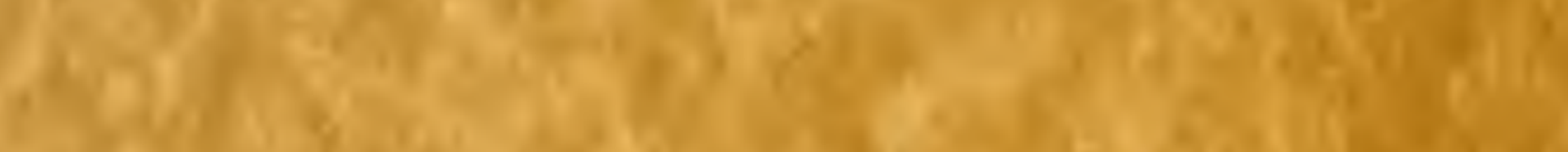
$8+1+x+1$

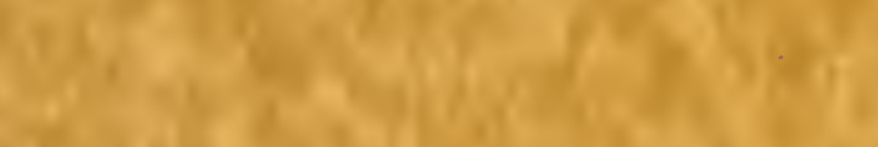

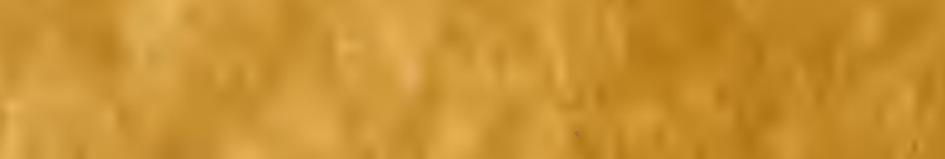

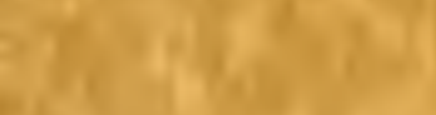

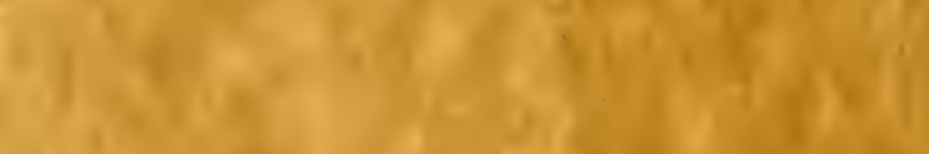

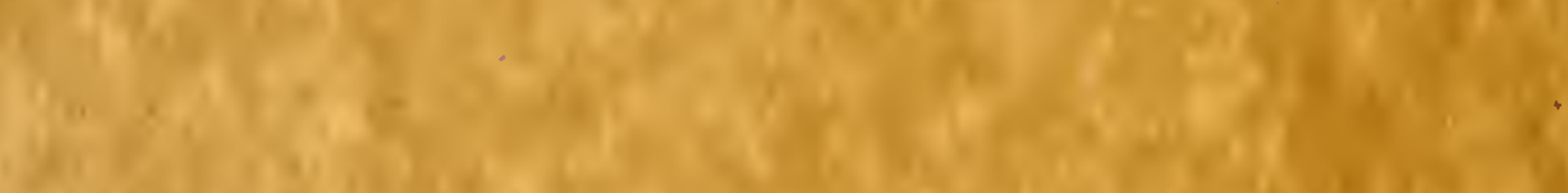

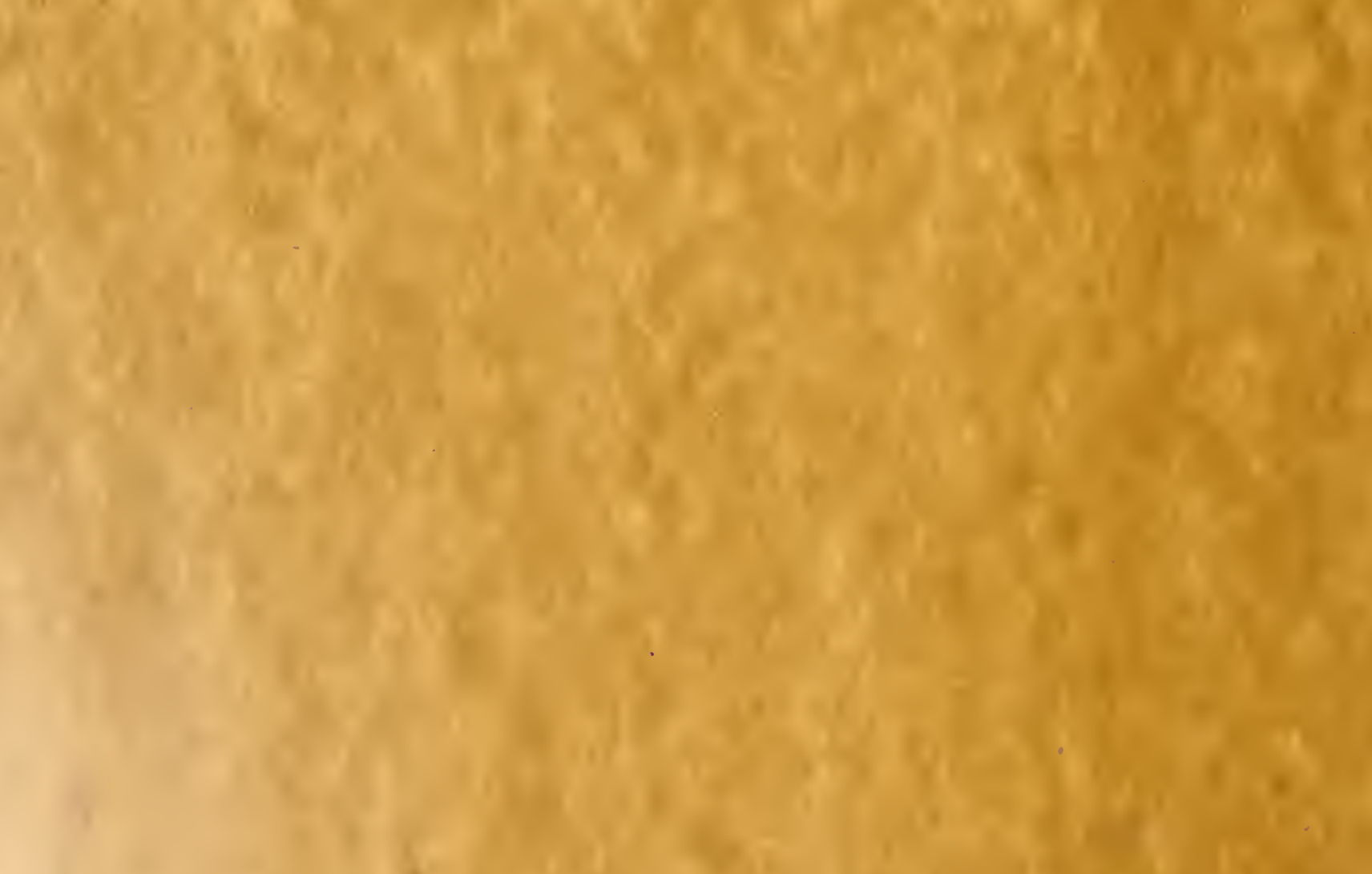


ACTA SOCIETATIS SCIENTIARUM FENNICAE TOM. XXXVII. N:O 4.

\section{ZUR KENNTNIS}

DER

MIRIDEN-UNTEREAMILIE CYLAPINA REUT.

VON

B. POPPIUS

(MIT EINER TAFEL)

BUREAU OF

AMERICAIN ETHINOLOGY.

19:0

Lesengerex.
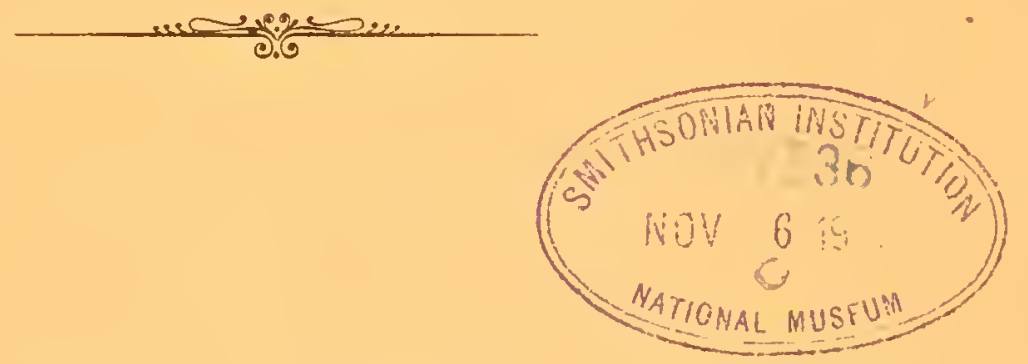
ACTA SOCIETATIS SCIENTIARUM FENNICAE TOM. XXXVII. N:O 4

\section{ZUR KENNTNIS}

DER

MIRIDEN-UNTERFAMILLE CYLAPINA REUt.

VON

B. POPPIUS

(MIT EINER TAFEL)

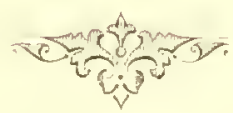





\section{Vorwort.}

In der letzten Zeit nit ier Classifation ier Capsirlen beschäftigt, hatte Herr Prof. 0. MI. Retter von verschielenen Museen ein sehr reichescxotisehes Naterial erhalten. Durch Frblindung liat er aber das grusse Material bei weitem nicht durcharheiten können. Auf Anregung des Herm Prof. Reuter's unternahm jeh eine Bearheitung des vorhandenen Materials der Unterfum. Cylapina und lege ich hiermit die Resultate ler offontlichkeit vor. Für die Liebenswiurdigkeit mit der Prof. Reuter meine Arbeit unterstütat hat, speche inh ihm meinen aufrichtigsten Dank ans.

Der Verfasser. 



\section{Sulfanin. Cylapina Reut.}

In einer balk erscheinenden Artheit „Nene Beiträge zur Systematik der Miriden" hat Prol. O. M. Reuter die Mirilen in mehreren Unterfanilien eingetheilt, darunter anch die "harakteristische und leicht kemnthehe Tnterfam. Cylapinu, die dir früheren Divisionen Cylapara Reгт. und Fulriuria Reut. umfasst. Als tör die subfamilio charakteristisch sei folgendes hervorgehoben:

Thie Tarsen foin und lang, das erste Glied wenigstens etwa ebenso lang wie the zwei letzten zusammen. Jin Klanen meistens fein, seicht wehogen, immer ohne Arolien. Die Schienen sind fein und lang, meistens zur Suitze vershmïlert, selten gleich breit, nur bei

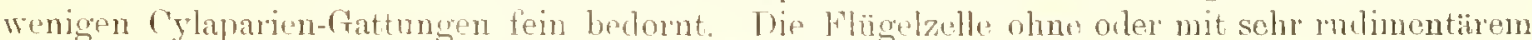

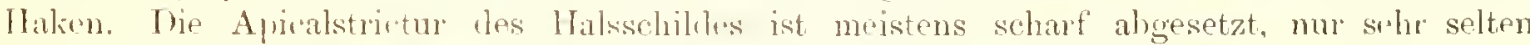

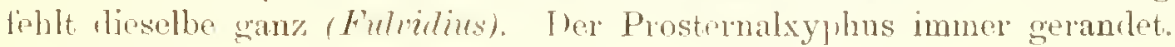

\section{Divisio Cylaparia Reut.}

Reut. Classif. 1. Capsic., 1905, p. 19. - Ann. naturh. Hofm. Wien, XXIr, 1907, p. 76.

Der Kürper meistens zrestreckt. Die Flügelzelle ohne Halien. Der Vorderturustxyphus an den Seiten frin gerandset. Dio Schienen schmal, selten mit teinen Dörnchen bewehrt, zur Spitzr etwas verschmälert, lang. Ije Füsse sehr dünn und fein, das erste Glied lang, ebenso lang oder länger wir die zwei letzten Gliesler zusammen. Der Kopf ist meln oder weniger vertical, selten fast horizontal (Khmocylapus), oft sogar sehr stark vertieal, meistens stark rorgezogrn und zugespitzt, lie Angen immer gross uncl vorspringend. Die Stim in der Mitte mit einer Längsfurche. Die Apicalstrietur des Pronotum ist dentlich, inmer vorhanien. Die Calli kurz, zuweilen sehr stark ansgeliklet, selten bis zur Mitte der Scheibe sich erstreckent. Die seiten sind ungerantet, sehr selten mit schwach atgesetrten Rändern. Die Fühler sehn lang, die zwei letzten Glieder sehr dïnn, lang.

Die Cylaparien sind eng mit len Fulviarien verhunden, indem bei mehreren Gattungen ler Kopf oft stark horizontal ist und in dieser Hinsicht an lemselben dor. Fnlviarien erinnemu. Von fast horizontalem Kóple zu einen vollsummen verticalen haben wir eine schöne Reihr

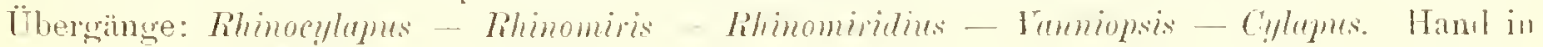

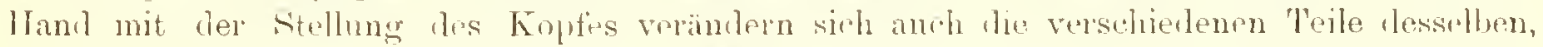

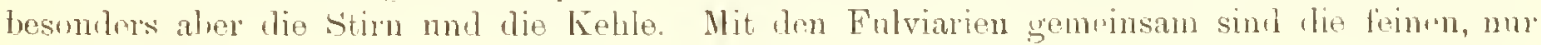


Lin und wienter hedornten Schienen, die bei den Fulviarien immer unbewhrt sinu, sowie Jie foinen Füsse, deren erstes Glied lang ist. Der einzige Untersuhied der beilen Divisionin, die vielleicht müssen zusammengeschlagen werden, ist die sehr langen und dünmen Fühler Jur Cylaparion, deren zwei letzten Ghedes sebr dünn unt ansserdem ziemlich lang sinı. Dieser Unterschied ist jedentalls nieht ganz scharf, in dem wir bei der Fulviarien-fiattung Cylapofulius ebenfalls lange und diunne letzte Fiihlergliefer haben. Wir scheint es larmm nicht ganz richtig, diese beiden Divisionen vom einanıler zu trennen.

Die Cylaparien sind sehr weit verbreitet. Sie sind aus allen Faunen-frebieten, das fralæalktische ausgenommen, hekannt und scheinon ihre grösste Entwickelung in den indomalaischen Archipel zu erreichen. Von hier sind nicht weniger als vier Gattungen mit 9

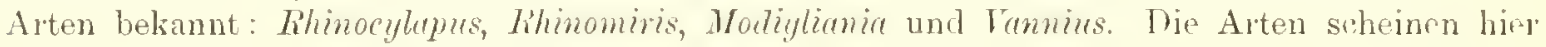
nur beschrinkte Verbreitungsgebiet? zn haben. Tom Festlande sind nur zwei RlimomirisArten bekannt: Fh. ricerius und intermedius. Ton Sumatra ist nur Modiglienia elongater und lihinocylapus sumatramus fiekannt. Auf Borneo lebt eine andere Alt der litzten Gattung. Rh. acufungulus und anf der lileinen Inselgruppe Mentawei eine dritte, Rh. simplicicollis, wo aussertem hhinomiris cumelus und Modigliuniu cuneulis nachgewiesen worden sind. Anf NenGuinea ist bis jetzt nur eine limnius-Art gefunden worlen, $V$. lrevis. Diese Gattung ist ausserdem anch auf Marlagaskar repräsentiert: I. annulicomis. Aus drm afrikanischen Festlande ist nur eine Gattung mit einer Art gefunden, lie hier jedoeh eine grosse Vertneitung in den westlichen equatorialen Teilen hat: Rhinomiridius acthiopieus. Eine sehr eigrnthïmliche, abweichende Gattung mit einer Art lebt auf Jen Nen-Hubiden. Ans der nenen Welt kemen wir zwei Gattungen, erstıns lamius, hier mit $V$. nubronittates und crassicomis reprisentiert, die sonst tin sehr grosses Verbreitungsgebiet hat. Ganz besonders aulfallend fï̌r sowohl dir nearktische, wie besonters die neotropische Rergion ist die trattung Cylupus mit seinen zahlreichen Arten.

Übersielit der Giattungen.

1. (8). Der hopf wenigstens otwas horzontal, die Stion nicht sehr kurz, allmühlich abfallent.

2. (3). Der Kopl' kurz und zur Spitze wenig vorgezogen, abgerundet.

Modiglianiu n. gen.

3. (2). Der Kopf gestreekt, immer spitz vorgezogen.

4. (5). Der Kof stark glänzend, fast horizontal, ilis Augen kleiner.

Rhinocylapus n. gen.

5. (4). Der Kopf matt, mehr oder weniger geneigt, die Angen grösser, stärlker vorspringend.

6. (7). Ler Körper sehr gestreckt, der Kopl" stark vorge\%gnn, Weniger geneigt, las erste

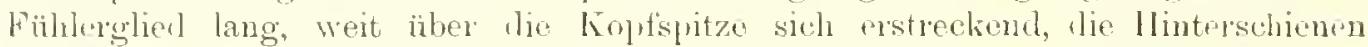
länger als die Hinterschenkel.

Rhinomiris Kirk.

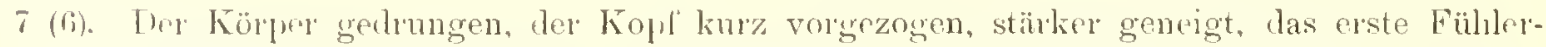
glied kur, die Kopfspitze nicht iibersehritemd, die Hintersehienen nicht länger als die llintersihenkel.

Rhinomirilius n. gen.

s. (1). Ther Konf suth stark rortical, senkrecht orler mit der Spitze nach hinten geneigt. 


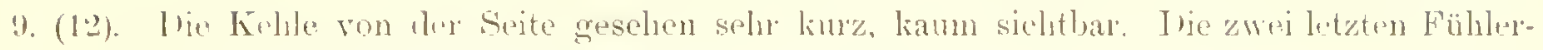
ulieder gleich lick, sehr dium.

10. (11) Derr Kür]er grüsser, nie gelb unl rot gefärlut.

C'ylupue: SAY.

11. (10). Jher Körper klein, gell, mit sehön roten Flecken.

linnius Inst.

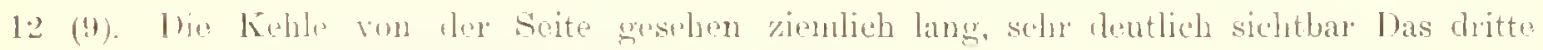
Fiillerglical etwals dicker als das vierte.

linmiopsis n. gen.

Modigliania n. gen.

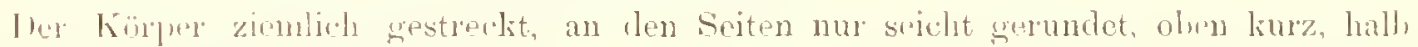

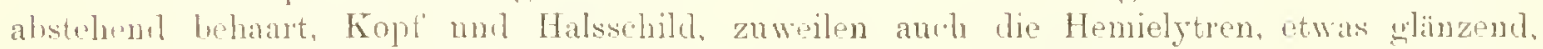

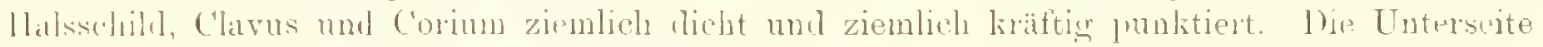

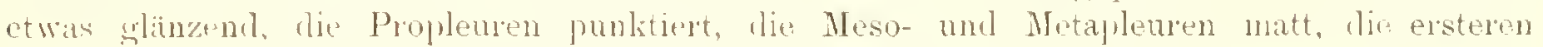

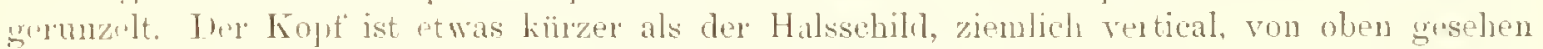

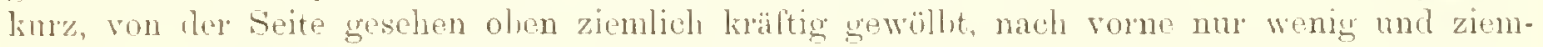
lich breit zugespitzt vorgezogen, die Kehle missig lang, die Zürel breit, unten undentlieh alugrestzi. Tir Augen sincl gross und starli vorspringend, hei weitem die Kehle niclit erreiehend.

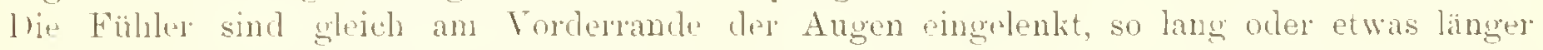

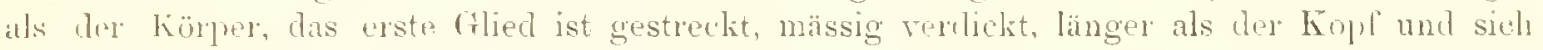

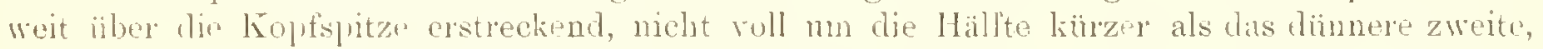
die zwei lotzten sehn dïnn, haarfoin, las vierte nur wenig kürzer als das dritte. Die Stirn in dej Mitte de länge nach fein gefurcht. Das Rostrum erstreckt sich fast bis zum letzten Ventralsegment, das prste Glied ist länger als der Kopf, nur etwa mo $1 / 4$ kürzer als das zweite.

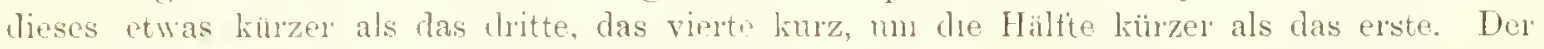
Halsschilu ist transversal, die Hinterecken nicht rorspringend und schwach abgerundet, die Seiten in der Mitte sehr seicht ausgeschweift, der. Seitenrand sehwach alygesctzt. die Strictura apricali selunal, aber scharl, die Calli, wie die Scheibe iberhaupt, ziemlich convex, sich nach hinten bis zur Hitte der Seheibe erstrecliend. Die Hemielytren beim o" länger, beim f ebenso lanı wio der Hinterlörper, der Cuneus ist dentlich abgesetzt. The Bejne sind kurz anliegend behart, dic Schipnen etwa ebenso lang wie die Schenkel.

Steht der. Gattung Khimomiridius m. nalue, unterseheidet sich von dieser, wie ron allen amleren beliannten Cylaprarien-Grattungen duelı dru Bau des Kopfes.

Ty\}rus: M. cuncalic n. sp.

\section{Modigliania elongata 11 . sp.}

Gestreckt, dunkelbraun, der Kopt linten und die Kelile, auf dem Halsschiltle die Calli, ein F'lechchen jederseits auf' der Mitte dre scheibe, ein Längsstrich in der Mittr der Basis, nach vorne bis zu den Calli sich erstreckend, und der Basalrand schmal gelburam, dias Schildchen

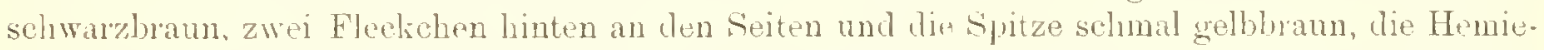
lytren dunkelbraun, die Mitte breit nud der Aussenrand seln schmal, auf dem Corium die Basis und der Innenrand selur schmal, ein Selmaler Quertleck in der Nitte, der nach hinten strichförmigr verlängert ist, die innere und diø äussere Apicaleck yolblich, die Basis des cuneus schmal

Nio 4. 
grelbrot, diu Nemlian immithall, des Conens heller. Die Unterseite gelb, die Pro- und Mlesopleuren und die Seiten des Hinterkörjer's brann. Dio Fühler braungelb, das erste (thlied heller, die Basis des dritten Gliedes schmal weiss. Das Rostrum gelbbram (die Beint, mutilliert).

Der Kopf mit den Augen ist breiter als die Spitze des Halsschildes, die Stim otwa doppolt breiter als der llurhmesser des Auges. Das erste Fühlorglied etwa ebunso lang als die Breite der Stirn unit den Augen, das zweite etwas länger als ier Basalrand des Halsschildes breit. 1)er Halsschilı ist am Basalrande etwa 1/4 breiter als in der Mitte lang, convex, the Seiten etwas vor den spitzen, schwach abgerundeten Hinterecken seicht ausgesthwoift, von hier his zur spitze fast seradlinig verengt, der Basalrand etwa doppelt broiter als der Apicalrand, in der Mitte nach hinten sehwach vorgezogen, jederseits sehr seicht ansgesthweift. I) Calli transversal, ron einander durch eine deutliche luänsturche getrennt. Das Schildelen ist hinter der Basis der Quere nach gefureht, hinten sehwach convex. Die Hemielytren sind beim etwas länger als der Hinterkörper, der Cunens etwas länger als an der Basis breit. - Long 7, lat. 2.5. $111 m$.

Sumatra: Si-Rambé!, XII. 1890 - 111. 1591, b. Modrguan, 1 o (Mus. Cis Genor.).

Modigliania cunealis n. sp.

(Fig. 1-1 a.).

Ziemlich gedrungen, der Kopf gelh, die Stirn vorne, der Clypeus und die Zijgel braun-braumscharz, der Halsschiłel hrannsehwarz, die Calli und der Basalrand schmal yell, las Schildehen sehwarz, zwei in der. Mitte zusammentliessende Elecken hinter dor Mitte rotgelb, die äusserste Spitze grelb, der Clavus braunschwarz, hinter der Mitte innon und der Aussenrand sehmal gelb, das Corinm gelb, vorne vertunkelt, ein grosser Fleck, der sich hinten bis zum Apicalrande ausdehnt, den Seitenrand aber nieht erreicht und nach rorne sich fast bis zur Mitte erstreckt, schwarzluaun, der Cuneus gell, die Menluran schwarzbraun. Die Bröste braun-braunschwar, die Pro- und Mesopleuren hinten sehmal, die Metapleuren rorme lueit gellurann. der Hinterkörper gelh, die vorderen Segmente an den Seiten ganz, die hinteren an der Apicalhälfte brannschwarz, das vorletzte Segment dunkel, nur die Spitzo selbbraun, das letzte Segment einfarbig gelb. Die Fiihler lraun-braunsehwarz, das erste Glied, das Rostrum und die Beine gelbbraun, das dritte Fühlerglied an der Basis sehr schmal gelbweiss.

Der Kopf ist nur wenig kürzer als der Halsschild, die Stirn mit den Augen deutlielı breiter als dor Vorderrand desselben, die Stirn doppelt breiter als der Durehmesser des Auges. Das erste Fühlerglied ist etwa um 1, kïrzer als die Breite der Stirn mit den Augen, das zweite etwa 1\% länger als der Basalrand des Halsschildes breit. Der Halssehild ist in der Mitte ungefähr $1 / 3$ kïrzer als die Breite des Basalrandes, ziemlich convex, die Hinterecken sind stumpfer, die Seiten seichter ausgeschweift als bei elonguta. Der Vorderrand nicht roll um die Hältte schmäler als der Basalrand. Sonst wie bei ler genannten Art greloaut. Das Sehildchen ist wie bei elongatu, nu ist dasselbo hinten weniger convex. Jio Hemielytren sind beim $\sigma^{x}$ etwas länger, beim $f$ ebenso lang als der Hinterkörper. Der Cuneus ist etwa ebenso lang als an der Basis breit. - Long. 4.9-6 mm., lat. 1.6-2.3 $\mathrm{mm}$.

Unterscheiclet sich ron $M$. elungata m. u. a. durch gednungenere Körperform, etwas gewöbteren Halssehild rnd durch andere Farbenzeichnung.

ms. Mentawei: Si-Oban!; Sipora, Sureinu!, IV-VIll. 1894, MondiLiani, zahlieiche Lixemplare (Mus. Civ. Genov. et Helsingr'.).

Tom. IXXVII. 


\section{Rhinocylapus n. unen.}

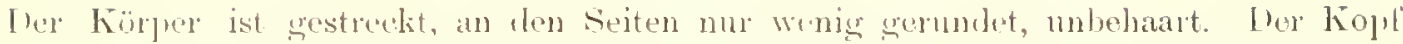
ist fast horizontal mit sely. Wenig abfullender stirn, schmal mol stark zugespitzt vorgerogen, oben glatt nnd stark glinzend, unten matt und chagriniert, die Augen gross und vorspringent, von oben geseluen rundliels oval, nach unten bei weiten die Kehle nicht erreichend. Wie

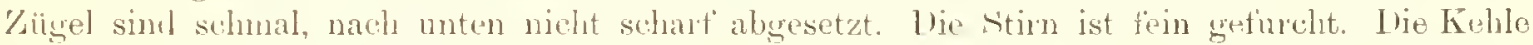
ist lang, der länge nach lein grekielt. J)e Fühler sind ziemlich weit vor dun Augen eingulenkt, etwa ebenso lang wio ler Kör|rer, das erste (ilied ist grestreckt, mässig verdickt, ehenso lang oder twas kürzer als der Kopt, weit äber die Kopt'spitze sieh erstreckent, mit

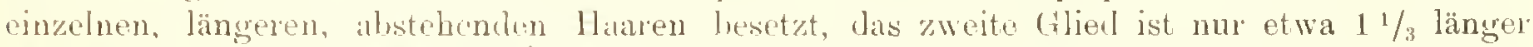
als las 'rste, schmäler als risscelbe, zur spitze alluählich verlickt und hier schwach gestreckt

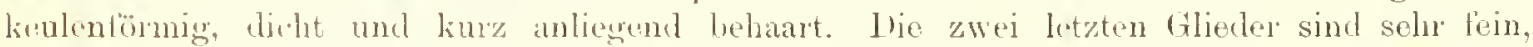
das letzte abenso lang wie das zwote, das dritte etwas lïnger. Las Rostrum erstreckt sich

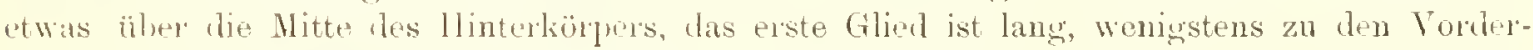
hüilten sich erstreckent. Der Halssehild ist ziemlich slianzend, mehr od weniger convex, linter den calli mehr oder weniger scharf eingeschnürt, hinter der linschniurung dieht umd kriltign punktiert, nicht lneiter als in der Mitte lang. Die Seiten laben eme sebr unclentliche Kimte und sind an der cingesehnïrten Stelle nehr onler weniger ansgeschweilt. Die Basis ist fast gerate abgesthnitten. I hie Strictura aphicali ist schmal, aber scharf. Die Calli erstrecken sich nach hinten fast bis zur Nitte ler scheibe und sind nur hinten dureh pine auch weiter angen dits Basis sich fortsetzencle l'urehe getrennt. Die Hemielytren sind dicht und krältig

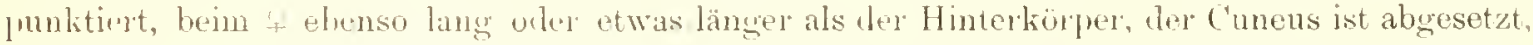
liinzer als an der Basis breit. Ilie Unterseite ist nur sehn wenig ölänzend, die Proplenren

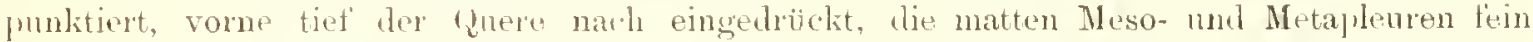
grenuzelt. Die Beine sind mässig lang, mehr oder weniger dicht abstehend behart, die sinienen etwas langer. als die sechenkel, unbedornt.

Steht wohl der Gattung lihinomiris Kirk, an nächsten, unterscheidet sich aber von dieser, wie von übrigen Gattungen besonders durde den eigenthiimlichen Bau des Koples.

Typus: Rh. simplicicullis n. s1'.

Ḯbersiclit der bekannten Arten.

1. (2). Las zweite Fühlerglied gell, las apicale Viertel sehwarz.

stumatrumes 11. sp.

․ (1). J Jas zweite Fühlerolied sehwarzbraun-schwarz, linter der Mittr mit einem hreiten, grelbengelbweissen Ring.

3. (1). Der Halsschild hinter den Calli schwach der Quere nach eingeselnärt, die Calli nur wenig conrex, das sohildithen flach.

simplicicollis n. sp.

4. (3). Her Halssehild hinter den Calli sehr krätig eingesedniñt, die Calli seln stark conves, buckelfüruig, das Schildchen hinter der Mitte burkellörmig erhaben.

acutentulus n. sp.

Rhinocylapus simplicicollis $\mathrm{n}$. sp.

(Fig. 2-2 a.).

Braun, der Kopl, das Suliddelın and die Brïste schwarzbram, ein Fleckchen jederseits und die Spitze des Schildhens, die imnere Apicalecke des Coriun, der Cuneus und die N:o t. 


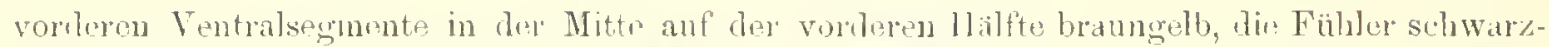
Jraun, das zwejte Glien hinter der Mitte mit etwa $1 / 3$ seiner Iänge gelbweiss, die Coxen und die Silienkel dunkelhraun, die Selhinen und die Füsse etwas heller.

The Stim ist kaum doppelt lreiter als der Inurchmesser des Auges, das erste Fülılerolied etwa $1^{1 / 3}$ länger als die Breite der Stirn mit den Augen, das zweite Fühlerglied ist etwas Jängrey als del Basalnand des Halsschildes breit. Das Rostrum erstreckt sich über die Mitte des Hinterkörpers, das erste Glied ereicht etwa die Nitte der Vordercosen, das zweite Glied ist etwa $1 \frac{1 / 4}{4}$ länger als das erste, das dritte ungefäbr $2 /$, kiirzer als das zweite. D(1 Halsschild ist gestreckt, dentlich länger als breit, am Vorderranile melu wie um die Hälfte schmäler als am Hinterrande, viel schmälel als der Kopf mit den Augen. Irie basis ist in drr Mitte fast geralle. vor den Hinterecken etwas nach vorne grebogen, wodurch diese ein wenig vorspringend rsclicinen und rechtwinlielig sind. Gleich imerhalb dru Hinterecken ist die Schejbe seicht eingelrizclit. Die Scheibe ist mässig convex, hinter den von der Ungebung nur wenig rrlabenen und undeutlich begrengten Calli schwach eingeschinirt, wodurel die Sejten nur seicht ausgesehweift erscheinen. l)ie Randung der letzteren ist hinten ziemlich dentlich. Das Sehildchen ist sehr wenig convex. Die Hemielytren sind beim $\sigma^{7}$ länger als drer Hinterköruer, ofler Cuneus viẹ diürzer ats an der Basis breit. Dr. Beine sind ziemlich dieht, hall, abstehend behaart. - Long: 7, lat. $2.5 \mathrm{~mm}$.

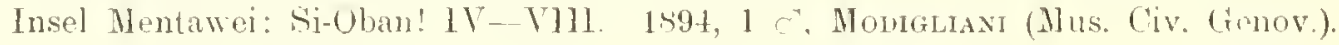

\section{Rhinocylapus sumatranus n. sp.}

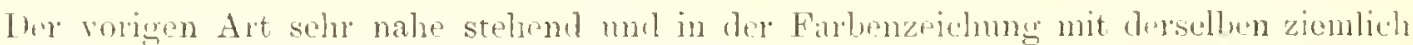

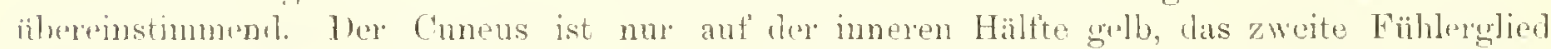

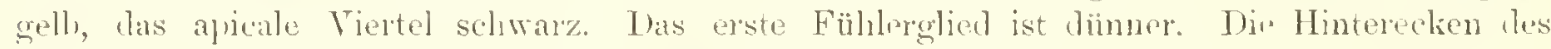
Halsschikes sind melur alygerundet und wenicrer vorspringend, die Scheibe ist hinter den convexpren und deutlicher abgesetzten ('alli scharl" der Quere nach ringesebnürt, woumrelı die suiten meln ansgeschweift erscheinen. Beim sind die Hemielytren etwas länger als der Hinterkörjer. Grösser, - - Long. 9, lat $3,2 \mathrm{~mm}$.

Sumatra: Liangagas !, 1 , DoHrs (Mus. Stettin).

\section{Rhinocylapus acutangulus n. sp.}

1)er ganze Körper einfarbig brann, etwas heller als bej den vorigen Arten, nur die Membran ist braunschwarz. Ire Zejchnungen wie bei sumutroms, die Fiihler wie bej simplicicollis, nur die Grundlarbe ist leller. Die Brine pinlarbig braunrot. Die Hinterecken des Halsschildes sind scharf, vorsuningend und etwas mach oben gerichtet, die Einschnürung ist sehr kräftig, die Seiten von hier nach vorne convex gerundet. Die Calli sehr stark convex, mit einander ganz zusammenfliessend, buelolförmig. Das Sehildelien hinter der Mitte stark buckellörmig erhaben. Ilie Hemielytren brjm q ebenso lang wie der Hinterkör]er. - Long. 8 , lat. $2,5 \mathrm{~mm}$.

Borneo: Sarawak!, 1 f, G. Doria, 1566 (Mus. Civ. Genov).

\section{Rhinomiris Kirk.}

Kirk. Trans. Ent. Soc Lond. 1!002, 1. 268, pl. V, fig. 6, pl. V1, fig. 14. - Mist. Fiun. Brit. Ind., Rlyyncl. II, p. 426. - Reut. Bemerk. Nearct, Caps., p. 65. 
Thersicht der Arten.

1. (2). The Lalsschild hinter den Calli zimnlich sthwach, an len Seiten stärker, in der Mitte surshtre einunsehnürt.

miearius (Walk.).

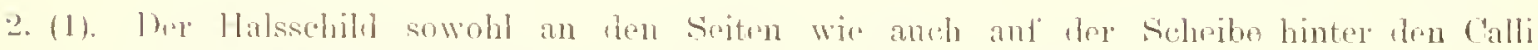
sehr stark ringresselniirt.

3. (t). Die (alli zientich stark burkelartig gewölbt, das Seliblichen vor der spitzo schwach antigntrielon.

intermolins n. sp.

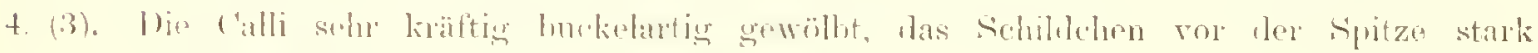
antigetrieluen.

camelus: n. sp.

Rhinomiris camelus n. sp.

Sohr gestreckt und sehmal, die lleminlytren parallelseitig odep nach hinten sogar soll wach versehoülert, matt, weitlïnfig und kurz, halh abstelsend hehaart. Kopf, Halssehild und

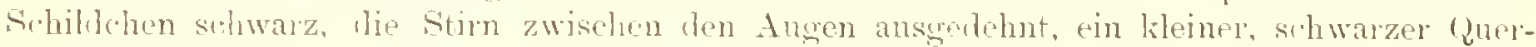
makel ansuenommen, und cin längsstrich jederseits an der L'nterseite gell, ein schmaler, schief der Gnere nach gestellter Strich etwas ror den Angen geltrot. Auf dem Halsschilde die Strictura apricali, der Seitenrand sehr schmal, ein selr schmaler Iängsstrich in der Mitte. "inige nnregelmässige Flecke anf' den Calli und die ganze Basalhalfte oben gelb. Dio Basis des Schith hens loranngelb durchschimmernd, ein Längsstrich in der Mitte, in die Spitze anslau fend, und ein Querstrich jederseits an der Basis yelb. Dex Clavis ist gethbraun, an der Basis, in der Hitte linil vor del Spitze schwarz, an Anssenrande ein schwarzer Längsstrich, der von gelbbraunen Fleckeluen untelurochen ist. Das Corium ist schwarz, innen etwas hinter dir Alitte lrann durchschimmernd, der Seitenram, der Spitzenrand in der Mitte und mehrere, in Isängsreihen georinete, znweilen mit einanler zusammentliessende Fleckchen grelbraun. Der Cunens schwarz, an Aussenrande und an der Basis brann. The Unterseite braunsehwarz, die Orificien und Flecken an den Seiten der Ventralsegmente gelb. Die Beine braun, der lintere Teil und ein Fleck rorne an der Basis der Tordereoxen, the Spitze der Nittel- und die Apicalhähte der Hintercosen und die Tarsen gelb, ein Ring an der Basis, ein vor der Mitte, ein vor der spitze und diese letztere selbst anf den Schenkeln und ein Ring gleich hinter ler Nitte der Tibien gelbrot, das Rostrum brann, die Finhler loraunschwarz, das erste Glied und die Basalhältte des zweiten gelb, die Basis des dritten ziemlich schmal weiss.

her hopl ist schmal und vorgezogen, zugrespitzt, fast horizontal, kanm kïrzer als ter Halsschild. die Stirn ist ebenso breit als der Turchmesser der grossen und vorspringenden, ron oben gesehen rundich eiförmigen, von der Scite gesthen die Kohle nicht erreichenden Angen. Ire Fühler sind fast an Vorderrande der Augen eingelenkt, dünn und sehr lang, das erste Gilierl nur sehr wenig verlickt, etwa dopprelt länger als die Breite der stirn mit den Augen. Das zweite Glied ist diinn, nicht roll doppelt länger als das erste, doppelt 3ängrer als der Basalrand des Hals. selihles. The zwei letzten ftlieder sind gleich dick, rünn und fast haarfein, viel dünn'r als das zweite, das dritte etwa um $1{ }^{1 / 3}$ länger als dasselle, das vierte Glied kurz. Das Rostrum

1. c., f. $2-1: 3$,

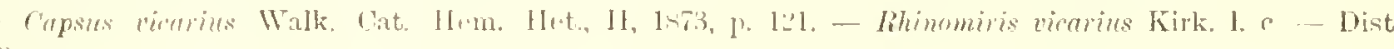

$\mathrm{N}: 0+$ 
erreicht fast die Spitze des Hinterkörjers, das erste Glied ist deutlich länger als der Kopf, etwa um clie Hälfte kürzer als das zweitค, diesos nur wenig länger als das dritte. Der Halsschilcl ist in der Nitte etwa ebenso langr als die Breite des Basalrandes, dieser mehr wie doppelt breiter als der Vorderrand. Die Scheibe ist kräftig gewölbt, etwa in der Nitte kräftig eingeschnürt, die Seiten zur Einsehnürung von der Basis stark, geradlinig verengt, von der Einschnürung zum Vorlerrande erweitert und halbeirkelförmig gerundet. Die Hintereeken sind spitz, nicht vorspringend. Die Strictura apicalis ist schmal, aber deutlich, die Calli sind seh. stark, gemeinsam gewölbt, von der Seite gesehen einen kräftigen Buckel bildend, der' vorne oben winkelig ansgeschnitten ist. Das Suhildchen ist vor der Spitze von der Seite gesehen winkelig aufgetrieben. Die Hemielytren überschreiten sowohl beim 우 wie anch

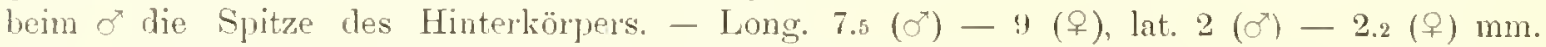
Unterscheidet sich von Rh. vicarines (Walk.) sofort durch den gestreckteren und schnnïleren Körper, durch den merkwürdigen Ban des Halsschilrles, durch anders gebautes Schildchen, längeren, mehr vorgezogenen Kopf, lurch längre und anders gefärbte Fühler.

Insel Mentawei: Si-Oban!, Sipora, Sereinu!, IV-Vl[t. 1894. Modigliani (Mus. Civ. Genov. et Hels.).

\section{Rhinomiris intermedins $11 . \mathrm{sp}$.}

Stimmt in ler Farbenzeichnung und in der Körperform gan\% mit Rh. camelus n sp. äberein, unterscheidet sich aber dureh das erste Fiihlerglied, das rotbraun und nur an der Basis gelb ist; die Calli sind von der Seite gesehen nu schwach und gleichförmig gewälbt, ohne Ausschnitt vorne auf der Oberseite. Die eckig aufgetriebene Stelle auf dem Srhildehen ist. kleiner. Die Unterseite des Hinterkörpers ist in der Nitte ansgedehnt hell gefärbt. Ton lih. vicurius (Walk.) zu nnterscheiden durch den schmäleren und grestreckteren Körper. durch den in der Nitte stark eingeschnürten Halsschild, dessen Calli kräftiger gewölbt sind u. s. w. Long. 7.5 , lat. $2 \mathrm{~mm}$.

Ein schlecht erhaltenes of aus Mittel-Tonkin, Tuyen-Quan!, 1901, A. Werss (Mus. Paris).

\section{Rhinomiridius n. gen.}

Der Körper ist ziemlich gestrungen, an den Seiten gerundet, mässig gewölbt, matt, sehr fein chagriniert, oben kurz und anliegend, weitlänfig, unten etwas länger und dichter hell behaart. Der Kojf ist ziemlich stark geneigt, gestreckt dreieckig vorgezogen uncl mässig. zngespitzt, die Angen gross und vorspringend. Die Zïgel sind ziemlich sehmal, dentlich begrenzt, die Kehle mässig lang, von der Seite gresehen etwas huckelig auluretrieben. Die Fühler sind gleich vor ten Augen eingelenkt, sehr lang nnd dünn, ziemlich viel länger als der Körjer, das erste Glied schwach verdickt, liurz, etwa um die Hälfte kürzer als der Kopt, das zweite Glied nur wong dicker als die bejien letzen, etwa dreimal länger als clas erste und $n \mathrm{~m}$ dir Hälfte kürzes als das dritte, alle Glieder sehr kmrz, anliegend behart. has Rostrum erstreckt sich etwas über die Nitte des Hinterköryers, das erste Gliel erstreckt sich zu den Vorderlü̈ften und ist ebenso lang wie das zweitr, las dritte ist um die lälfto liürzor, das letzte deutlich länger als das erste. Dry Halsschild ist am Basalrancie nur wenig breiter als in ler Mitte lang. Dio Hintereken sind sticht alggerundet, nicht vorspringend, die Seiten etwa in ler Nitte seicht ausgeschweitt. Dhe strictura apicalis ist schmal, aber sehart, "lie

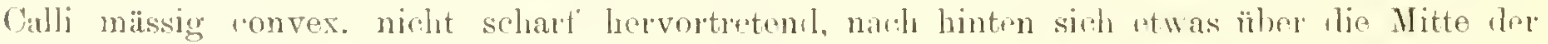
Stheibe erstreckend. Das schihlehen ist hinten convex. Die Hemielytren sind in beithen 
(iucchl chtern ctwas längre als der llinterkörper, ler C'nneus nicht alugesetzt. Die Schienen sind nur wenig längr als die Schenkel, wie die letzteren aussen auf den hinteren Brinin kurz beborstet, ansserilem anliegend bohaart.

Nahe verwandt unt lihinomilis Kirk. Der Körper ist copdrungen, der Kopl stärker

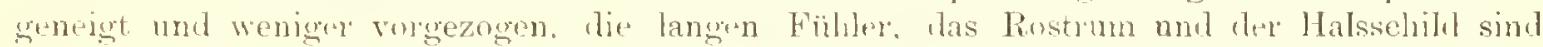

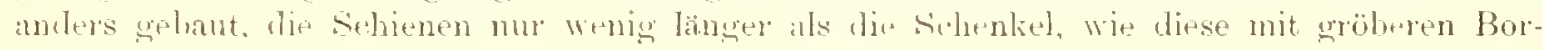
stentraaren liekleidet.

Tylus: lih. whiopieus n. sp.

Rhinomiridius athiopicus n. spl.

(Fis. $3-3: 3$ : .).

Schwarzbaun, der Kopf binten mul lings ron Augen braungelb-gellolich, unten gell, ein Laingsstrich in di.r. Mitte des Halsschildes und zwo seitliche, nach imen convergierende,

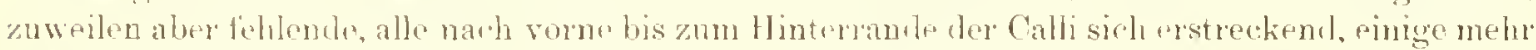
whr. weniger ausgequägte Fleclichen rorne an den Seiten, meistens anch die betzteren und der Basalrand melur oder wriger drutlich gell, win Fleckchen jederseits an der Basis und he

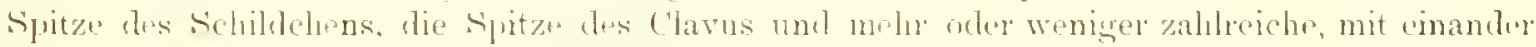

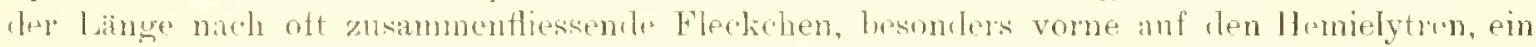

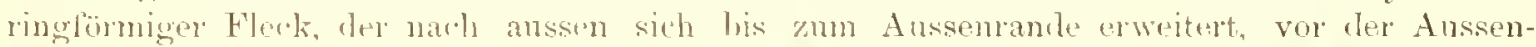
whe und der Innemand tes Corims sell, dis Memluan ranchlorann, in der Mitte etwas hel-

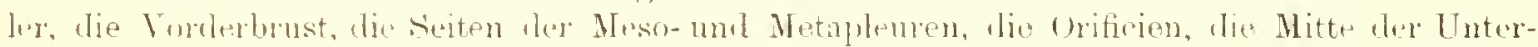
scite mehr out wentger ansurulehnt und kloine Fleckelien an den Seiten der Ventralsegmente gell, das letzte Sirgment ant der vorderen Hälfte sihwarzluann, hinten gelb; die Fülıler hraungell, die Brine braun. Jir Mittelschenkel vorne lis über die Mitte nnel ansserdem vor der suptze, die Hintersehenkel vorne an der Basis und in der Mitte, ein Ring vor der Spitzu,

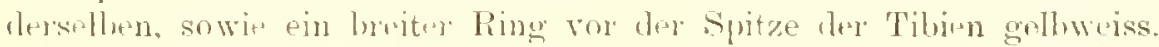

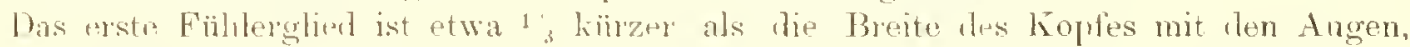

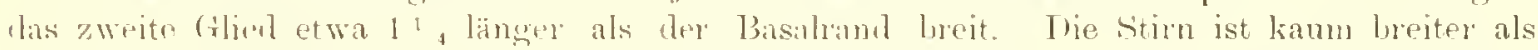

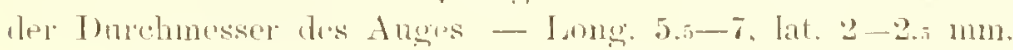

West-Afrika. Ins. Fernando-Po!, 1!01, L. Conrator, mehrere Fxx. (Mus. Palis et

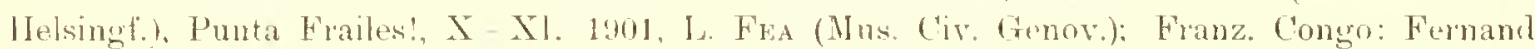

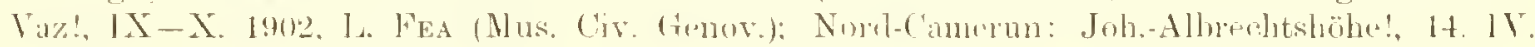

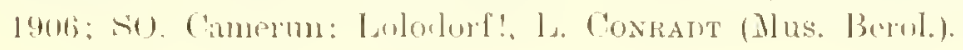

\section{Cylapus say.}

Say, Hem. N. Amer. 1. 7!). 18:31. - Compl. Vrit. 1, 1. 347. - list. Biol. "'entr. Amer.,

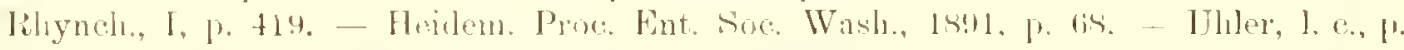

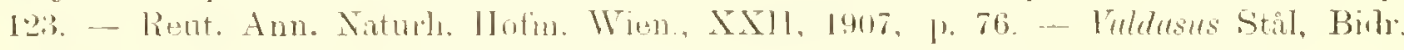

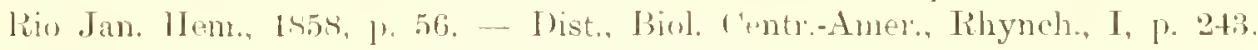

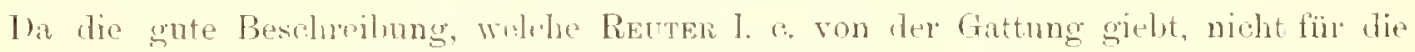

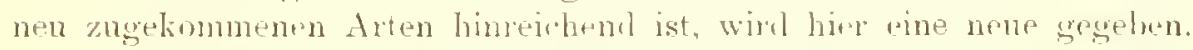

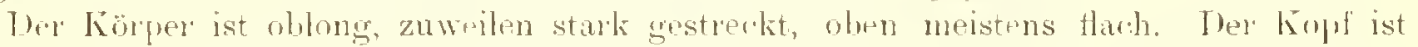

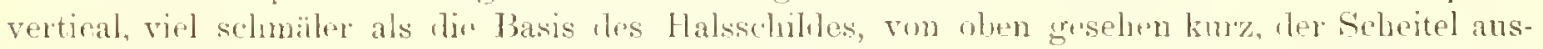

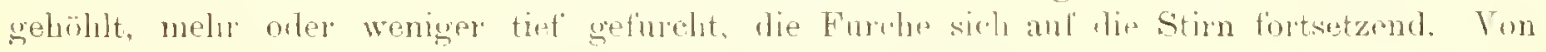

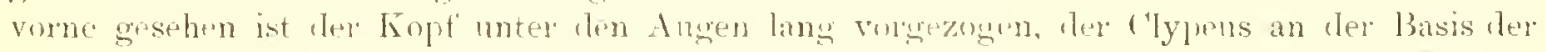

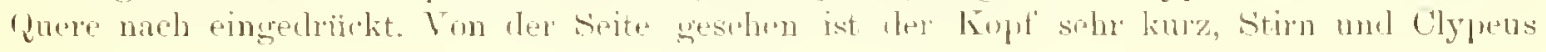


senkiecht gestellt, der letztgenannte mehr oder wrnigrer deutlich, zuweilen ziemlich kräftig convex, die Spitze flach, die Basis desselben im apicalen Drittel oder Viertel der Kopfhöhe gelegren. Die Zügel sind meistens depress, zuweilen die Spitze sehwach convex, der Hinterrand derselben thach gekielt, der Kiel gegen die Einlenkungsstelle der Fühler verlaufend, die Kehle sehr kurz. Die Augen sind gross und sehr stark vorspringend, fast gestielt. Das Rostrum erstreckt sich zu oder etwas iiber die Hintrrcoxen. Die Fühler sind gleich vor den Angen eingelenkt, das erste Glied ist mestens kurz und stark verdickt, das zweite meistens dünn, selten zur Sjutze stark keulenförmig verdickt, die folgenden sehr dïnn, das dritte länger als das vierte. Der Halsschild stark transversal, zur Spitze stark verengt, die Strictura apiealis deutlich, schmal, die Calli melu oder weniger stark convex, meistens durch eine Furehe ron einander getrennt, selten vorne zusammenhängend. Die Scheibe ist plan -- ziemlich stark eonvex, zuweilen uneben, der Basalrand meistens ausureschweift. Das Schildchen sehr varjabel, zuweilen fast plan, zuweilen sehr stark convex, oder mit einem hohen Längskiel. Dio Henielytren sind mehr oder weniger prallel, selten zur Spitze verengt oder hinter der Mitte erweitert, punktiert, der Cuneus glatt, meistens länger als an der Basis breit. Die Membran zweizellig. Die Beine lang, die Schenkel gestrecht, an her Basis etwas verdiclit, die vorderen zur Spitze stä̉rler verengt. Die Füsse lang, tein, das Basalghlied ebenso lang wie die zwei letzten zusammen.

\section{Typus: Cylapus tenuicomis Say.}

Die Gattung ist selw heteromorph. Unter den mir vorliegenden Arten sind wenigstens drei gut begrenzte Untergattungen zu unterscheiden, von denen eine vielleielst als pigrene Gattung zu betrachten wäre. Zu welchen dieser. Untergattungen alle die bis jetzt bekannten Arten grehören, ist mir nicht möglieh gewesen klar zu stellen, da die meisten, zahlrcichen Arten, die Distant in 13iol. Centr. Amer., 1. e., beschreibt, mir unbelannt sind und die Beschreibungen liurz und novollstäntig sind. Die Untergattungen wären:

\section{Cylapus s. str.}

Das Schildchen Hach. Der Halsschild ohne Uncbenheiten auf der Scheibc. Das zweite Fïhlerglied dünn. Die Beine kurz anlingend behaart, die Hinterschenkel am Hinterrande mit einigen selı langen Haaren bewehrt.

Als sicher zu dieser. Untergattung zu rechnen sind folgende Arten: temuicomis Say ${ }^{1}$ ). schönherri (Stål) ${ }^{2}$ ), famularis (Stå) ${ }^{3}$ ), marginicollis Dist. ${ }^{4}$ ), striutus Rent. ${ }^{5}$ ), molnilis n. sp). und politus n. sp. Mit grösster Wahrscheinlichkeit gehören hicrher auch die meisten der centralanerikanischen Arten, die ziemlich denselben Fühlerban und dieselbe Farbenzeiehnung wie famularis und murginicollis haben. Diese wären: stcllutus 1)ist. ") funebris Dist. i), erebeus Dist. ${ }^{8}$ ), cerliereus Dist. "1), stygins Dist. ${ }^{10}$ ) und picatus Dist. ${ }^{11}$ ). Unsieherer ist es, wohin mulhlus Dist. ${ }^{12}$ ) zu stullen ist.

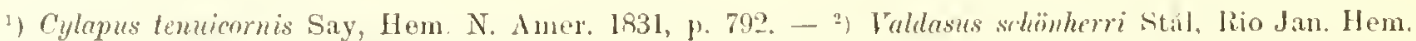

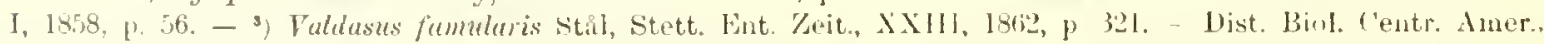

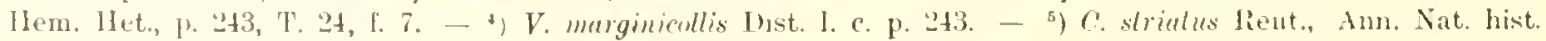
Hofm. Wien, XXll, 1907, p. 77. - ${ }^{\text {B }, ~ V . ~ s t c l l a t u s ~ D i s t . ~ I . ~ r . ~ p . ~ 243 . ~-~ 7) ~ H i s t . ~ I . ~ c . ~ p . ~ 244, ~ T . ~ 24, ~ 6 . ~ 8 . ~-~}$

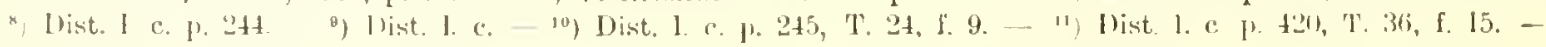
12) I Iist. I. c. p. 421. 
Peltidocylapus 13. subgren.

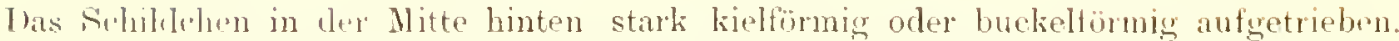

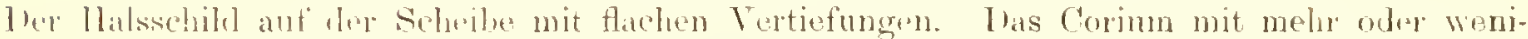
ger abgebrochenen langswiilsten. Inas zwrite Fühlerglied rïnn. Dit Vorderbeine (die ande. ren untilliert. wher die Bohaarung rer Hinterschenkel unbeliannt) kurz anliegrnd behaart.

Hierher (' sentelleris' n. sl'. und sicher auth rugosus Dist. ${ }^{1}$ ).

Trichocylapus n. subiren.

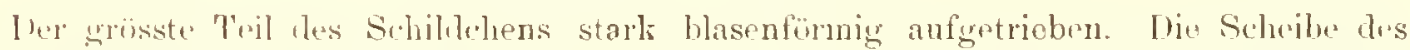

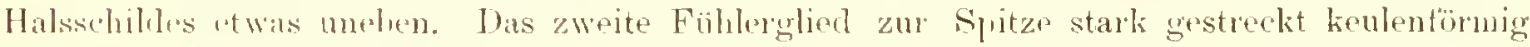
rrdekt. The Vorlerbeine mit einzelnen, die Hinterschenkel und Schienen dicht mit langen, abstehemden Haaren bekleilet.

Ilierher nur C. clavicornis n. sp.

Cylapus (s. str.) nobilis n. sp.

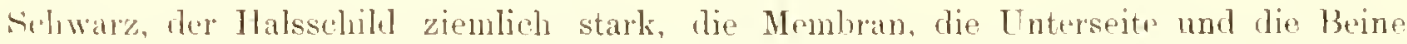
stark glänz'nd, die übrigen 'Teile matt; ohen kurz, ziemlich dieht abstehend behart, auf dem Kople ein schmaler (Querstrich vorne zwischen dru Augen, zwei grosse Flecke anf der Stim, von einamler nur dureh einen schmalen, schwarzen längsstrieh getremnt, die Zügel vorne und der ganze Hinterteil unten gelb, der Halsschild an den Seiten breit, die Proplenren und ein sehr kleiner Fleek ganz an der Basis des Corium dunkelrot, die Spitze des Clavus gelbbraun, die äusserste Ausseneeke des Corium und ein schmaler Quermakel an der Basis des Cuneus sowie die Basis des dritten Fülnlerghiedes weiss, der Hinterrand der Mesopleuren, die Orificien und die äusserste Spitze der binteren Coxen gelb. Der Halsschild, das Schildchen und die Hemielytren dicht und ziemlich kräftig punktiert. Der Kopf ist kmrz, die Stirn in der Nitte tief gefurelit, die Augen sind gross und starls vorspringend, der Buckel auf den Clypeus ist klein. Ile Stirn ist nicht voll doppelt breiter als der Durchmesser des Auges. Die Fiihler sind sehr lang und dïnn, viel länger als der Körper, das ersto Glied verdickt, kurz, kimm längrer als die Stirn mit den Augen breit, das zweite Glied ist etwa dreimal länger, selmäler als das erste, alın viel dicker als die sehr dünnon letzten, dopfrelt länger als der Basalrand des Halsschildes breit, das dritte etwa 1\%/4 Mal länger als las vierte, dieses ebenso linur als das zweite. Das Rostrum erstreckt sich bis zu clen Hinterhüfton, das erste Glied erreicht die Nlitte der Torderhüften. Der Halsschild ist doppelt breiter als lang, der Basalrand ist etwa $1^{2 / 3}$ lyeitry als der Vorderrand, fast gerade, die Hinterecken sind starls abgerundet. Die Seiten sind nach vorne ziemlich schwach gerundet. Die kurzen und breiten Calli sind schwach convex, von cinander durch cine feint Längsfurche, die hinten in ein kleines Grübchen enclet, getrennt. Die scheibe ist gleichfömig, schwach gewölbt. Das Schildehen sehr sehwach convex. Die Hemielytren sind nach linten versehnälert, wolurch die grösste Breite des Käriers an der Basis derselben sich befindet. Sir erstrecken sich buim or weit iiber die syitze des Hinterkörpers. Der Cuneus ist betentend länger als an der Basis breit. Die Beine sind einfach kurz anliegend behaart, dio Sthienen dicht, die Schenkel weitlänfig. - Jong. 9, lat. $2.6 \mathrm{~mm}$.

1) Valdawes Dist. 1. c, p. 245, T. 24, f. 10.

N:o 1. 
1)urel die Farbo und arch die Körperform von allen anderen Arten der Gattung selir versehieden.

Tenezuela, $11^{\circ}, 8^{\prime}$ s. Br., $75^{\circ} 17^{\prime}$ W. von Greenw., 1890 m. it. d. M., I1. IX. 1906, 1 , $\mathrm{N}$ ICOnnikorf (Mus. Moscou).

Cylapus (s. str.) politus n. sp.

Mlässig gestreckt, when und unten starli glänzend, oben weitläutige, kurz abstuhrund

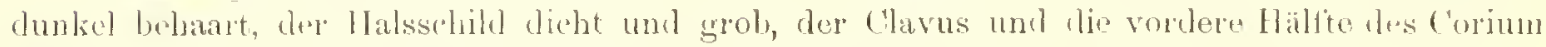

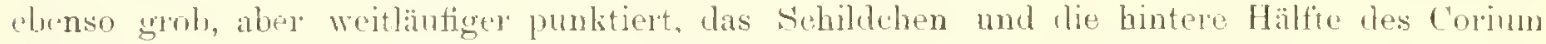
fast glatt. Bram, die spitze des Clypeus, die hintere Hälfte des Kopfes unten, ler Innonrand des Corjun des ganzen Clavus entlang sehmal, die äussere Uälfte desseben, die sich in cler Nitte nach inmen fast bis zum Clavus in einem spitzen Qurmaliel ansdrhnt, unu des Cuneus braungelu, the Basis des letzten und das Schildehen, das basile Tiertel ausgenummen,

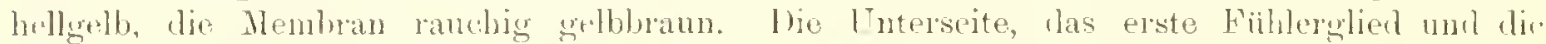
Brine groblatun, die Bristo, die seiten und die spitze des Hinterkörpers brau. Wre Kopt ist kurz, lie Stirn in der Mitte fein grefurcht, rlie Augen sind moss und stark vorspringend,

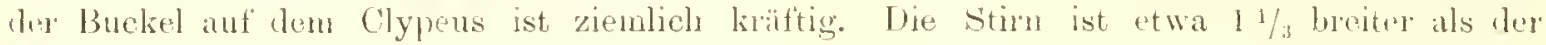
Durchnesser des Auges. I)as erste Fihhlerglied ist mässig verdielit. kurz, etwa $1 /$, kürzer als alic Breite der Stirn mit len Augen (die anderen Gilieder sind nutilliert). Las Rostrum erstreckt sich etwas äbre die Hinterlü̈ften, las ersto Glied erreicht etwa die Nitte ler Vorderhïlten und ist etwis kïrzer als das zwoite, dieses ebenso lang wie das dritte. Der Halsschild ist etwa doppelt hreiter als lang, der Basahand ist etwa doppelt breiter als der Vorderrand, jederseits sejcht ausgerandet, die Hinterecken sind seicht abgerundet. Die Sejten sind nach vorne geradlinig verengt. Die Calli sind ziomlich convex, von cinandog durch eine ticfe Längsfurche wetrennt, die Scheibe ist ziemlich convex, ohne Unebenleiten. Ilas Sichidchen ist last flach. Tie Hemielytren sind his etwas ror dem Cunens gleichbreit, dann zur

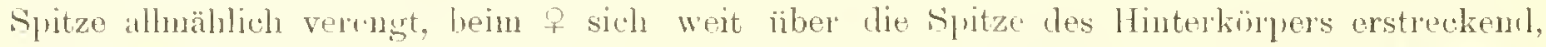
der Cuneus deutlich länger als an der Basis breit. Ibe Beino liurz, wenig dicht anliegend behaart, die Hintersehenkel ausserdem mit emigen sehr langen Haaren bewelırt. - Long. 5.9, lat. $23 \mathrm{~nm}$. versehieden.

Inrch den glänzenden Körper sowie auch durch dis Farbe von allen anderen Arten

Brasilia: S:t Catarina!, Lünerwaldt, 1 P (Mus. Stettin).

\section{Cylapus (Peltidocylapus) scutellaris n. spl.}

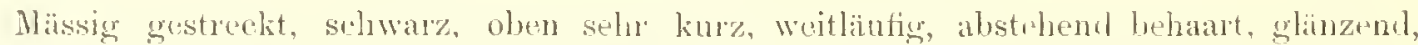
die Calli, das Schildchen, die Apieathälfte les Clavos, das apicale Drittel des Curium, der Cuneus, dis Meso- und Metapleuren matt; aut dem Koplfe Fllecke vor und hinter den Auren und in dor Mitte der Stron gubbram, die Basis des Schihlehens braun, ein kleiner Fleck an der Basis des Corium, ein ähnlicher jerlerseits aussen vor der spitze anf doun Clavus und vin urö̈serer Querfleck an der Basis des C'uneus gelbweiss, lie Nembran rauchbraun mit einigen hellen Flecken, die Fühler braunsehwar, dit Basis des ersten und die Spitzo des zweiten Gliedes schmal gelb, das letztgenannte zur Basis otwas heller, das Rostrum unil die Vorderbeines schwarzbrann (liw andren mutilliert), die suhienen holler, ein Ring in der Mitte der schenkel gelbweiss, die Meso- und Metapleuren braun. 
Jer Konf ist kurz, die Stim in der Mitte tiel gefurhat, die Angren gross und starli

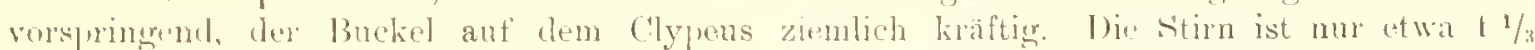
l,reiter als der lurchmesser des Austes, Das erste Fühlergfied ist kurz, stark verlickt, wwal $1{ }^{1}{ }_{3}$ linger als die 13reite der Stim mit den Angen, das zweite Glied ist dünn, glejelhbejt, nur wenig dicker als die feinen letzten, last viermal länger als das erste, etwa ${ }^{1}{ }_{s}$ liürzer als das dritte, dieses etwa rbenso lang wie das letzte. Das lostrum erstreclit sich etwas nibre die

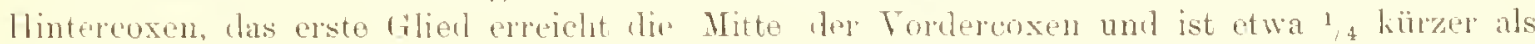

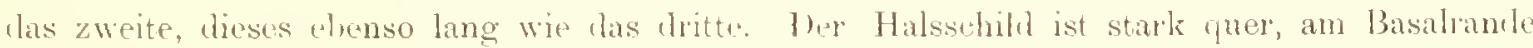

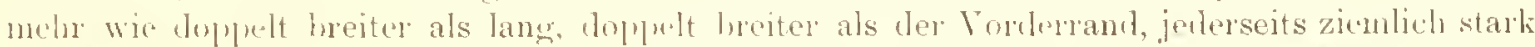

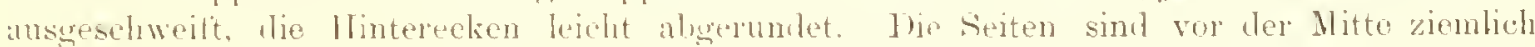
auscreschweift. Jhe Calli sind mässig convex, vorne mit einander zusammentlessend, indem die Längsturehung in der Nitte plötzlich anfhört. Wie seheihe ist ditht, ziemlioh fein punktiert, mässig convex, jederseits an der basis und rof den Hinterecken tawh der Luinge nats

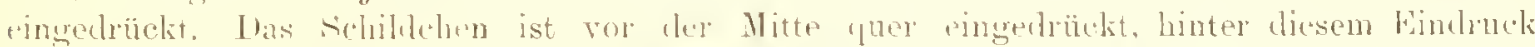

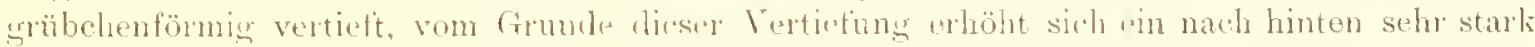
hervortretender. Buckel, der jedoch die Seiten des Schihlehens free lïsst, und der hinten stril,

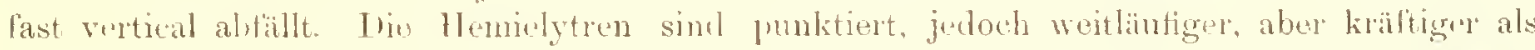

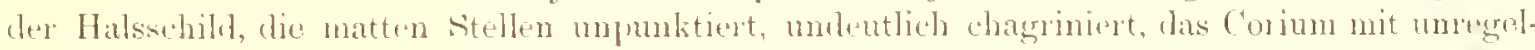
mässigen, der länge nach verlaulenden Erhebungen. Lic Soiten sincl gleich hinter dur Nitte

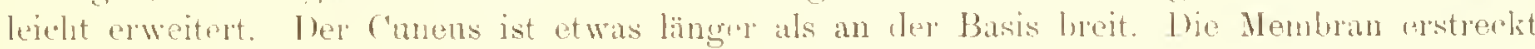

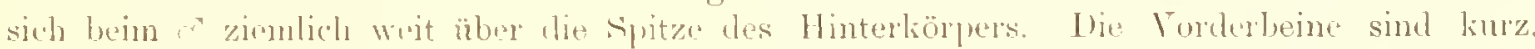
anliegend behitart. - Long. 5., lat. 21 mm.

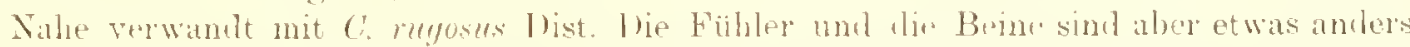

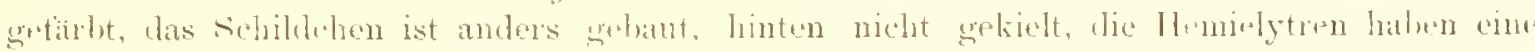

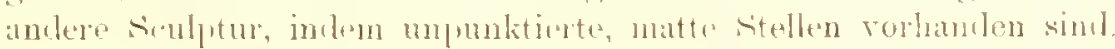

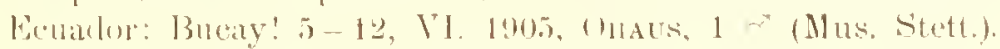

\section{Cylapus (Trichocylapus) clavicornis $n$. sip.}

(Fis. 4 ia.

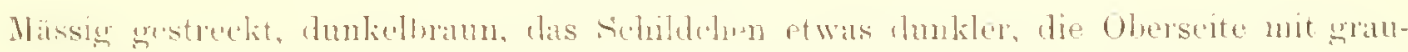

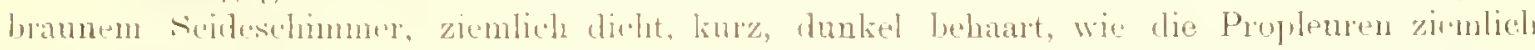
bioht uml groh, punktient, die Punkte aut den Hemielytron im Grunde schwarz, der Kopf

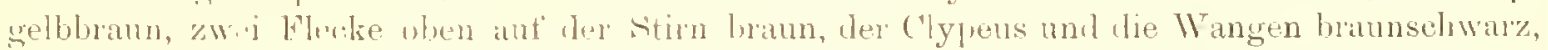

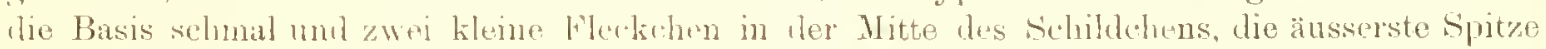

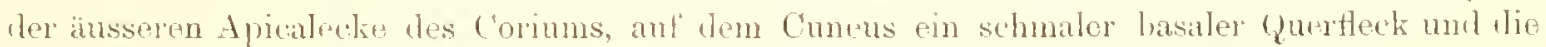

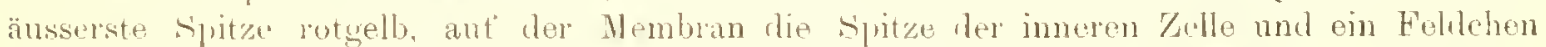

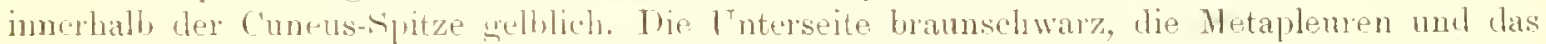
Ventrum ardhot, die siltze hes letztupnannten bram. Die Fühler gelbrot, die äusserste Spitze des ersten Gliedis, die Krulf des zweiten und die zwei letzten Glieder sehwarz, das dritte in der Basis weiss. Die Beine schwarzhaun, die Mitte und dir Spitze der schenkel quer gell. weiss geringelt. Ler kopl ist sehr kurz, zimlich klein, die stirn in ley Nitte tiel, aber lejn grefturcht, die Augen sind wross und sehr stark rorspringend, der Buckel aul dem Clypens ist selwach. Die stirn ist etwa doprelt breiter als der Duchmesser des Anges. Das crste Fühlor-

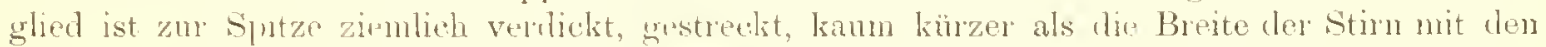
Augen, das zweite Glied zur spitze swhr stark, gestreckt keulenförmigrerdickt, et was mehr wie doppelt länger wie das erste, die zwei lolgenden harfein, das dritte etwas länger als das zweitu. has erste Rostraludien ist kurz umd erstreckt sich nur bis zur Basis der Vortercoxen (dic anderen Glieder nicht zu sthen). Der Halssehild ist stark yuer, am Basalrando mehr wie doppelt

N:o 4 . 


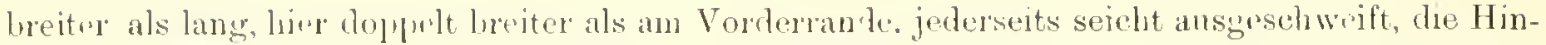

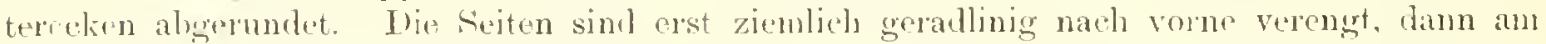
Hintermande des Calli etwas eingrsehüit. Die Calli sind zienlich stark convex, Aurch rine, anch hintre denselben sich schwath fortsetzend", zwischen denselben aber liältige umd tiofe läingsfurche getrennt. Die seluilue ist stark convex, nach vorne ziemlich starlí abfallend, an deg

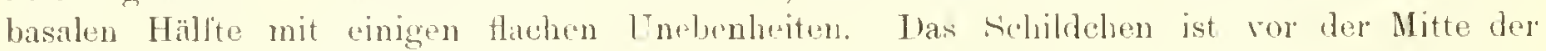

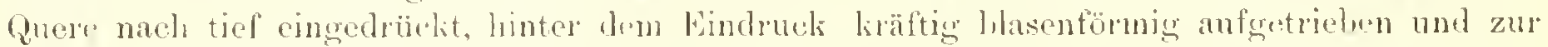

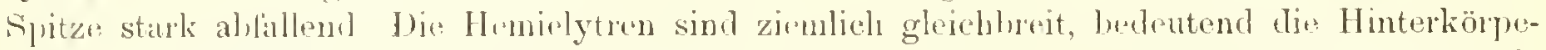

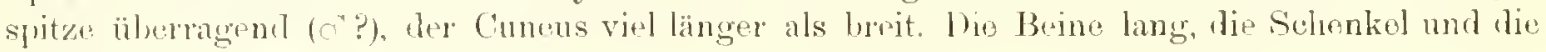
sebienen mit ziemlich langen, greichlörnigen, alstehenden Haaren brkleidet. - I song. 7. , lat. $3 \mathrm{~mm}$.

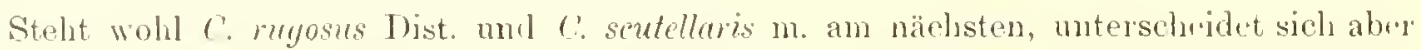

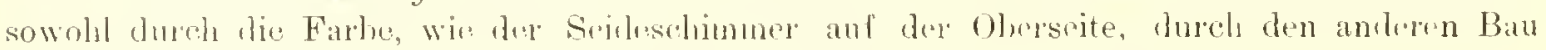

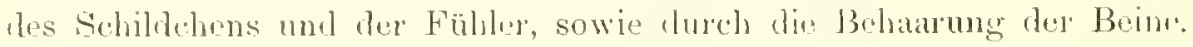

Pert: Sicuani!, 1 Ex., लै? (Mus. Nat. Hung.).

\section{Vannius list.}

Dist. Biol. Centr.-Amer, Rhynch., I, 1) 245.

Übrasicht are Arten.

1. (i) I als zweite Fülulerorlied viel dümm als das reste.

2. (3). Dic Seiten des Halsschileles rot.

rulmovittutus bist. ${ }^{1}$ ).

3. (2) Die Seiten des Halsschildes grelb.

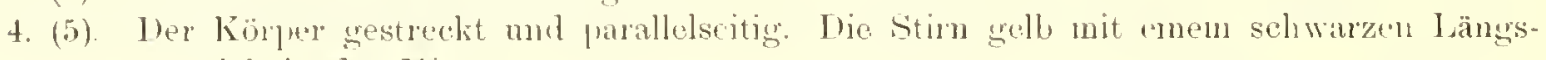
strich in der Mitte.

ammlicornis n. s].

5. (4). Iter Körper kurz und gedrungen, an den Seiten gerundet. Dio stirn einfarbig gelb. brecis n. sp.

6. (1). Das zweite Glierl dieli, nuy etwa um dio Hälfte schmäler als das erste, rot und schwarz mit weisser Spitzi"

erwiconis n. s!).

\section{Vannins annulicornis $11 . \mathrm{s} 1$.}

Gestreelit, an don Seiten nur wenigg gerunilet, matt, oben mit lalb alsstehenden, dunk-

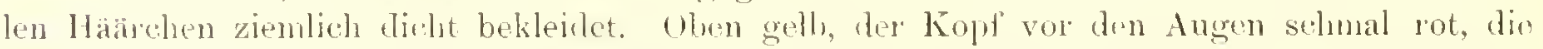
Augen rothraun, auf der Stirn ein schmaler, schwarzr I ängstrich, zwei breite I,ängbinten auf llom Halsschilhe, die sich nach hintrn äber die Basalecken des Sehildehens und über den Inntwrand des Clavus bis etwas äler die Scutellspitze lortsetzen, ant dem Corium eine lorite länglunde an Innenamle, die gleich hinter der Basis beginnt und fast bis zur Spitze des Clavus sich erstrecht, ein kloiner lateraler Makel hinter ter Mitte und oin grosser Makel an

1) Dist. 1. c. p. 246, T.XXIT, f. 11. 


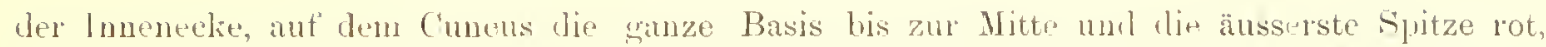

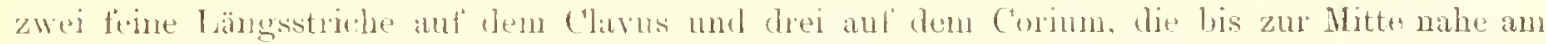

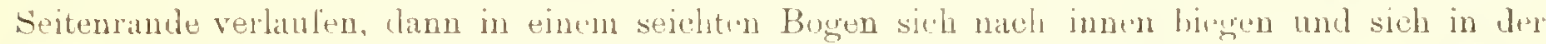
Mitte des Coriums fortsetzen, suwie die äusserste Aussenecke desselben sehwarz, Jie Mem-

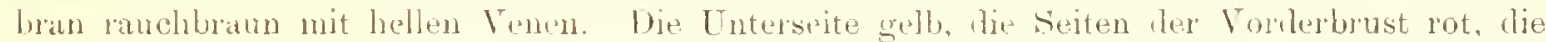
sipitze des Hinterlörpers hraun. Die Fühler braunschwarz, las orste Glien rot, das zweite Glical an der Basis rot, hinter dem roten, die Mitte und die spitze breit weiss. Das Rostrum gelburaun, das erste Gilied rütlich, die Beine gellorot.

Der Koplf ist ziemlich lilein, die Augen gross. Der erstgrmannte ist etwa $1 / 4$ liürzer als der

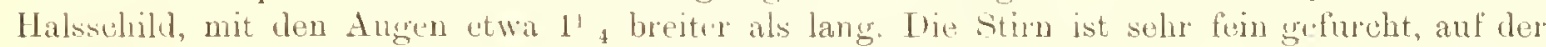
lureitesten Stelle etwa cbenso broit wie der Inuchnesser des Auges. Die Augen erstrecken sich nuwh hinten bis zum Forderrande Jes Halssehildes. Die Fühler sind etwas vor den Augen eingelenkt, das erste calied ist stark verliekt, knrz, obense hang wie der liopt, etwa um ${ }^{1}{ }_{3}$ lï̈zzer als die Breite der Sirm mit den Angen. Die folgemlen Glieder sind sehr lang, zusammen ebenso lang wie der Körper, das zweite etwas dicker als die selm dünnen letzten, etwa dreinal länger als das erste, kimm länger als las vierte, etwa um 1/4 kürzer als das dritte. Das Rostrum ist dick mol erstreekt sich nur wenig über die Hintercoxen, das crstr Glied ist ebenso lang wie dis zweite, das dritte etwas längred, has vierte kurz. Das erste erstreckt sich ein wenig über die Nitte der Vordereoxen. Der Halsschilel ist stark transversal, am Basalrande twa dojpelt breiter als in der Mitte lang, tlach, der Basalland jederseits lirätig ausgeschweift, die Hinterecken abgerundet, nicht vonspringend, die seiten nach vome last geradlingrg vesengt. Der Vorelermul ist kaum schmäles als der Kopl mit den dugen, etwa ${ }^{1}{ }_{3}$ sehmäler als der Basaltancl. Ije Strictura apicalis ist ziemlich breit, sehart alugesetzt. Die Hemielytren strecken sich beim + mit etwa ${ }_{4}$ ilner länge über dis? spitze des Hinterliörjers, die Menubran ist normal ausgebildet, der Cnncus länger als an der Basis breit. Die Beine sind lang mit langen sehienen, die hinteren Sohienen etwas dichter und stiorker bedornt als bei lreves. - long. 4, lat. $1.3 \mathrm{~nm}$.

Durch die Farbe sofort ron den drei anderen drten dor Gattung zu unterscheiden (Mus. Paris).

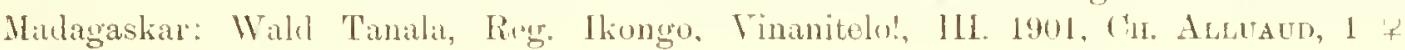

\section{Vannius brevis $\mathrm{n}$. $\mathrm{sp}$.}

Furz und gedrungen, an den s'eiten ziemlich gerundet, selar wenig glänzend, oben ziemlich weitlïufig mit halh atulrecht stehend $n$, schwarzen Häarchen bekleidet. Oben hell strohgr.lb, der Kopl mit einem sehr sehmalen, kurzen Querstrich an der Füllerbasis, aut dem

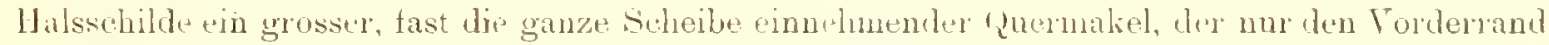
in der Nitte ziemlich sehmal und die Hinterceken brejt frei lisst, der Basalteil dus Clarus bis

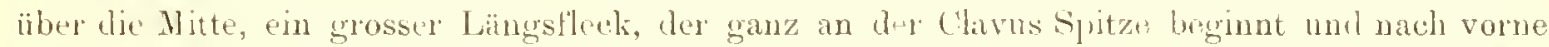
bis zur Mitte desselben reiclit, lier aber nach aussen zu einem grösseren, last den Seitenrand

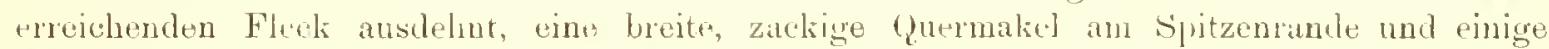
ganz kleine Fleekchen am Aussenrande auf dem Coriun sowie ein Quertleck vor der Spitze des Cuneus schön rot. Dio Unterseite gelb, die Propleuren schön rot, mehr oder weniger zusammentliessende Zeichnugen auf lem Hinterkörper, die zur Spitze ausgalehnter werlen, rotgelb. Das erste Fühlerglied rot, das zweite gelb, zur spitze rötlich, die letzten braun. Die Beine gerb, die Hintersclienler hinter der Mitte mit zwei roten Ringen. Das Rostrum gelb, das erste Glied rot, die Augen branneut.

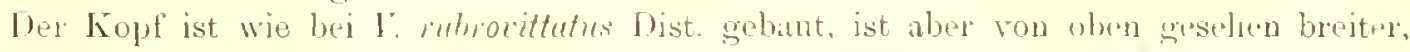

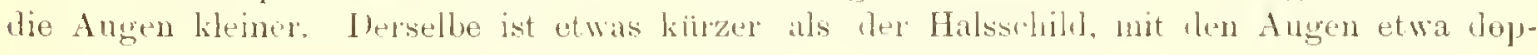
$N: 04$. 
pelt breiter als lang. Die Stirn ist sehr tein der länge nach grelurcht, etwa $1{ }^{1}{ }_{4}$ breitre als

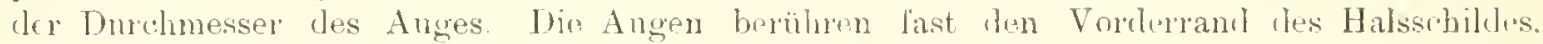
Tie Fühle, sind etwas ror den Angen eingelenkt, las prste Glien ist ziemlich stark rrelickt,

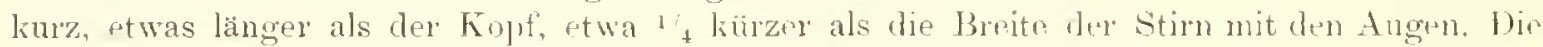
folgenden Glieder sind sehr lang, zusammen lingrer als der Körprer, das zueitr etwas dicker als the selu fuinen letzten, etwa dreimal länger als has erste etwas länger als das drittr, las ebenso lang wie das rierte ist. Tas Rostrum ist zimlich dick und erstreckt sich etwa zim basalen Drittel des Hinterliörgers, die drei ersten Glieder alle fast uleich lang, das vierte sehr liurz. Der Halsschild ist sehr starli transversal, an Basalrande mehr wie doppelt breiter als in der Mitte lang, ziemlich Hach, der Basalrand jederseits krältig ausgeschweift, die Hinterecken spitz, nicht vorspringend, die Seiten kaum merkbar ausgeschweift. Der Vorderrand ist etwas schmäler als der Kopf mit din Angen, nicht voll um die Hälfte schmäler als der Basalrand. Die Strictura apicalis ist broit und scharf aloresetzt. Hie Scheibe ist in lin Mitte und vor le Basis sehr fein fuer gefureht. Die Hemielytren sind beim fotwas länger als ler Hinterkörper, ziemlich gorlnungen und an clen Seiten gerundet. Die Membran ist kurz, ausserhalb der Cuneus-Spitze nur mit der Länge des Cuneus sich erstreckend, der letztypnamntr ist sehmal, Jänger als an der Basis breit. Die Beine sinı lang, die Sichienen länger als tie Schenkel, die Hintershienen aussen mit einzehen, feinen Dönchen bewehr. Die Hinterschenkel etwas vor der Spitze mit drei sehr langen Haaren. - Long. 2.1, hat. $1 \mathrm{~mm}$.

Obgleich diese Art eine gedmungene Körperform nnil einen sehr breiten IIalssehild hat, kann sie meiner Ansicht nach nicht von der Gattung l'tunius Dist. generisch gretronnt werden. Die leinen Sjinula sind auch, obgleich noch teiner, bej l: murortfutus Ibist. vorhanten und mit dieser Art stimnt auch ter Ban der Fühler und des Rostrums. Fie linrze Membran kann wohl als Geschlechtsdimorfismus angeselen werden.

Nen-Gninea: Simbang, Huon-Golf, Brro, 1898, 1 of im Mus. Nat. Hung.

\section{Vannius crassicornis $\mathrm{n}$. $\mathrm{sp}_{\mathrm{p}}$.}

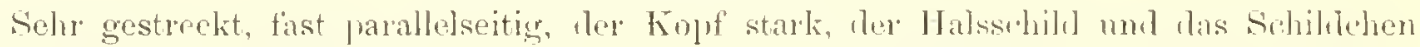
schwach olänzend, die Hemielytren matt, olien mit labl, abstellenilen, kurgen, hellen Haren

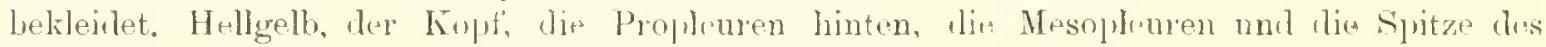
Hinterköpers schwar, der rotgenamte zwischen den Angen brammot; eine breite Qurrbinde auf tem Halsschilit, the sich anch auf then Proplenren forsetzt, Jas Sehildchen, das äussere Drittel des Clavus, Jas Corium längs der Clavalsutur breit und ein grosser Fleck linten, aussen rom Inmenrande des sehmalen fimboliuns beginnend his zur Innenecke nach innen sich erstreckend, und etwa die Hailfte der. Mumbransutur einnehmend, die inmere Hälfte hes Cunens und die äussere Membranvene, das erste Fühlerglied und die basal Hällte des zwriten sehön rot: die andere Hälfte des zwriten Fühlerghiedes, die äusserste spitze ausgenommen, lie weiss ist, unı das dritte seluwarz (das vierte mntilliert). die änsserste Spitze des Jritten gelbweiss; das Rostrum uni lie Beine gelb, die Vomlertïsse sehwarzbran.

Der Kopf ist klein, fein der Lïnge nach fast bis zur Basis des Clypens gefurcht, die Furche olerhalb der Antennenbasis grübehenlörmig erweitert. Am Hinterrande der Augen eino feine Querfurehe. Die. Stim ist von der. Seite gesehen gewoll, ni.ht wie bi den and.ren Arten winkelförnig abgeneigt, beim o" otwa ebenso lneit wir ler Durhmesser des Anges.

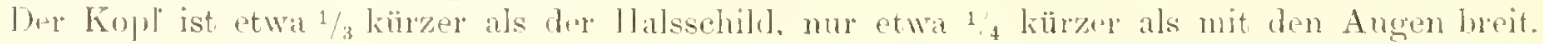
The urossin Angen erstrecken sirh nach hinten first his zum Vorderrand des Halsschildes.

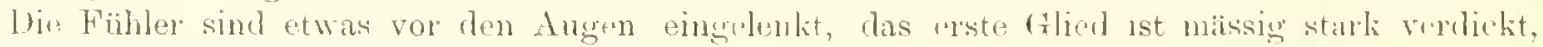

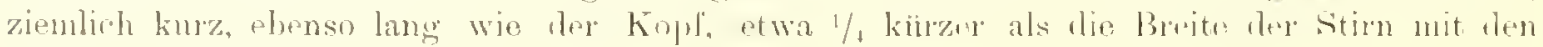

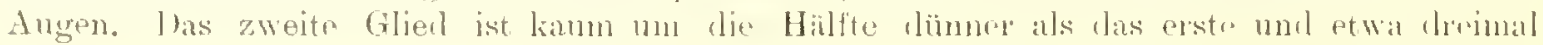


länger als dasselbe, das dritte ist selyr diinn, ebenso lang wie das zweite. Ter Halsschild ist stark transversal, am Basahrante kaum doppelt broiter als in der Vitte lang, flach, ler Basalrand jedprseits krältigr ansgeschweift. die Hintererdken breit abgerundet, nieht vors]ningond, die seiten sehn sejcht ansueschweift, ungrandet. IDer Vorder'an ist dentlich schnäler als der Kopt' mit den Augen, etwa $n$ die Hälte sehmäler als der. Basalrand. Die Strietura apicalis ist breit, scharl abgesetzt. Lle Hemielytren erstrecken sieh beim zienlieh weit über die syitze des Hinterkörpers, her ('uneus ist länger als an der Basis breit. Tie Beine langr mit langen schienen, die cinzeln f'ein bedornt sind. - Lomg. 3.n, lat. $1.5 \mathrm{~mm}$.

Von allen bekaunten Arten der Gattung dureh den Ban des Koples und der Füiller soliont zu untersideiden. Die Art ist jedoch in anderen Hinsichten so nahe mit l. rubronittutus Dist. verwanlt, dass sie kitum als Repräisentant diner eigenen Gattung zu betrachten ist.

Bulivia: Najiri:, $20^{\circ}$ (Mus. Nat. Jumg.).

\section{Vanniopsis n. «en.}

Ther Körper ist gestreekt, parallelsejtig, glänzmol, olwn besonders anf dem Kopfo und

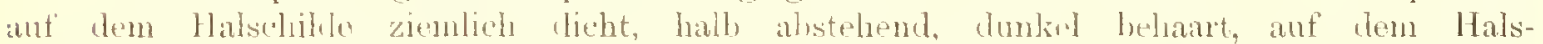
schible und anf den Hemielytren fein, ziemliels weitlantig raspelartig gewirlit. Der

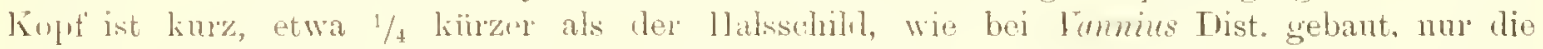
Kehle ist länger und ron der Seite Jentlieher siohtbar. Die Stirn ist lein golureht, etwas sehmither als der Durchmesser der grossen Angen. Iliesn erstrecken sich nach hinten bis zum Torderrande des Halsschikles. Lljo Fühler sincl ganz an Vordermande der Augen eingelenkt,

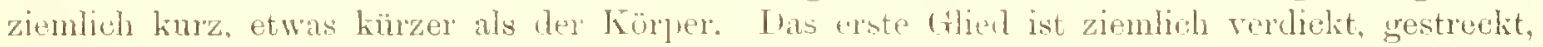
fast ebenso lang wie der Kopf und der llalssehild zusammen, das zweite Glied ist etwa um die Hälfte dimmer, nur etwa $1^{1}$, länger: Das dritte Glied ist etwas dicker als das vierte, hell geringelt, etwa nm die llälfte kürztr als las zweite, dieses etwas lrürer als das vierte. Alle Glimler sind lieht, zienlich anliegend behart. Ias Rostrum jist dick und erstreckt sich zu den Hinterhüften, das erste Glied ist stark verlickt, die drei ersten Glieder annïhernd gleich lang, das letzte kurz. Der. Halssehihl ist quer, an Basiluande kaum doppelt Jreiter als lang. der Vorlerrand ist etwas sehmäler als ler Koll mit drin Angen, fast um die Hälfte schmäler als der Basalrand, dieser kamm merklar ansgeschweift. l) Hinterecken sind annäherud rechtwinkelig, nicht vorspringend, die Suiten nach vorne gerallinig verengt, der Seitenrand abgrerundet. Die Strictura apiealis ist breit, schurd abgesetzt. Irie Calli sind seln undeutich, von rinander durch ein likines Grübchen getrennt. The Hemielytren sind gestreckt, parallelseitig. Ter Cuneus ist an Aussenrande durch eine kleine Einbuchtung vom Corium getrennt, schmal, berlentend länger als an her Basis breit. Die Membran zweizellig. Die Vorderbeine sind mäs-ig lang, halb anliegend behaart, die schichen ausserdem nit einigen teinen Dörnchen. (I)ie Hinterbeine und (ler Hinterkör]er mutilliert).

Die Gattung stelnt dem Fannius List. sehr nalse, unterscheidet sich aber durch rie längere Kelin, dureh den abweichenden Ban der Fühler, durch den greraden Basalrand des Halsschildes, durch die gestreckten, parallelseitigen Hemielytren, durch den vom Corium aussen alygesetzten Coneus sowio dureh die raspelartige Senlptur der Oberseite.

Typus. I. méscens n. s].

Vanniopsis rufescens $\mathrm{n} . \mathrm{sp}$.

(Fjg. 5 - 5 a.)

Oben grinlieh branngelb, die Apicaliallte des Clavus mit rötlichem Anstrich, das

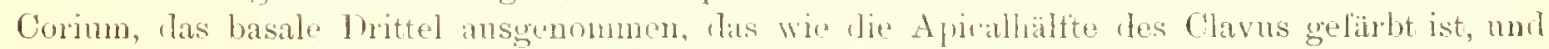
der Cuneus rotbraun, die Membran rauchig lorunschwarz. Das erste Fühlerghted rotbram, 
die übrigen schwarz, das zweite an der Basis sehr schmal, die Mitte und die Spitze desselben breit und die Spitze des dritten Gliedes etwas schmäler weiss. Die ganze Unterseite des Kopfes und die Coxen gelbweiss, das Rostrum und die Beine gelb, die Tarsen dunkler. Long. 3.5, lat. $1 \mathrm{~mm}$.

Neu-Hebriden: Insel Dauphin, Espiritu Sante!, V. 1902, Dr. Joly, 1 Ex. (Mus. Paris).

\section{Divisio Fulviaria Reut.}

Div. Teratodelletia Reut. Cien. Cim. Eur., p. 7. 1875. - Hem. Gymn. Enr., IH, 11. 564. Fulvarin Uhler, Check hist. Hem. Het. N. Amer., 1s\$6. p. 19. - Reut. Ent. 'Tielski. Steckh., 1895, p. 133. - Hem. spee. 1. 1, 17.

Der Körper meistens grestreckt und mehr oder weniger parallelseitig, zuweilen aber ziemlich stark gedrungen mit gerundeten Seiten. Die Flïgelzelle ist ohne oder mit rinem sehr rułlimentären Haken versehen. Der Torlebrustxyphus ist fein grerandet. Arolien fehlen, die Schienen schual, ohne Stachclchen, zur Syitze meistons etwas verngt, selten gleichbrit. Die Füsse sind sehr diunn und fuin, das erste Glied gestreckt, wenigstens ebenso lang, oft längrer als das zweite. Der Kopl' ist meistens zienlich stark vorgerogen, meistens krältigr zugespitzt, die Zïgel schmal, sowohl unten wie oben deutlich begrenzt. Die Augen immer gross mml vorspringent. Wie Stirn in der Mitte mit einer feinen längsfurche orler flach eingerlrückt. Das Pronotum ist meistens horizontal, zuweilen aber ziemlich kräftig gewölbt, tie Apiealstrictur ist meistens vorhanden, zuweilen sehr fein oder von den grossen Calli bedeckt, sehr selten ganz fehlend (Fulvidius m.). Diese letzteren sind gross, nach hinten wenigstens zur. Witte Her Scheibe sich erstreckend, meistens mehr odu weniger convex. Die Seiten sind meistens scharf, zuweilen ist tie Kante nur vorne und auch hier nur sehwach vorhanden.

Die Fulviarien scheinen in allen Regionen vorzukommen. Besonders zahlreich sind sie in der neotropischen und in der indo-malaischen Region vertreten. Besonders in der letzten Region kemmen mehrere eigenthiimliche, aberrante und wie es scheint für diese Gegemlen eharakteristische Gattungen ror. In fast allen Regienen, auch in der paläarktischen unt nearktischen ist die Gattung Fulvius vertreten. Fin eigenthïmlicher Untersehied existiert jerloch zwischen den Arten der alten und der neuen Welt. Alle nearktische und neotropische Arten haben nähmlich die Basis des Cuneus weiss oder gelblich gefleckt, während alle bekamnte Arten der alten Welt den Cuneus einfarbig dunkel haben. Zu diesen gchört auch der jetzt überall in wärmeren Ländern durch Schiffsverkehr vorkommende Fulvius brevicomis Reut., der auch nach Siil-Frankleich eingeschleppt worten ist, und den ich aus Afriea, Senegambien, Congo, Central-Amerika, Sit Thomé, Cuba und Martinique kenne und von welcher Art ich anch Lxemplare aus Ost-Indjen, Bhamo in Birma gesehen habe. Da ausserdem in der into-malaischen Region eine selır wahe verwanlte Art $F$. dimidiutus m. vorkommt, dürlen wir whl annelmen, dass diese Art auch in lieser Region ihre eigentliche Heimat hat.

Von den ïbrigen Gattungen lieser Division hat nur cine ein grösseres Verbreitungsgrobet mm zwar Pritrupis. UHuER. Die meisten Arten finden sich in der iudo-malaischen Regrion, wo auch ziemlich wechselnde Formen verkemmen. Ausserdem kennt man eine Art, I'. saldwformis Unuer aus Nord-Amerika. Ausschliesslich der indo-malaischen Resrion zuhörig sincl die Gattungen Trichofulvius m., Euchilofuldins m., Cylapofulvins m., Fuludius m. und lironielle m.

Aus der aethiopischen Region sind nur drei Arten, ausser dem versehleppten $F$. lire-

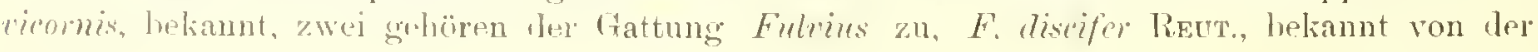




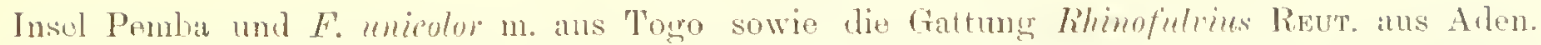
Ans der anstralisehen Region (Vietoria) ist nur ein. Gattmm mit einer Art, C'entofuleius claricomis ReuT., belkannt.

Übersicht der Gattmigen.

1. (2). Iner Halssehild olne Apiealstrietur.

Fulvidius 11. gen.

2. (1). [1.r. Ilalssehild nit Apicalstrictur, die zuweilen von den Calli berleckt ist.

3. (10). Jie Augen erstrecken sich nath unten nicht bis zur Kehle.

4. (5). [ler Kör]er gredrungen, an len Seiten ziemlich kräftig germulet.

Cylapofulvius n. gen.

5. (4). [lor Körper schmal und gestreckt, mehr oder weniger parallelseitig, an den soiten selten seirht grerundot.

6. (7). Die Oberseite des Kärlers mit langen aufrecht stehendon Haaren belileidut. Der Kopf wenis vorgezogen, rertical.

Trichofulvius $\mathrm{n}$, gen.

7. (6). Die Oberseite liahl oder mit kurzen, anliegrenden Häarchen belileidet. Dor Kopl" rorezosem und horizontal.

4. (9). Has zweite Fiuhlerglierl zur sintze nicht verdiclit; las erste Rostralglied erstreckt sich nach hinten nur bis zur Nitte der Augren.

Lhinofulvius ReuT. ${ }^{1}$ ).

9. (\$). Das zweite Fühlerglied zur Spitze kräftis, gestreekt keuknlörmigr verdickt; das erste Rostral-Glied ebenso lang als der Kopt'.

C'crutofulines ReuT. ${ }^{2}$ ).

10. (3). Lie Auren erstrecken sich nach unten bis zur Kehle.

11. (14). Der Körper sestreckt, zuweilen an den Seiten sthwach werundet, Kopt und Halssehild nie metallisch. Die Hinterecken des Halsschilues etwas vorsuringend, dio Seiten mehr ocler weniger seicht ausgesch weift vor der Basis.

12. (13). Las Embolium der ganzen Längre nach zienlich gleich breit. Lie Fühler am Vorderrande der Augen eingelenlit.

Fulvius STÃL.

13. (12). Las Embolium rom zweiten Basaldrittel kräftig erweitert. [rie Fiilhler zienlich weit vor den Augen eingelenlit.

Euchilofulvius n. gren.

14. (11). Her Körper gedrungen, an den Seiten ziemlich kräftig germulet, selten gestreckter, dann Kopf und Halsschik metallisch grün. Die Hinterecken des I Ialsschildes nicht vors]ningend, die Seiten nach vorne gerallinig verengt.

15. (16). Körper oben matt, gedrungen.

Peritropis UHLen.

16. (15). Körper gestrecliter, Kopf und Halsschild metalliseh grün.

Bironiella n. gen.

1) Öf. Finsk. Yet. Suc. Förlı. XLIY, 1902, p. 156. - 1. c. XLV. N:o 6, 1900, 1. 1. - ${ }^{2}$ ) 1. c. XLIV, 1902, p. 156 .

N:o 4. 


\section{Fulvidius $n$, gren.}

Der Körper ziemlich westreckt, an ren Seiten sehr wenig remulet, sehwach glänzencl, die Hemielytren, dis Monban ausgenommen, natt, oben sehr kurz, hab abstohenil trehant, ziemlich krätigg punktiert. Du Kopf ist lreit, broit zugespitzt vorgezomen, etwas vertical, von der Sejte gesehen mit dem eonvexen Halsschilde grledolönmigr gewölbt, etwa rbenso lang wie die Stisn mit den Augen breit, die Zijgel schmal, oben und unten scharl lesprenzt, die Augen gross, die Kehlo nicht erreichend. Fie Fiihler sind gleich vor len Augen eingelenkt, tas erste Ghed kurz anliegend bohadrt, las zweite mit kiirzeren und längeren, abstehruden Haaren bekleidet (die anderen Glierler mutilliert), las ejste Glier ist ziemlich gestreckt, selu

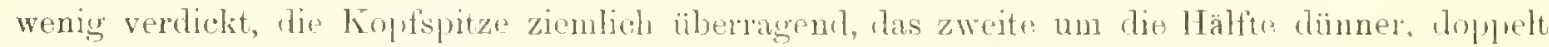
länger. bas erste hostralghed ist unbedoutend länger als der Kopf. Tre stim ist suh tein, etwas runzelig̨ junktiert, der Clypeus stark ghänzend, ghatt. Der llakschild jst dicht junktiert. die Calli feiner un weitläufiger. die Strictura apicalis ist nicht ansgebildet, die Calli sehr schwah convex, otwas ïher die Mitte der Scheibe sieh nach hinten erstrekend, ron "inan-

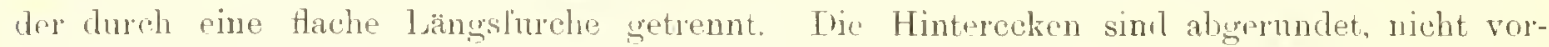
springend, der Basahand fast gerad abgeschnitten. die Seiten seicht ausgeschweift, der garzen Iänge nach schart gremdet. T)as Schildchen ist ziemlich convex, gheich hinter der Basis flach eingedrickt, dicht punktiert. Die Henielytrea sind boin länger als der Hinterkör.

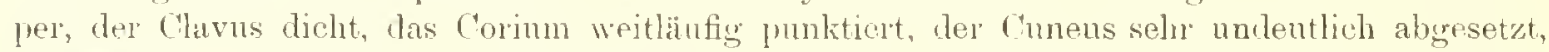
die Nembran zweizellig. Die Hinterfügel mit einen l’ulimentären Zelluaken. Die Beine lein anliegend behaart, ohne Dörnehen, lie Sehienen schmal, das erste Fussglied lang.

Von allen Fulviarien-Gattunsen sofort durch die nicht ausgebildete strictura apicalis zu unterscheiden.

Typus: $F$. punctutus n. sp.

Fulvidius punctatus n. spl.

(Fis... (i.)

Schwarbraun, anf hom Halssehilde in ller Mitte ein knrzer, schmaln, ein anderer, breiterer Lïngsstrich jederseits innerhalb cler Hinterecken, diese letztere und der seitenrand, die Seiten des Sehildehens sehr schmal, dic Sutura chavi loreit, die Busis ausgenommen, der Aussenrand des Clavus schnal, auf' dem Corium die innere Basalhälfte nach hinten bis zur Ilitte, von den im Grunde schwarzen Punkten unterbrochen, zwei schnale längsstriche aut der basalen Aussenhälfte, der ganze Apicalrand his zur inneren Cunens-Basis und ein kurzes luängsstrich von him ansgehend, suwie dio Apicalbälfte des Cuneus und die Propleuren unten schmal

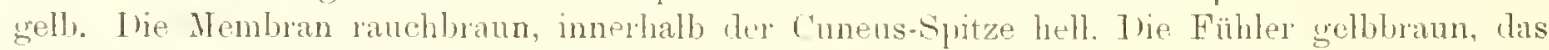
zweite Glied zur. Spitze etwas dunkler, das Rostrum um die Beins braun, die A jicalhältte der. Schenkel unk die spitze der Schienen gellb.

Drex Kopf ist etwa 1/3 kürzer als der Halssshik, mit den Augron kaum sehmäler als der Vorderrand desselben. Die Stirn ist nur wenig breiter als der Durehmesser des Augres,

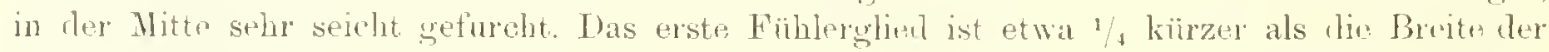

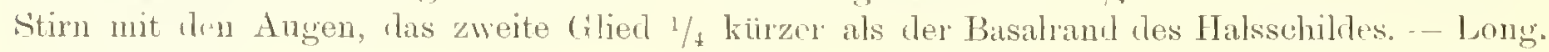
4.5, lat. 2 inm.

Carin Chebá, 900-1100 m. ü. d. M., V-Xll. 1sis, L. FeA, 1 (Mus. Civ. Genov.).

\section{Cylapofulvius n. gen.}

Der Kö̈rer ziemlich gedrungen, an len Seiten mässig grerundet, matt, die Oberseite

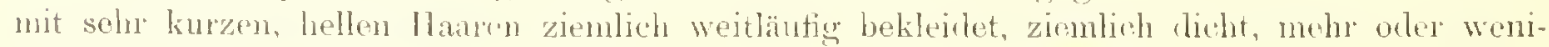
ger fiein punktirrt, die Unterseite sehr foin chagrinitert, der Hinterkörper zun 'Teil schwaeh 


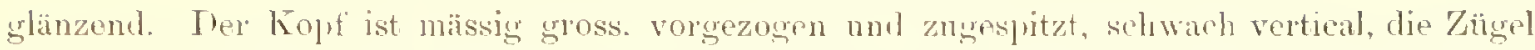

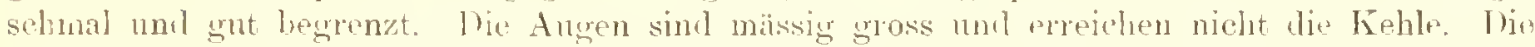

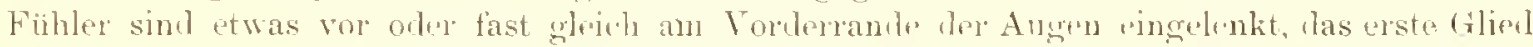

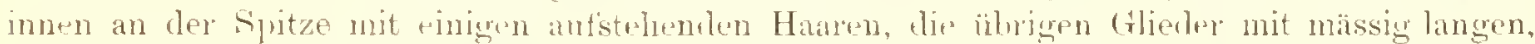
halb abstehenden Haaren helkleilet. Tas erste Glied ist gestreckt, nur wenig verdickt, sich

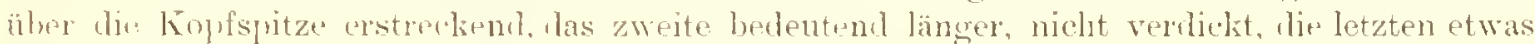
dianner als das zweite, das dritte ebenso lang orler wenig kitiper als das zweite, das vierte etwas kürzer als das erste. I bis crste Rostral-Glied ist wenso lang oder ptwas linger als der.

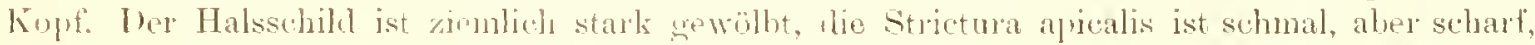
dip Calli sind mässig gewöht und arstrecken sich nach hinten etwas über lie Mitte der seheibe. Die Hinterpelien sind annähernd wehtwinkelig, kaum abgerundet und nicht vorspringrond, lie Seiten sind etwa in ler Mittr immer dentlich ausgresehweift, nur vorne gekantet, der Basalrant ist fast perade abrestutzt oder schwach convex. Das Sohildehen ist Hach gewölbt. hinter dre Basis der Quere nar h etwas abgeflacht. Die Hemielytren sind beim '+ entweler kürzer oder etwas liinger als der Hinterkörper, dẹ Cunens ist auch beim Mämehen nicht ouler sehr undeutlich alugesetz. The Membran ist zweizallig. Tie Vordertibien (die anteren sind bei den vorliegrnden bemplaren nicht vorhanden) sind zur Spritze sehwach verdickt.

Ife eigentiumliche und abwichende Gattmug ist wohl an nächsten mit Peritropis Uhler verwandt.

Typus: ('. munctutus 11. sp'

\section{Cylapofulvius punctatus 11.8 . 1 .}

$$
\text { (Fig. } 7 \text { - } 7 \text { a.). }
$$

Der Kopt', Halsschild, das Schildchen, der. ('lavus, das Corimm, lio äusserste Spitzo des lutztgenanten ansgenommen, und die Proplemen ziemlich licht und mïssig stark punktiert, die Meso- um Metapleuren tein runzolig gewirkt. Ohen hrann, anf hem Kopfe der Clypeus. die Zügrel nnil zwej Flecke vorne anf ler Stirn an den Angen schmal hell grelïrbt; auf dem Halssehilde die schmale Strictura apiealis, lie Calli in der Mitte und ein sehmales Längsstrich zwisehen denselben, zwej broitere, naels vorne etwa bis zur Ititte der Seheibe rejchenle I:ingsstriche jederseits an der Basis und die Hinterecken gelb, die Umrandung der Calli an den Seiten und etwa $2 / 3$ des basalen Seitenrandes, die Hinterecken ausgenommen, zienlicl, hreit schwarzbraun. Das Sclildchen am basalen Aussenrande sehmal gelbbraun, die Spitzo gelbweiss. Der Clavns mit likinen und zwei grösseren Flediehen am Innenrande, anf dem Corium einige kleine vorne, zwei grössere hinter der Mitte und einige kleine Fleckehen auf der inneren Apicalhälfte, sowje das Embolinm bis zmm apicalen Drittel am Aussenrande mit einigen Fleckchen und ein urosser (Querfleck vor der Anssenspitze gelb, die äussere Hälfte des Corium vor dem hellen querfleck oder bis zum Innenraule breit braungelb gefärbt. Die Nemluran rauchig schwarzbram, the innere Basalecke nnt ein querband gloich hinter der Witte hell. Die Unterseite bramschwarz, die Proplenren vorne, der Hinterrand der Metaplenwn schmal, kleine Quertleekehen an Vorderande der Segmente auf dem Connexivum, ein grosser Längstleck jederseits in der Mitte und eine breite Querbindc vor der spitze anf der Unterseite des Hinterkörpers gelbweiss. Tas erste Fühlerglied gelb, die übrigen loram. (Die Beine inntilliert).

Der Kopf ist ziemlich gross, vorgezogren nnd zngespitzt, etwas kiurzer als der Halsschild, die Stinn ist narh vorne massig alilallend, etwa $1{ }^{1 / 3}$ breiter als der Durchmesser des Auges. Die Augen sind mässigr grross, von oben gesehen breit eiförnig, von der Seite gresehrn sowohl am Torder - wie anch an Hinterrande nicht ansgeschweift. Die Fiihler sind vor 
den Augen eingelenkit, das erste Glied ist gestreckt, zicmlich schwach verlickt. etwa 1/ t kürzer als die Breite der Stirn mit den Augen, das zweite Glied ist dremal länger als das erste, zur. Spitze kaum merkbar verdickt, etwa obenso lang als der Basalrand des Halsschildes, das dritte Glied ist dimn, nur um etwa $1 / 4$ kiurzer als das zweite (das vierte ist zerbrochen). Das Rostrum ist braun und erstreckt sich etwas über die Witte iles Hinterkörpers, das erste Glied etwas kürzer als der Kopf, mehr wie um die Hälfte kürzer als das zweite, das dritte ebenso lang als das zweite. Der Halsschild ist an Vorderrande viel schmäler als der Kopf mit den Angen, die Länge in der Mitte ist deutlich kïurzer als der Basalrand breit, die Sclreibe ist kräftig gewölbt, die Seiten sind nach vorne von der ausgeschweiften Stelle in der Mitte zifmlich stark gerundet verengt, der Seitenrand ist an der vorderen Hällte seharf, hinten verwischt. Der Basalrand ist fast gerade abgeschitten. Die Hemielytren sind beim liürer, beim $\sigma^{x}$ etwas länger als der Hinterkörpes: - Long. $4\left(c^{7}\right)-4.5$ ( + ), lat. $2 \mathrm{~mm}$.

Neu-Gumea: Stephansort, Astrolabe Bai, 1897, Bro, q (Mus. Nat. Hung.).

\section{Cylapofulvius grisescens $n$. sp).}

Der Kopf, der Halsschild, las Schildchon, der Clavus und das Corium lein und zienlich weitläufig punktiert, die Plenren sind fein gerunzelt. Ter Kopf ist grangelb, die Unterseite, die Zügel, der Clypeus, die Stirn vorne und zwei Längsstriche in der Mitte, die hinten Aureh ein Querstrich mit einander verbunden sind, schwarz. Der Halsschild sehwarz, der Torderand schmal, in der Mitte dreieckig nach hinten erweitert, ein schmaler, melır oder weniger ausgezogener Jängsstrich in der Nitte, der Basalrand schnal und einige lileino längsflecke auf der Scheibe graugelb-rotgelb. Das Schildehen schwarz, eine schmale Querbinde in der Mitte rot, die Spitze gelb. Die Hemielytren grangelb, mehrere Flecke, die mit einander zu schmalen, zackigen Querbinden mehr oder weniger zusammentliessen, der Clavus vor der Spitze breit und eine breite Querbinde hinten auf dem Corium schwarz, der sehr undeutlich begrenzte Cuneus in der Mitte graugelb, die Membran rauchig braunschwarz, clie Fühller schwarzbram, das erste Glied gellbraun, das Rostrum braun, die Ränder der Propleuren und die Orificien, Flecke an Vorderrande der Segmente auf dem Connexivm und ein grosser Fleck jederseits vor der Spitze gelblich-nelbgrau, der Hinterrand der Mesolleuren golbrot. Die Vorderschenkel braunschwarz, zur. Spitze heller, die Vorderschienen braun, an der Basis und vor der Spitze gellilich.

Der Kopl ist mässig gross, vorgezogen und zugespitzt, kaum kürzer als der Halsschild, die Stirn nach vorne mässigr abfallend, etwa $1^{1}{ }^{\prime}$ breiter als der Durchmesser des Auges. Die Augen sind gross und rorspringench, von oben gesehen rundlich eiförmig, von der Seite gesehen am Hinterrande kaum merkbar ansgeschweitt. Die Fühler sind fast gleicl an Vorderrande der Angen eingrelenkt, das erste Glied ist nu wenig verdickt, etwa um 1 kürzer als die Breite der Stirn mit den Angen, dremal küurzer als das zweite, dieses etwa $1 / 4$ kürzer als iler Basalrand des Halsschildes, dünn, zur Spitze kaum verdickt, die zwei letzten (ilieder diimner, das dritte ebenso lang als das zweite, das vierte etwas länger als das erste. Das Rostrum erstreckt sich etwas über die Mitte les Hinterliörpers, das erste Glied ebenso lang als der Kopf, nicht voll un die llälfte kïr'zer als das zweite, das ehenso lang als das dritte ist, das vierte etwas kürzer als das erste. Der Halssehild ist gewölbter und transversaler als boj punctatus und an den Seiten etwas seichter ausgeschwoift, ler Seitenrand ist muleutlicher, nur vorne abgesetzt, der Basalrand ist nach hinten schwach convex, die Calli weniger gewölbt. Das Schildchen ist etwas flacher. Die Hemielytren sind beim und f lainger als der Hinterkörper, der Cuneus ist undentlich abgesetzt. - Long. 3.5, lat. $1.8 \mathrm{~mm}$. 
↔. O. Neu-Guinea, Morolia!, 1300 m. alt, YII-IX. 1893, Lonia, 3 Exx. (Mns. Civ. (innor.).

Unterseheidet sich von pumetutus lurch andere Farbr, anderen Ban aler Fïhler und des Rostrums, andere Form des llalsschikles u. s. w.

\section{Bironiella n. wen.}

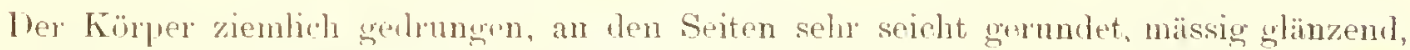
Lopf und Ialsschih mit Metallschinmer, dicht runzelig punktiert, oben ziemlich dicht mit kurzen, etwas sehuppenlïmigen, dicht anliegenden Häächen bekleidet. Der Kopf ist gross und breit, ziemlich kraitig zogespitzt, dis grossen Augen erstrecken siel nach unten bis zur kehle. Die Fühler sind dicht vor den Angen eingelenkt, das arste Glied ist riemlich gestreckt, mit etwa der Hälfte seiner Ijünge die Kopfspritze überragend, mässig verdickt, has zweite ist lang. hedentend länger und nur wenig dünner als das erste, beide dicht. anlirgend kurz hehaart, dic zwei letzten Glieder sind kurz, dïnm, mit einigen alustehenden, lïngeren Haaren bekleitet. I as erste Glied des Rostrums ist ebenso lang wie der Kopf.

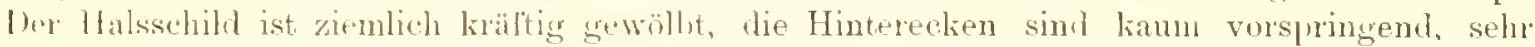
seicht abgerundet, die suiten sind nicht alygeflacht, schart serandest. Irie strictura apicalis ist nur rom ler Seite sichthar, oben ganz von den grussen, convexen Calli bedeckt. Die letztgrnannten erstrecken sirh nach hinten über die Hitte der reheilse. Was Schikdehen ist mässig rewölbt. Der Cuneus ist dentlich algesetzt, die Memlran zwrizellig. Die Vorderbeine (die anderen mutilliert) sim mässig lang, die Schienen dünn, zur Spitze schwach verschmälert, olme Dörnchen, die Fiässe schmal, das erste Glied lang, die Kílauen fein, ohne Arolien.

Nahe verwandt mit P'eritropis Thhler, unterscheidet sich u. a. dureh die Punktur und hurch itn Metallsehimmer des Koples nut des Jalschildes sowit dureh glanzende Oberseite.

Typus: Ii. motullesems n. sp.

\section{Bironiella metallescens n. sp.}

Kopf und IIalssehile grünlich metalliseh schimmernd, das Schilichen schwarz, die llenielytren brannschwarz, las ziemlich breite Embolium und der Comens dunkler, die Beine, die Fïller und das Rostrum dunkellurann.

I)er Kopf ist kaum kïrzer als der Halsschild, die Stirn in der Mitte tief gefurcht, nacb vorne schwach abfallend, etwas schmiller als der Durchmesser des Auges. Das erste Fïhlerglied ist etwa um liürer als dir Länge des Kopfes uml etwa ebenso viel kürzor als die Breite der Stim mit ren Angen. Das zweite Glied ist mehr wie dremal länger als ler Basalrand des Halsschildes. Din zwei letzten Glieder sind gleich lang, zusammen mehr wie nu die Hälfte kürzer als das zweite. Das Rostrum erstreckt sich etwas äber die Hintereoxen, das erste Glied ist fast 10 die Hälfte kürzer als das zweite, das ebenso lang wie das tritte ist. Die Lünge des Halsschildes in der Mitte ist $1 n$ ehr wie 1 m die Hälfte kürzer als die Breite des Basatrandes, theser etwa doppelt breiter als for Vorderrand, jederseits ohne Ausrandung, die Seiten sint nach vorne fast greradlinig verengt. Thie Calli sind von einander. durch eine ziemlich hreite mitl tiefe Lüngsturche getrennt. I)as Schildchen und die Hemielytren sind fein und etwas weitläufiger als der Halsschild, nicht aber runzelig punktiert. Die letztgenannten erstrecken sich heim co etwas üler die S Spitzc des Hinterkörpers, der Cunens ist et wa ebenso lang wie an der Jasis hreit. - Long. 4.3, lat. $1.7 \mathrm{~mm}$.

Neu-Guinea: Huon-Goli, Sattelberg. 1899. Bró, 1 r. (Mus. Inng.).

$N: 14$. 


\section{Gattung Peritropis. UHL.}

Peritropis Uhler Proc. Ent. Soc. Washingt., I1, 1s91, 1. 122. - Reut. Bemerk. Nearct. Caps., 1. 66, 1909. - Mevius Dist. Faun. Brit. Ind., Rhynch. II, p. 453.

Der Körper gedrungen, an den Seiten ziemlich kräftig gerundet, matt, die Oberseite last kahl oder mit weitläufig stehenden Schuppenhaaren bestreut, dio Unterseite des llinterkörper's oft mit kurzen Haaren bekleidet. Der Kopf ist gross und ziemlich breit, yestreckt und zugespitzt, die grossen Angen erstrecken sich nach unten bis zur Kehle. Die Fühler sind dicht vor den Augen eingelenkt, das erste Glied ist kurz, nicht oder nur wenig die Kopt'spitze überragend, wenig verdickt, das zweite Glied ist lang. beim meistens etwas verdiclit, verhältnismässig wenig schmäler als das erste und immer viel längel ats das letztgenannte, die zwei letzten Glieder kurz. Das erste Glied des Rostrums ist ebenso lang wie der Kopf. Der letztgenamnte hinten Haeh eingedriickt. Der Halsschild flach — ziemlich krättig gewölbt, die Hinterecken sind nicht rorspringend, spitz orker abgerundet, die Seiten siml abgeflacht, der Seitenrand scharf, the Seiten nach vorne geradlinig verengt. Die Strictura apicalis ist schmal, zuweilen von den Calli bedeckt, diese letztere gross. weit nach hinten sich erstreckend. L)as

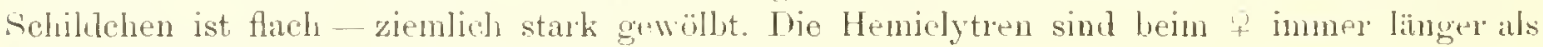
der Hinterliörper, der Cuneus deutlich ausurebilkt.

Typus: $P$. suldatormis Ubles.

\section{Übersicht der Unterwattungen und Arten.}

1. (6). Die Membran mit zwei Zełlen, die äusser st’n klein, aber dentlich. Die Hinterecken des Halssehildes abgermulet.

Subgen. Peritropis s. str.

2. (3). Kleine, nicht 3 mm. crreichende Art. Das zweite Fühlerglierl verdickt.

saldaformis Uhler ${ }^{1}$ ).

3. (2). Über $3 \mathrm{~mm}$. messende, grössere Arten.

4. (5). Das zweite Fülleruliel sehr wenig verdickt, lraunschwarz, in du Mitte schmal weiss. Der Halsschild unıl das Sehildehen ziemlich kräftig gewölbt.

jacanicus n. sp.

5. (4). Tas zweite Fühlerglied ziemlich verdiekt, in der Mitte weiss, vor der Mitte lranngelb, hinter derselben braunschwarz. Der Halsschild und das Schildchen schwach gewölbt.

similis $\mathrm{n} . \mathrm{sp}$.

6. (1). Die Membran einzellig. Dio Hinterecken des Halsschildes nicht abgerundot.

Subgen. Mprius (Dist.).

7. (10). Das zweite Fühlerglied weiss geringelt. Kleine, höchsstens 3 mm. messendo Arten.

8. (9). Die Schienen und das zweite Fühlergherl mit melneren, breiten, weissen Ringen, die Schenkel hell mit dunklen Ringen.

ammiticornis $11 . \mathrm{sp}$.

3) Uhler, Proc. Wint. Soc. Washingt, II, 1891, 1, I'? 
1. (s). Die Schienen und das zweite Fühlerolied nur in ler Mitte mit einem sebmalon, hellen Ringe, die trundtatie der Beine dunkel.

luguluris n. sp.

10. (5). Mas zweite Fïhlorglied einfinbig Innkel. Grosstre, 5 mm. messende Art.

lewisi Dist.

Peritropis (s. str.) javanicus n. sp.

Gestreckt oval mit ziemlich gerumleten Körperseiten, matt, oben mit weitlänfig stehenılen, sehr knrzen, siluppentömigen hellen Häarchen bekleilet, hraunschwar, der Kopt in ter Mittr mit einem Längsstrich, der sirh nach hinten etwa bis zu Mitte der Angen erstrevkt, und an len Sciten fü̈l Pilar nach hinten convergierende Längsstribhe, von denen der letzte kur\% ist, hinter diesen ein Guerstrich, der sieh jedersits erst prallelseitig, dann vor den Angen sich nach anssen biegent fortsetzt, gell, der Halsschild mit zahlreichen Punkten auf der Scheihe, jederseits mit zwej, mit clen Seitenrande parallel lantenden Längsstrichen, von denen der innere kürzer, sowie der Basal- nnd der Torderramil selmal, die Seiten sehr sehmal gejl, das schildehen hinter dex Basis mit zwei mit dunklen Punkten bestrenten Fleeken nnd in der. Nitte mit einiren kleinen, kmzen Längs-

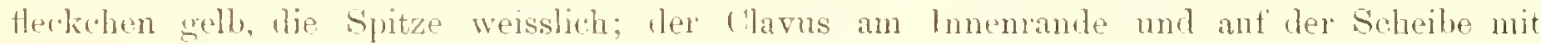
singen ziemlich breiten Längsstrichen und ainzelnen ktemen Pünktchen gelb; das Corimn immerliall, der Vena exterior mit einigen grösseren Längsflecken und ziemlich dicht gestellten kleinen Pïnktehen, ausserlalb del. Tena mit dicht gestellten Pünktehen, am Aussenrande ausserdem mit einigen Flecken und vor den cunens mit einer ziemlich lueiten Guerbinde crelb. Ter Cuneus ist an der Basis sehmal gelb, sonst lramn, einzeh mit gelben Pünktehen bestrent. lie Membran ist rauchschwar, ziemlich dicht mit hellen Punkten bestrent. Der ungelogene Sieitemand les Tlalsschildes und die Hinterxänder der Brüste welb. Der Hinterkörjer ist yelbbraun, an hen seiten braunschwarz. Die Fühler sind hrannsehwarz, das zweite Glied in der Mitte ziemlich schmal weiss (die Beine und das Rostrum fehlen).

Der Kopf ist ziemlich gross und vorgezogen, zugespritzt, ebenso lang als der Halsschild, aut' der Stirn flach eingedrïelit. Die Augen sind gross und vorspringend, von oben gesehen gestreckt eitörmigr, von der Seite gosehen sich his zur Kehle erstreckend, am Hinterrancle seicht ansgeschweift, ihr Durchmesser nur wenig kürzer als die Breite der Stirn. Die Fïhler sind gleich vor den Angen eingelenkt, das erste Glied sohwach verdickt, kamm die Koptspitze überragend, etwa un 1/s kürzer als die Breite der Stim mit den Angen, das zweite Glied ist lang, "was sehmäler als las erste, zur spoitze nirht verdiclit, nehr wie dreimal lïnger als las erste, etwa thenso lang als iler Basalrand les Halsschildes (die iibrigen Glieder sind zerbrochen). Jer Halssilnild ist an Torderrande etwas schmäler als der Kopf mit ilen Augen, lie Länge in lier Mitte ist mehr wie um die Hälfte kürzer als der Basalrand breit; die Strictura apicalis ist dentlinh, aber schmal, nie Calli smo ziemlich convex, weit über dio

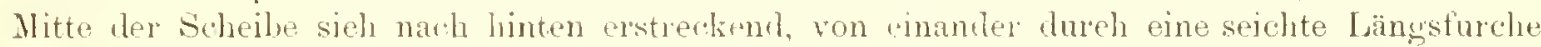

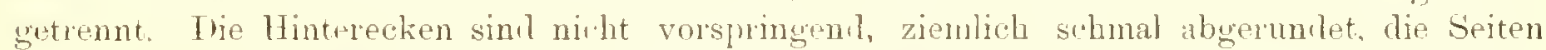
sind nacll rorne gerallinig verengt, stbmal flach alyesetzt. Die Basis ist in der Mitte sehr seicht ansgeschweift, der Basalranil etwa hoppelt hreiter als der Vorderand. Das Sehilhlehen ist liraltig gewölbt. Die Henielytren sind bein ; hellentend länger als der llinterkürper,

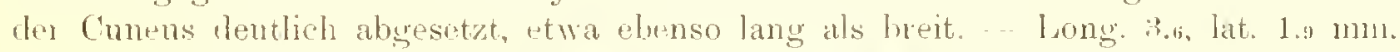

Nahe verwandt mit $P$. similis m., nnterscheidet sieh aber leicht dureh dünnere Fühler,

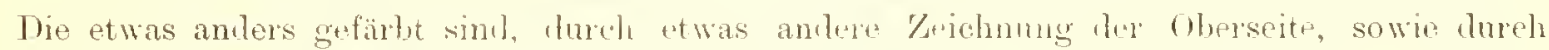

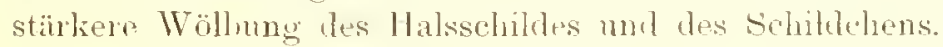

West-Java: Pengalengan!, $400 y^{\prime}$ alt., Fruwstorfer, 1593, 1 - (Mus. Vinlob.). 


\section{Peritropis (s. str.) similis n. sp.}

Ist sehr nahe mit juranicus m. verwandt. Der Kopf ist ron rerselben Farbe. Der Halsschild ist viel diehter grell, gefleckt, in der Mitte der Scheibe sind the Fleckehen zu mregehnässigen grösseren Fleeken veremingt, die Längsstriche an den Seiten sinu in Flerken anfgelöst, der Seitenrand ist brann. Der Clavus ist nur mit hellen Flecken bestrent, die innere Hälfte des Cormus ist ansgedehnter dunkel, die helle Querbinde vor dem Cuneus ist viel schmäler. Der letrtgenannte ist dunliler. Das erste Fühlerglied ist etwas länger und dicker, etwa 1/4 kiuzer als die Breite her Stirn mit den Augen, das zweite Glied ist bedentend dicker, nur wenig schmäler und kamn 3 Mal länger als das erste, etwas länger als der Basalrand des Halsschildes. I as tritte und vierte Glied sind dünn, gleieh lang, zusammen etwas länger als das erste. Das Rostrum erstreckt sich etwa bis zur Hitte des Hinterkörpers, ras erste Glied ist ebenso lang als del Kopf, nicht voll mu hie Hälfte kiurzer als rlas zweite, dieses etwa $1 \frac{1}{5}$ länger als das vierte. Der Halsschilh ist weniger stark transversal, der Jasalrand nieht voll doppelt breiter als der Vorderranu, die Calli sind weniger convex. Das Sehildehen ist flacher. Des Hinterkörper ist unten dunkler gefürbt, an den Seiton mit ein far. Fleckehen auf den Seymenten hell. Die Coxen sind gelbweiss, die Selienkel sind sehwarzbraun, die Schienen braun, hie äusserste spitze der elsten, die Basis, die Nitte und alie spritze der letzteren gelbweiss, die Tarsen braun. - Long. $4-5$, lat. $2-2.5 \mathrm{~mm}$.

Ost-Indischer Archippel: Insel Engano, Bua-Bua!, V-T1. 1891: Malaconni!, V1. 1891, Monglian, mehrere Hxemplare (Mus. Civ. Genor. et Klelsingfo.).

\section{Peritropis (Mevius) annulicornis n. $\mathrm{sp}$.}

Gestreekt oral, flach, matt, oben mit weitläufig stchenden, sehr kurzen Schuppenhäarchen hekleihet, oben hell strohgelb mit nehr orler weniger zusimmenfliessenden braunen Flewen bestreut, die brsonders an dun Seiten iles Halsschikles zu grösseren Flecken mnd Binden verbunden sind und die anf der Stirn und in der Mitte des Halsschildes mehr rötlich sincl, das Schildchen schwarz, an der Basis mit einigen Fledken und die Spitzo grelb, auf dem ('or'inm in runder. Fleck vor der Mitte und die innere Apiralecke braun, das Fmbolium brann mit gelben Flecken. ler Cunens braun, innen mit gelb ansgemischt. die Spitze hell, (lie Membran ist ranchig Hrannschwarz mit ziemlich dicht stehenden kleinen, rmuen, hullen Flerkchen, die Unterseite lirannschwar, der Hinterkörper unten in der Hitte gell, an den Seiten mit einigen gelben Flecken. Jas Rostrum und das erste Füllerglied sind gell, das lutztgenannte braum besprenkelt, in Apr Mitte mit einem quer gestellen sehwarbramnen Ring, die übrigen Fühlerglieder braunschwarz, las zweite $j$ m basalen Drittel mit zwei schmalen, in der Mitte mit einem breiteren Ring und die äusserste Spitze grelhweiss. Dir Beine sind selb. die apicale Hälfte der Vorderschenkel, die äusserste Syitze ausgenommen, die Mitte lureit und ein schnillerer Ring der Mittel- mal Hinterschenkel, ein sehr schmaler Ring an der Basis mol zwri lireitere auf den Schionen liranschwarz.

ber Kolf ist gross, vorgezogen und zugespitzt, ebenso lang als der Halsschikd. Die Augen sind gross, von oben resehen rundlich, von ler Seite gesehen sich his zur Kehle erstreckend, an Hinterrande seicht ausgeschweift. Lio Stim ist etwa $1 \frac{1}{3}$ breiter als der l'urehmesser des Anges. Die Fühler sind gleich vor den Augen eingrelenkt, diss erste rilierl

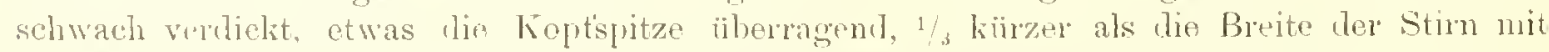

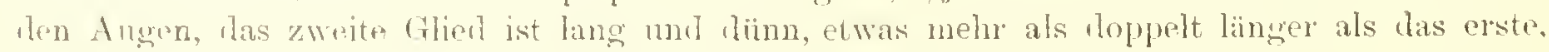

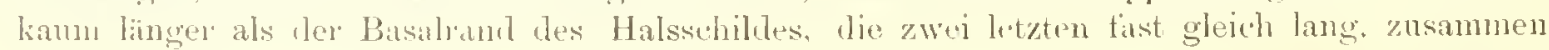




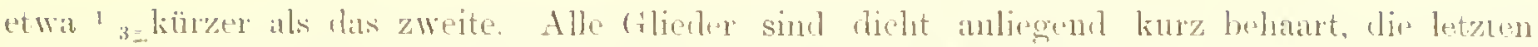
ansserdem mit längeren, abstehenten llaaren hesetzt. l has Rostrum erstreatit sich etwa zum Spitzenviertel des Hinterköpers, thas erste Glied fast "benso lang als das zweite, dieses ".

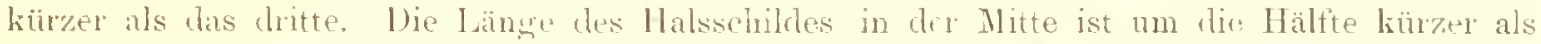

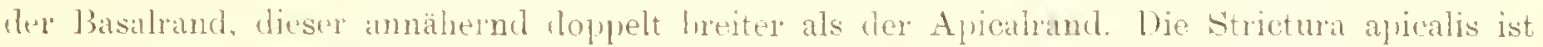
deutliels abgesetzt, schmal, die Calli sind ziemlich convex, sehr gross, wheich hinter der strictura apicalis leginnend und nach hinten tiast bis zmun Basalrande sich erstreckend, von ein-

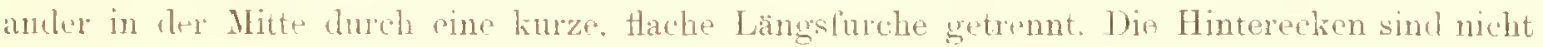

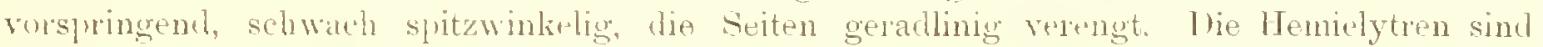

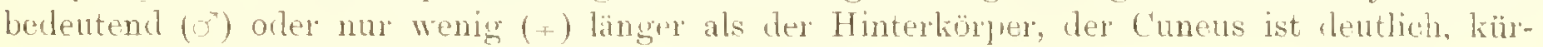
zer als an der Basis breit. - Long. 2.5-3, lat. 1.2-1.5 $\mathrm{mm}$.

The Art erimnert seln an $P$. sulderformis Uhler, unterscheidet sich lurch gestreckteren Koprt, sehmäleren und rerhältnismässig längeren Hakschilk, dessen Seiten narlı rorne weniner stark verengt sind, grössere unel convexere Calli. dimnere, anders gefarbe Fühler, dureh anderen Bau des Rostrums sowie durch anders gefärbte Beine. - Von P. (Jevius) lewisi Dist. sotort zu unterscheiden dureh elen kleineren Kürper und die andere Farbe der Füliler.

Nen-Gnineat: Sinbang, Hun Golt: Stephansort, Astrolabs Bai; Erini, Astrolabe Bai,

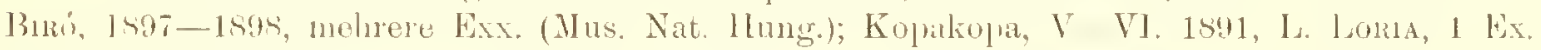
(Mus. Civ. (Henov.).

Peritropis (Mevius) Iugubris $11, \mathrm{~s}$.

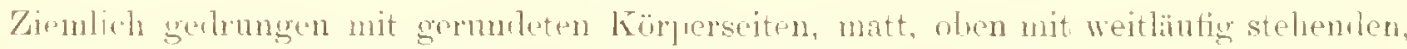
sehr kurzen, schulprenförmigen, hellen Hiärchen hekleidet, schwarzhrun, die spitzo des Kopfes, drei kleine Fleckehen am Basahande und die Hintererken des Halsschildes sehr sehmal, cin kleines Fleekehen jederseits an der Basis un die äusserste surtze des schilithens. der Hinterkörper unten, die Coxen, die Basis der Sthenkel und das Fostrum brann, das erste Fühlerglied an ter Basis, ein sehr schmaler Ring in der Mitte les zweiten diliedes und ein etwas breiterer Ring in der Nitte nnd ein anderer, sehr schmaler an der Basis der schienen nnd die Fiisse gelbbraun, lie Membran granswharz nit kleinen, weissen Flecken. lier Kopl ist ziemlich gross, mässign vorgezogen, etwa elenso lang wie her Halssehilı, ant dr. Stim tief' eingedrickt. Die Augen sind gross nuth vorsplringend, von oben gesehen ziemlich rund. lirh, von der Seito geselen sich bis zur. Kehle erstreckend, am Hinterrande seicht ansgeschweift, ihr Durchmesser beim nur wenig küror als die Breite der Stirn. Die Fühler sinn gleich vor den Augen eingelenkt, das erste trlied sehr wenic verlickt, kaum die Kopfispitze überragend, mehr als ${ }^{1}{ }_{3}$ kürzer als die Breite der Stirn mit den Augen, das zweite ist lang, etwas schnäler als das erste, zur riptzr sehr schwach rerdicht, etwa lreinal längrer als das erste, etwas kiirzer als der Basalrand des Halsschildes (dip übrigen Glieder mutilliert). Der Halsschild ist an Vorderrande etwas schmäler als der Kopt mit den Augen, in der Mitte: mehr wie um die Hïltte kürzer als an Basalrande heit; die Strirtura apicalis ist nur an clen Seiten zu sehen, oben von den Gilli bedeckt, diese letztere sind ziemlich convex, nach hinten etwas über dio Mitte der Shoibe sich erstreckend, von einander in der Mitte lurch ein tiefes Grübchen getrennt. Din Hinterecken sind nicht vorspringeml, spitz, die Seiten sind nach vorne geradlinis verengt, nicht. abgetlarht. J) Basalrand ist in der. Nitte seiclat und breit anscreschweift, etwa roppelt breiter als der Tonlerand. Das schiluchen ist ziemlich Hach gewölbt. Die Hemielytren sind bein + etwas länger als der Minterkörper, der Cuneus ist deutlich abgesetzt, kürzer als an der Basis breit. - Long. 2.s, lat. $1.5 \mathrm{~mm}$.

N:o 4 , 
Habituell sehr don dunklen Varietäten les I'ritropis suldeformis Uhler ähnlìh, unterscheidet sich aber 11. a. sofort hurch die einzellige Menturan und durch die nicht abgerundeten Hinterecken des Halssehildes. Von P. ammlicomis no. durch andere Farbenzeichnung getrennt.

Singapore, Buí 1s:s, 1 + (Mus. Hung.).

\section{Euchilofulvius n. gen.}

Der Körper ist ziemlich gerlrmgen, an den Siten gerundet, matt, Kopl, Halssehild und Sthildchen sowie anch die Tnterseite fein und hicht chagriniert, die Cberseite und die Pleuren mit einzeln stehenden, gyestreckten, weissen Sebuppen bedeckt. Der Kopt ist lany vorgezogen, zngespitzt, nicht vertical, die Zïgel sind dentlich. Die Augen erstrecken sich bis zur Kehlo. Thie Fühler sind etwas vor den Augen eingelenkt, alas erste Glied ist ziemlich lang, die Koplspitze etwa mit der Hälfte der Länge überschreitend, mässiğ verdickt, das zweite Glied ist zu. Spitze alluählich verdickt und lier kamm sehmäler als das erste, kaum um die Hälfte lïnger als dasselbe, die zwej letzten kurz, alle sehr liurz, anliegend hehaart, das letzte ausserdem mit längeren, abstehenden Haaren besetzt. Das erste Rostralgried erreicht nur die Nitte der Augen. Der Kopt ist hinten breit der Quere nach eingedriiclit, vor dem Eindruck in der Nitte mit einer ganz kurzen, feinen I ängsfurche. Dor Halssehild ist liäftig gewölbt, nach vorne stark abfallen , die Hinterecken sind schwach abgerundet, nicht rorspringend. Die Sitrictura apicalis ist ziemlich selarf abgesetzt, die Calli sind mässig gross, nach den Seiten zu wenig scharf begrenzt, nach linten bis zur Mitte der Schibe sich erstreckend. Das Schildehen ist nach hinten ziemlich stark abfallent, gleich binter der Basis Hach eingedrïckt. I bie Hemielytren sind beim f. etwas länger als der Hinterkörper, der Cunens ist gut ausgrebilitet, das basale Drittel des Eumboliums ist an den Seiten fein gekerbt, ziemlich schmal, von bier an nach hinten stark erweitert.

Diese Gattung bildet einen Übergang ron den Peritropis-ilhnlichen zu den Fulviusähnlichen Gattungen. Von don letztgenannten ist als Lnterschied 1. a. besonders das erwejterte Embolium horvorzuheben. Besonder's latrvortretemi ist der stark gewölbte Halsschild.

Typus: E. titralis n. sp.

\section{Euchilofulvius tibialis n. sp.}

(Fig. 8-8 a.)

Schwarzbraun, der Kopt, ein sehr schmaler Länusstrich auf den Clavus, das Coriun, der Hinterlörper, die Sclienkel, die basale Hälte der Vorder-Tibien und das erste Fühlergliul braun, der Cuneus, das Fmbolinm und das zweite Fühlerglierl, das braunschwarze, apicale Viertel ausgenommen, rotbraun, die zwei letzten Fühlerglieder, die apicale Hälfte ler VorderTibien, die Hinter-Coxen und die Spitze der Mittel-Coxen gelbweiss, das erste Rostralglien braunschwarz, das zweite bram gelb, die letzten lraun, auf dem llalsschilde der Basalrand schnal, die Hinterecken unı ein ganz kurzer längsstrich in der Mitte der Basis braungelb, der Aussenrand des Cuneus fast der ganzen Länge nach sehr schunal schwarzbram, auf rem Corjum ein kleiner, drejectiger Makel am Aussenrande vor der Mitte und vor dem Cumeus eine schmale Querbinde, dir sich his zum Aussenrande les Emboliums erstreckt, weiss, das

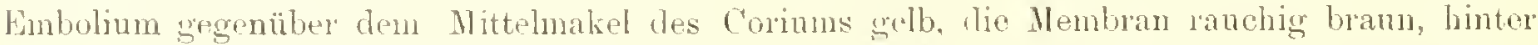
den Cuneus ein durchsichtiges, helles Flockchen. (The Mittel- und Hinterbeine sind nutilliert).

Der Kopl ist gross, länger als mit den Augen breit, etwas kürzer als der Halsschili. die Angen sind gross und vorspingend, ron oben yesulen rumllich eiförmig, ron der Seite gesehen am Hinterrante ausureschweift. Die Stirn ist beim $₹$ etwas breiter als der Dureh- 
messer des Auges, nath vorne sehr thath abfallend. Dois Rostrun elstreckt sich etwas ibber

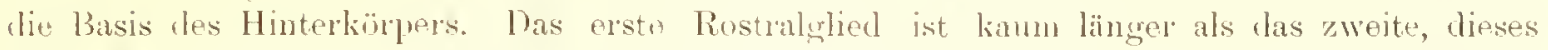
etwa ${ }^{1}{ }_{4}$ kürzer als das dritte. Das erste Fühlerglied ist etwa $1 / 4$ kiurzer als die Breite der stirn mit den Augen, das zweite ist etwa ebenso lang als cler lBasalrand des Halsschililes, das letzto ist etwas länger als das dritte. beide zusammen etwa $1 / 3 \mathrm{kiurzer}$ als das zweite. Jer Ilalsschild ist in der. Nitte fast ehenso lang als am Basahrande breit, der letztrenannte meln

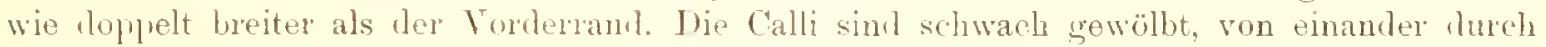
eine breite, seichte längsfurhe gretremt. Ilie Seiten sind vor den Hinterecken sehr seicht ausgeschweift, von hier nah vorne fast gerallinig verengt. Ier Basalrand ist fast gerale alogesehnitten. Der Cunens ist etwa hemo lang als an der Basis hreit. - Long. 3, lat. 1.2 mm.

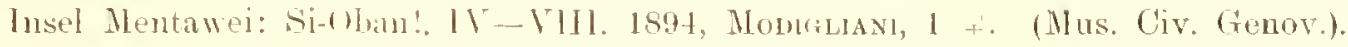

\section{Fulvius S'TAL.}

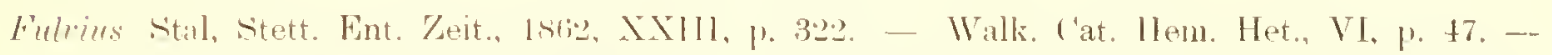
I)ist. Biol. Centr. Aner., Rhynch., 1. 184t, 1. 2241. - Uhler, Check list Hem. Het. N. Anter., 1ss6, 1. 19. - Reut., Ann. Ent. France, 1s:2, LXI. 1. 391. - Rent. Lint.

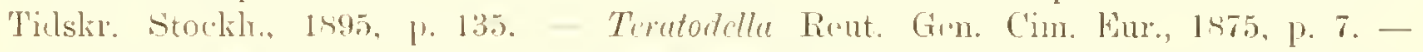
Bergr., knt. Nachr., 1s79, 1. 34 et los. Cameloeapsus Reut., Ann. Soc. Ent. Franto,

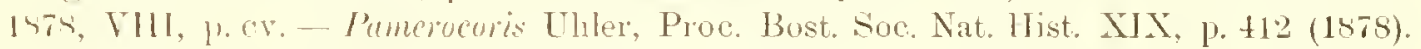

Der Körler gestreckt, fast prarallelseitig, selten gerlumgen und an den seiten serumlet. I ie Uberseite matt, selten glinzend, mit kurzen, anliegenilen, selten sehwach schupıenähnlichen Häärehen bekhilet, meistens glatt, selten wwas gröber chagriniert, (discifrr u. a.). Ter Kopf ist rimlich gross, horizontal, vorgezngen und zugespitzt, selten etwas gedrungener, ziemlich geneigt (humbtus), die Ziigel schmal und deutlich alugesetzt. Die grossen Augen erreichen immer die Kehle." 1)ie Fiihler sind immer an Vorlerrande der Ausen eingelenkt, die zwei ersten Glieder kurz anliegend behant. Das erste Glied ist verdickt, das zweite immer bedeutend länger als ùs erste, zur. Spitze meistens alluählich verdiclit. Die Stim hat in der Mitte eine teine längsturche. Der Halsschild ist meistens horizontal, selten grewölbt, die Apicalstrictur schart' abgesetzt, die Calli convex, yross, oft übel die Mitte der Seheib. nach hinten sich erstrekent. die Hinterecken sind zugespitzt und vorspringend, die Seiten vor denselben seicht ausgreschweitt. Der Basalrand ist ausgeschweilt. Das Schildehen ist flach. Ine Hemielytren sind selten kürzer, meistens länger als der Hinterkörper, der. Cuneus ist leutlich abuesetzt, das Fimbolium ist der ganzen Längre nach grleichbreit.

Tyjus: Fulvius unthocoroides STiL.

Übersicht der Arten ').

1. (24). Der Cuneus einfarbig, braun-sehwarz.

2. (23). Kopf und Halsschild eintarbig braun-schwarz.

3. (6). Die Füller braungelb--braunschwarz, einfarligg, das zweite filier zur Spitze nie heller. Die Hemielytren ohne gelblichn onder weissen \%eichungen.

4. (5). Körper gedrungen. Die Henielytren gelbbraun.

pallidus n. sp.

5. (4). Körper gestreckt, die Hemielytren braunschwarz.

unicolor n. sp. menfallt.

2) In dieser C̈bersicht fellt $F$. allumuculatus I'ist., der velleicht nit $F$. bisbistillatus stal zusam- 
6. (3). Die Fühler zweifarbing, indem das zweite Glied zur Spitze immer hrller erscheint.

7. (18). Jie Basis der Hemielytren heller als die hintere Hälfte.

8. (!). Nur das basale Drittel des zweiten Fühlergliedes dunkel guefärbt. Dio hellen Zeichnungen der Hemielytren gelbbraun.

flavicomis n. sp.

9. (8). Wenigstens die Basalhälfte des weiten Fühlerglierles dunkel. Die hellen Zeichnungen der Hemielytren rotgelb, gelbweiss oder weiss.

10. (11). Die apicale Hälfte des zweiten Fülllergliedes weisslich. Die hellen Zeichnungen der Hemielytren rötlich grelbweiss.

subnitens $\mathrm{n}$. sp.

11. (10). Nur das apicale Drittel oder Viertel des zweiten Fühlergliedes weisslieh.

12. (13). Die Basis der Hemielytren seln schmal hell gelärbt, auf' lenselben in der Mitte ein kleines, helles Fleekchen. Die Beine schwarzbraun.

discifer Reut. ').

13. (12). Die Basis der Hemielytren ansgedelnt hell grefärbt, in der Mitto dersellyen kein helles Fleckehen. Dio Beine meln oder weniger ausgedelnt braungelb - grelb żefärbt.

14. (17). Jas erste Füllerglied kurz, nur wonig die Kopfspitze iiberragend.

15. (16). Her Kopf ziemlich kurz zugespitzt. Das zweite Fühlerglied ziemlich kurz und dick, nicht länger als ter Basalrand des Halsschilles. Nur das basale Drittel der Hemielytren hell gofärbt. Die Sehenlel schwarzbraun, nur an der Spitze rötlich. brevicomis ReUT. ${ }^{2}$ ).

16. (15). Der Kopf gestreckt zumespitzt, das zweite Fühlerglied ziemlich dünn, länger als der Basalrand des Halsschildes. Etwas mehr als die basale Hälte der Hemielytren hell. Die Schenkel gelblich.

dimidiatus $11 . \mathrm{sp}$.

17. (14). 1)as erste Füblerglied nit etwa der Hälite der Längre die Koptspitze uiberragend. Nur etwa das basale Drittel der Hemielytren hell. Die Beine gelb.

oxyc(renoides RetT. $\left.{ }^{3}\right)$.

18. (7). Die Hemielytren an der Basis brannsehwarz-schwarz.

19. (20). Das Corium an der äusseren Apicalecke vor dem Cuneus mit einem klemen, gelbweissen Fleckchen.

nigricomis $\mathrm{n}$. $\mathrm{sp}$.

20. (19). Das Corium an der äusseren Apicalecke ohne helles Fleckchen.

21. (22). Das erste Fülılerglierl braunschwarz, nur die Spitze schmal rötlich. Auf den’ Corium ein ganz kleines yelloweisses Fleckclsen etwa in der Mitte des Innenrandes. Der Körper gestrecliter.

bimaculatus 11. sp.

22. (21). Ias urste Fublerglied einfarbiy rotgelb. Vor der Mitte des Coriums tin grosser, weisser, halb Jurelssichtiger Fleck, der sich fast bis zum Aussenrande erstreckt. Der Körper gedrungener.

bifenestratus n. $\mathrm{sp}$.

1) Offr. Finsk. Vet. Soc. Förh. XLIX, N:0 7, 1906-7, p. 28. - 2) Tratodella anthocomides Reut. Bih. Sr. Tet. Ak. Hanll, Bd. HII, Nio 1. 1875, 1\%, 8. - Fulvius brevicornis, Ent. Tidskr. 1495, P. 136. - 3) ('amelo-

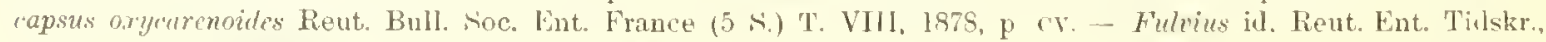
1895, p. 139. - Amblytys? onnatules Jak. Ilo. liakк. края, p. 138. id. Reut. Hem. Gymn. Eur., 111, p. 470. 
23. (2). Kopt" und Halsschilı mit hellen Zeichnungen.

ieniegutus: n. sp.

24. (1). Der Cunens an der Basis meln orler weniger ausuredelnnt gelbwoiss - weiss gefärbt.

2.5. (4(i). Corium braun-schwarzbran.

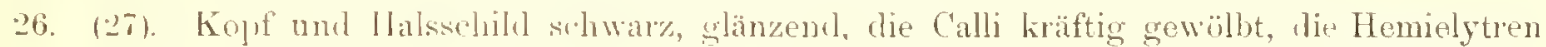
braun mit weisser (Querbinde vor der Mitte des Coriums. Sehr kleine, nur 2 wm. lange Art.

lunulatus Uhler ${ }^{1}$ ).

27. (26). Kopt und llalsschilh von derselben Farbe wie die Lemiolytren, matt, die Calli sehwach orler mässig grewölht. Grössere Arten, die wenigstens 3 mm. messen.

29. (33). Thas Schildehen jedprseits mit einem hellen Fleckchen und mit weisslicher. Spitze.

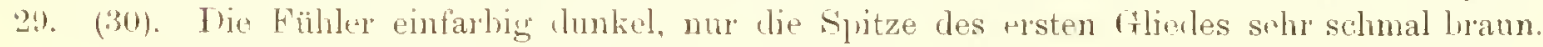
Die litlen Zeichnngen der Hemielytren undentlich.

sulmaculatus $\mathrm{n} . \mathrm{sp}$.

30. (29). Das zweite Fühlerglied ganz orler wenigstens die Splitze dessellen hellgelb. Ihe hellen Zeishmungen der Hemielytren deutlich.

31. (32). Tas zweite Fühlerglied etwa $22 / 3$ länger als das erste, die Basis und die Spitze. oder auch fast das ganze rlied grelbweiss.

brumeus Prov. :).

32. (31). Das zweite Fïhlerglied kaum doppelt länger als das erste, nur die Spitze hellgelb. stillutipennis $\mathrm{STAR}^{3}$ ).

33. (25). Das Schildchen einfarbig lraunschwarz, selten sind jederseits an der Basis zwei hellere Fledidlen vorlatnden, nie aber ist die spitze hell.

34. (45). Die Spitze des zweiten Fühlergliedes weisslieh.

35. (44). Wenigstens das apicale Tiertel des zweiten Fühlergliedes weisslich.

36. (37). Was erste Fühlerglied übersehreitet bedentend lie Kopfspitze und ist dentlich länger als die Breite des Lioptens nit den Angen, das zweite Glied ist etwa $1 / 3$ länger als dej. Basalrand les Halssehildes.

heidemanni REUT. ${ }^{4}$ ).

37. (36). Das erste Fühlelgrlied ist lü̈rhtens ebenso lang als die Breite des Kopfes mit den Augen, das zweite Gilied liurzer: hüchstens unbedeutend länger als die Basis des Halsschildes.

3.. (39). Der Kopll mit hellen Fleckchen, die Calli braungelb, die Querbinde vor der Mitte des Coriums ist nicht sehart begrenat und erreicht nicht den Aussenrand.

brumpiceps n. sp.

39. (35). Ter Kopf eintarbig, dunkel, die Calli von derselben dunklen Farbe wie die übrigen Teile des Halsselildes.

40. (43). Wenigstens die Mittel- und die Hintercoxen Weisslich.

${ }^{1}$ ) I'roc. Zool. Soc. Lomdon, 1494, p, 192. - 2) Lygus brunneus Prov. Nat. Can, 1V, 1572, 1). 104. -

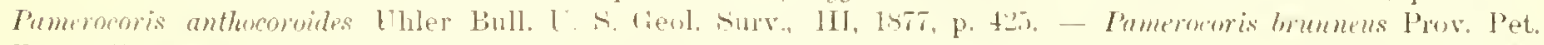

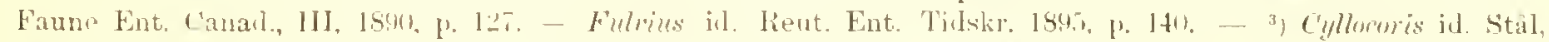
Rin Jan. Hem., p. 57, 155s. - Reut. 1. c., 1. 14: .. +) Reut. 1. c., 1. 142.

N:O 4 . 
41. (42). Das erste Fühlerglied braun, das zweite last oder doppelt länger. Die Vordercoxen braun. Die Sehenkel gelbrot - braun, die hinteren inmer zur Spitze oder ganz braunrot - braun.

quadristillatus STÅ̀' ').

42. (41). Das erste Fühlerglied und das basale Viertel des zweiten gelb-gellnot, das zweite mehr wie doppelt länger als das erste. Die Basallıälfte der Vorrlercoxen weisslich. Alle Sehenkel hell.

lisbistillatus STAL ${ }^{2}$ ).

43. (40). Alle Coxen einfarbig dunkelbraun. Grössere Art, 42, mm. lang̣.

hreddini Reut, $\left.{ }^{3}\right)$.

44. (35). Nur etwa 1/6 des zweiten Fühlergliedes an der Suitze gelblich, dasselbe Glied doppelt längerund ebenso dick als das erste. Die Schenkel gelh, an der Basis. die hinteren auch an der Spitze dunkel.

dulines Reut. ${ }^{4}$ ).

45. (34). Das zweite Fühlerghied einfarbig schwarz, las erste braungelb. Die Schenkel braungelb, an der Basis braun.

atratus Dist. $\left.{ }^{5}\right)$.

46. (25). Die Hemielytren graugelb-braungelb, braun gresprenkelt, der Cuneus braum, mit oder ohne gelhem Quermakel an der Basis.

47. (50). Das zweite Fühlerglied einfarbig schwarz.

48. (49). Corium mit hellen Zeichnungen.

fuseuns Dist. ${ }^{6}$ ).

49. (48). Corium einfarbig braun.

simillimes n. sp.

50. (47.) Das apicale Viertel rles zweiten Fïhlergliedes weisslich.

anthocoroides STÅL ${ }^{7}$ ).

Fulvius pallidus n. sp.

(Fig. 9.)

Ziemlich gedrungen, matt, olen sehr kurz, weitläufig anliegend hell behart, hellbraun, die Hemielytren heller, die Basis und die äusserste Aussenspitze des Coriums heller als die äbrigen Teile, die Seiten des Coriums schmal und der Cuneus röttieh braun, die Fühler, das Rostrum und die Beine braungelb, die Unterseite braun.

Der Kopf ist nach vorne mässig vorgezogen und zugespitzt, ebeuso lang als der Halsschild. die Augen sinıl gross und mässig vorspringend. Die Stim ist sowohl beim or als auch beim f etwa doplelt lreiter als der Burehmesser des Auges, nach vorne sehr sehwach abfitlend. Die Augen sind von oben gesehen gestreckt eifürmig, von der Seite gesehen sich

1) Cyllocoris quadristillalus Stål Rio Jan. Hem, 1, p. 5t (1858).- Fulvius Simoni Rent. Ann. Soc. Ent. France, 1492, p. 391. - F. quedristillatus Rent., Ent. 'Tidekr. Stockh., 1845, p. 144. - ${ }^{2}$ ) Cyllocoris bisbislillatus

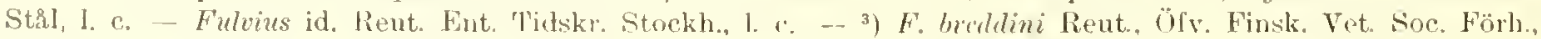

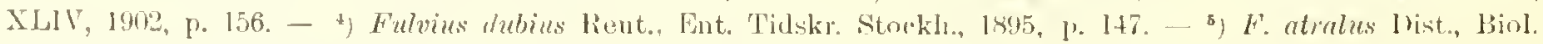

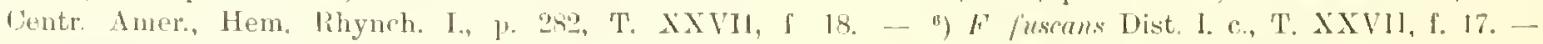

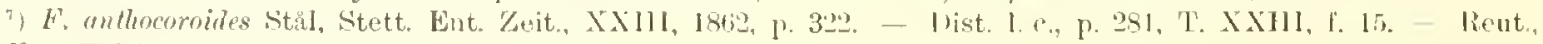
Fint Tiiskr. Stockl., 1895, I' 149. 


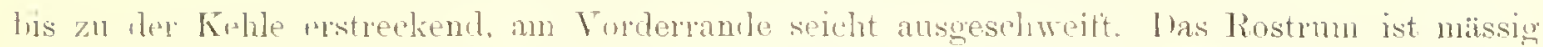
lang unl erstreckt sich his zur sintze les zwejten Ventralsegmentes, das erste Glien ist Henso lang als del Kopt, etwa ${ }^{2}$ " kürzer als das zweite, dieses etwa $1 / 4$ küuzer als das dritte. Die Füllı. sind gleiels an Vorlerrande des Anges eingelenkt, fein anliegend, die zwei letzten

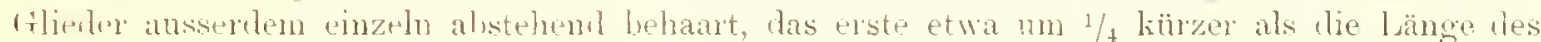
Lopfes. etwa ehenso lweit wie die Stim zwischen den Angen, das zwrite fast $12 / 3$ länger als clas erste, etwas liürer als der. Basahand des Halssehildes, zur Spitze nicht verdiclat, selnuäler als das verdiclite erste, die zwei letzten zusannen liamm länger als das zwrite The Länge des Halsselildes ist in der Mitte etwa un dio lä̈lfte kürzer als ler Basalrand breit, elieser letztere etwal duphelt breiter als der Apicalrand. Dis Strictura apicalis ist schart algesetzt, die Calli sind ziemlich eonvex, nach hinten sich wit elstreckend und vou einanter durel eine feine

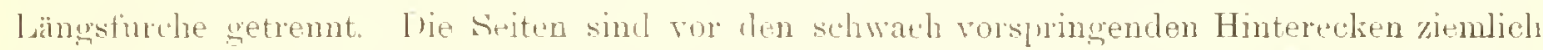
seielit ansgeschweift und von hier his zur. spitze mïsig gerundet verengt. Fie Hemidytren

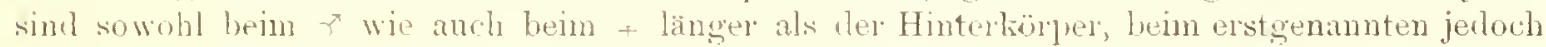
otwas linger als bein +, ler cunens ist deutlich, etwas kiurzer als an ler Basis breit. Long. 2.9. $+3 \mathrm{~mm}$., lat. $1.5 \mathrm{~mm}$.

Die Art gren̈rt wohl zum Verwandtschattskiveise des Fr. hrevicomis Rent, ist aber von

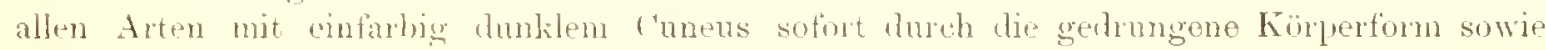
anch durch die pigenartige Farbe zu unterscheiden.

Nen-Gininea, Simhang bei Huon-Golf, + und , lists, Brri (Hus. Nat. Hunge).

\section{Fulvius dimidiatus n. sp.}

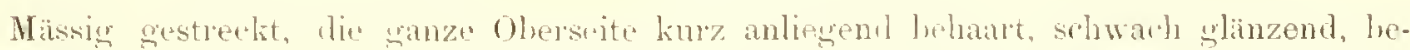

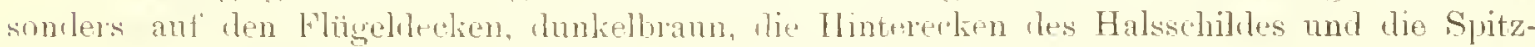

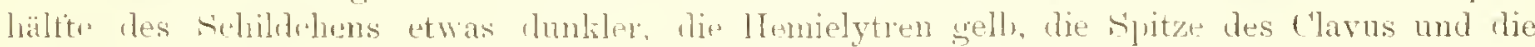

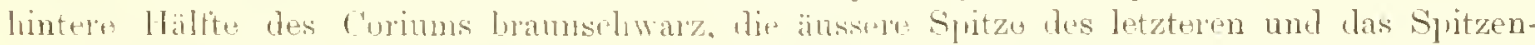
fönftul des zweiten Fühlergliedes weiss, die Membran ranchsohwar, die übrigen Teile der

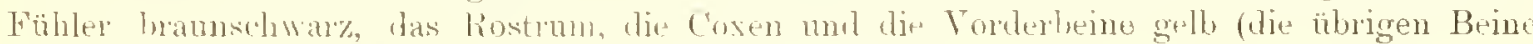
sind mutilliert), dis Basis der Vortersehenkel verdunlielt.

Der Kopl ist zienlich gross, yestreclit zugespitzt, ebenso lang als der Halsschilu, die Angen gross, aber ziemlich wenig vorsmingent. Die stim ist deutlich breiter als der

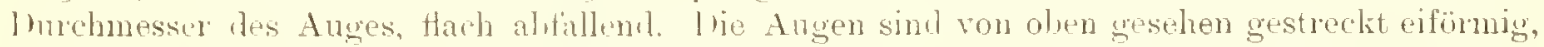

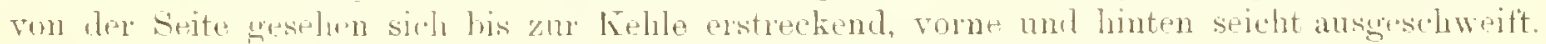

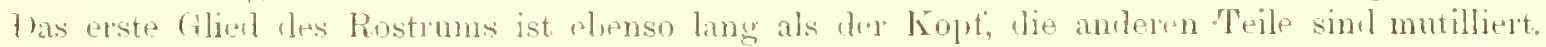

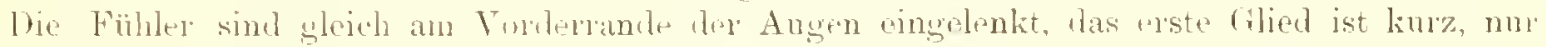

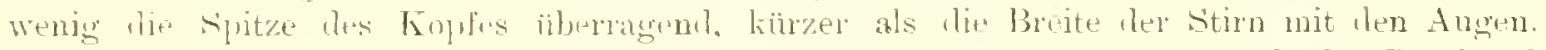
flas zweite Glied moln wir doppelt lïnger als das erste, nur wenig länger als der Basalrand

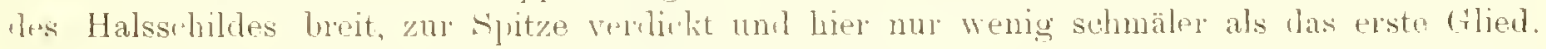

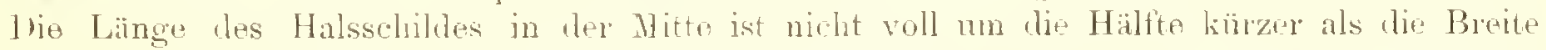

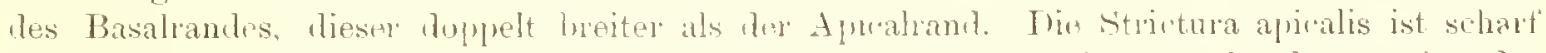

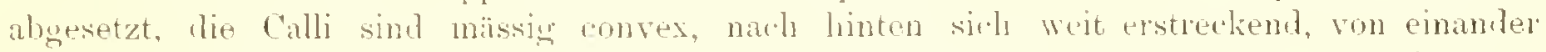

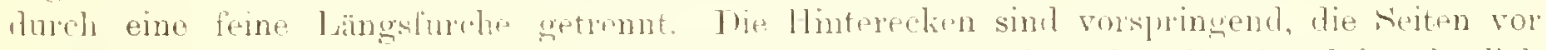

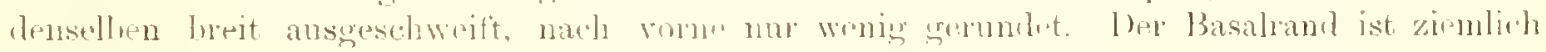

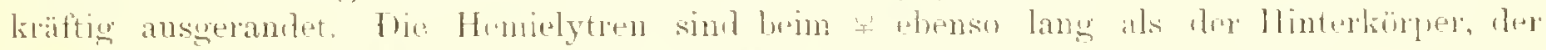
C'uneas ist deatlich abgeretzt, obensn laug als an ter Basis breit. - long. 3 mus. 
Nahe verwandt mit $F$. orycarenoides Rent, unterscheidet sich aber sofort durch das kurze erste Fühlerglied. In dieser Hinsicht an F. brevicomic Rent. erimernd, unterscheidet sich aber durch amlere, an die erstgenannte Art erimernde Farbenzeichnung.

Ust-Indion: Pulo Penang!, 600-800 m. alt., II. 185!), Fea, 1 in Mus. Civ. Genor.

\section{Fulvius flavicornis n. sp.}

Gestreckt, sehmutzig dunkelbraun, matt, kurz anliegend lraun behaart, das ersto Fühlerwhed an der Basis, tas basale Viertel des zweiten und die hasalr Hälfte des zweiten Rustralgliedes gellbraun, lie äbrigen Teile des ersten und des zweiten Fiiflergliedes und di، Basal-

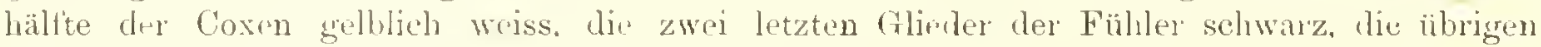
'Teile des Rostrums und der Coxen brannschwarz, die Basis der Hemielytren, die äusserste Spitze des Clavus und die Aussenecke des Coriums schmutzig gell. (Die ülnigen Tejle des Beine sind mutilliert).

Der Ḱopf ist vorgezogen und ziemlich zugespitzt, ehenso lang als der Halssehild, die Augen sind gross und verlältnisuässig wenig rorspringend. 1)ie Stim ( $f$ ) ist fast ebenso Ineit als der Durchmesser des Auges, nach vorne schwach abtallend. Die Angen sind von oben geschen gestreekt eiförmig, von der Seite gresehen lis zur Kélıle sieh erstreckend, sowolıl ler Vorder- als anch her Hinterrand seicht ansgesehweift. Das Rostrum erstrecht sich etwa zun apicalen Viertel des Hinterlsörpers, das erste Glied etwa so lang als der Kopf, das zweite dolpelt länger, das dritte rtwa un ein Viertel länger als das zweite. Die Fïluler sind glejch an Torderande les Angen eingelenkt, foin anliegend behart, fas erste trlier etwa mm 1/5 kïrzer als die Lünge des Kojfes, etwas längres als die Breite ler stirn mit den Augen, das zweite etwas mehr als doppelt linger als der Basahand des Halsschildes, zu. Spitze nicht verdickt, schmäler als das erste. Die Länge des Halsschildes ist in ler Mitte etwa un 1/3 kiürer als die Breite des Basalrandes, dieser ctwa doppelt breiter als der Vorderrand. Die strictura apicalis ist scharf' abgesetzt, die C'alli sind schwach eonvex, undentlich abgresetzt, nach linten sich weit erstreckend und von einander durch eine scharfe Längsfurche abgetrennt. The Seiten sim gloich vor den vorspringenden Iinterecken seiclat ausgeschweift und von lier nach vorne ziemlich kräftig gerundet verengt. Die Hemielytren sind länger als-der Hinterliörper, der Cunens dentlin, länger als an der Basis breit, - Long. $4 \mathrm{~mm}$.

Ist wohl am niehsten mit $F$. Irevicomis Reut. verwandt, unterscheidet siel aber durch andere Farbe, anders gelaute und gretirbte Fïhler, dureh andere Form des Halssehildes, sowi durch die längeren Flïgeddecken des f.

Sumatra: Si-Rambé!, 1 q am XII. 1890 - IlI. 1891, E. Modritiant (Mus. Civ. Genov.).

\section{Fulvius subnitens n. sp.}

Gestreckt, sehr kur\% anliegond geh, huhart, ziemlich glänzend, hesonders anf tem

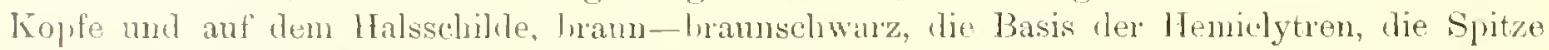
Ars Charus und die äusserste Spitze des Cuneus rïtlich gelbweiss, die Spitze der Cosen zrell,weiss, die Beine und das Rostrum gelb, der Clypeus und die Selenkelspitzon, ott anch lie änsserste Splitze des ersten Fühlergliedes rötlich.

Der Kopf ist ziemlich gross, gestreckt mud zugespitzt, ebonso lang als ler IJalssehild,

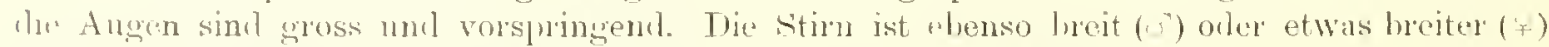

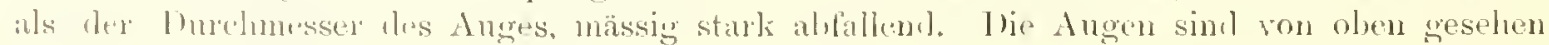

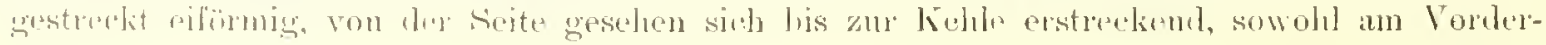




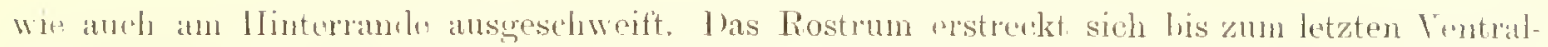

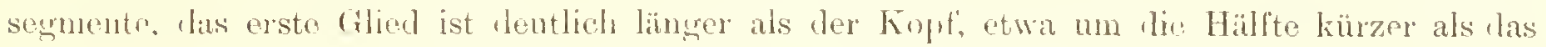
zweite, das etwa ${ }^{1}{ }_{3}$ kïrzer als das vierte ist. Dre Fühler sind gleieh am Vorterrandw der Augen eingelenkt, kuz, lalb anliegend behaart, das erste Glied etwas liüzer als dir Länge des Koples, ebenso ein wenig kürzes als die Breite der Stim mit den Auren. Das zwits (thier ist doprelt linger als das erste, zn spitze selu schwach erwoitert, diinner als das schwah verliclite crsto Glied, etwas länger (c) oder ebenso lang (f) we der Halsschild au Basalrande breit. Die länge des Halsschikles in der Mitte ist um die Hälfte kiurzer als die Breite des Basahandes, dieser doppelt breiter als der Apirabant. Bie Strictura aplealis ist seharf aluresetzt, die calli wind schwach convex, nach linten zu weit rorgezogen, von cinander dureh rine feine längslurehe getrennt. Die seiten sind vor ten vors]ringenden Hinterecken

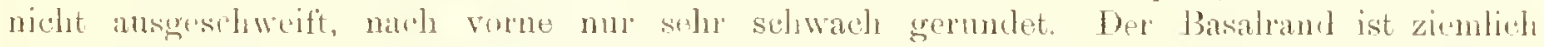

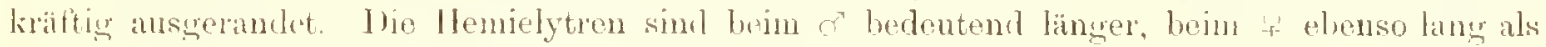
der Hinterkürper, der C'mens ist dentlich, otwa ebenso lang als an der Basis breit. -- Long. $3.3 \mathrm{~mm}$.

Unter den Arten mit dunkel grefäbtem Cuneus unterscheidet sieh liesc besonders

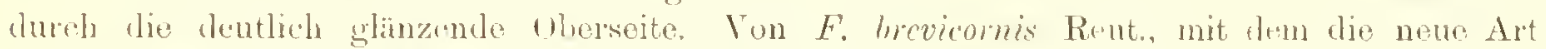
nahe verwand ist, ansswdem zu untersehejden durel etwas gestrecktere Kürperform, längere

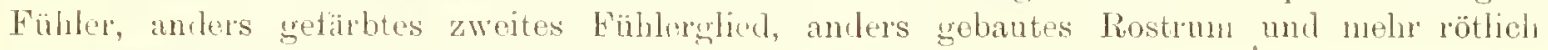
gellweisse Flecken aut ren Hemielytren.

Sincll. Nen-quinea, J3njakori!, VIlI. 1590, Ighihirei, VII-VIII, 1890, Fl. Paumomm, Sl-Xll, 1892, L. Joma, mehrere Hixemplare (Mns. (iv. Genov. et Holsingfors), Astrolabe: Bai, Stephansort!, 19m0, B1ke (Mus. Nat. Hung.); Ins. Mentawei, Sipora, Sereinu!, V-VI.

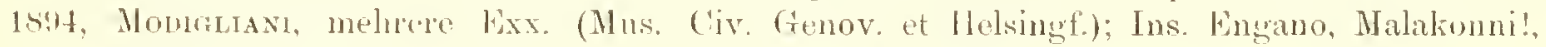

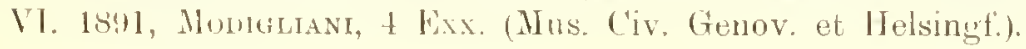

\section{Fulvius bifenestratus $11, \mathrm{~s}_{1}$.}

Gerstrecht, matt, schwarz, lie Hemielytren braunselwarz, ein Elerek auf dem Corium, das zweite Tiertel desselben einnelumend, und sich nicht bis zmm änssersten Seitenrando erstrerkend, und die innere Basalecke der Membran weisslich, glasartig lurchsiehtig, das apicalc Drittel des zweiten Fühlergliedes gelbweiss, der Clypeus, das ersta Fühlerglied, die Coxen, die Basis ausgenommen, die Spitze des ersten Rostralgliedes und das zweite rotgelb, die zilmigen Teile des Rostrums und des zweiten Eiahlergliedes braun, die letzten Fïllerglieder schwarz. (Die Beine sind mutilliert.) Der Kopf ist liein, spitz und ziemlieh kräftig vorgezogen, ebrenso lang als der Halsschilu, die Augen sind gress und rorspringend. Die stirn ist bein etwa um $1 \frac{1}{3}$ breiter als des Durchmesser des Auges, nach rorne riemlich alufallent. Die Augen sind von oben gesehen gestreckt eifömigr, von der Seite greschen bis zur Kehle sich erstreckend, an Vorder-umel an Ihintrrande ausgeschweitt. Das Rostrum erstreckt sich bis zum letzten Ventralsedmente, das erste Glied ist kaum länger als der Kopf, das zweite etwa un $1{ }^{1 /}{ }_{3}$ länger als das crste und ${ }^{1}{ }_{3}$ laürzer als das dritte. Die Fühler sind gleich am Vorterrande der Angen eingulenlit, liurz anliegend behart, das erste Glied etwa $1^{1 / 5}$ länger als die Lüngre des Koptes, etwas mehr als $11_{t}$ länger als die Breite des letzteren, fast um die Hältte liiuzer als das zweite, dieses fast doppult länger als der Basalrand fles Halsschikles, zur Spitze nicht verdicht, etwas sthmäler als das sehwach verdickte erste. Dio Länge des Halsschilıles in der Mitte ist etwa um die Hälfte kürzer als dio lireite des Basalrandes, dieser fast doppelt breiter als der Aprealrand. Die Strictura aprealis ist schart abur"setzt, die Calli ziemlich convex, weit nach hinten sich erstreckend, von einander durch einc

Ni:o 4 , 
feine längsturehe getrennt. Lie Seiton sind gleich ror den vorspingem len Hinterelen sehr

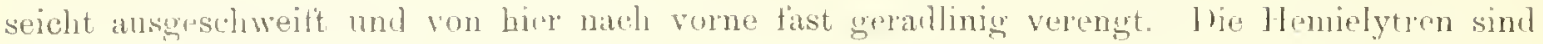

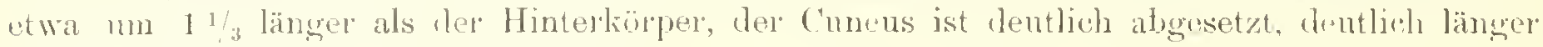
als an der Basis breit - long. + mm.

Lurch die Fanbe sofort von allen bekannten Arten der Gattung zu untrischeiren, mit bimeculutus m. wohl am nächsten venwantt.

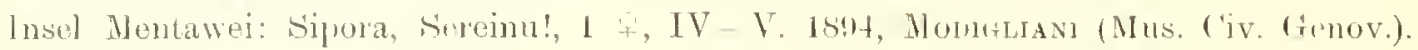

\section{Fulvius bimaculatus n. sp.}

Gestreckt, fein uml weitlinfig hell behaart, matt, sehwarz, ein kleines fleckelen am lnenranke etwa in der Mitte des Coriums und das apieale Irittel les zweiten und du äusserste

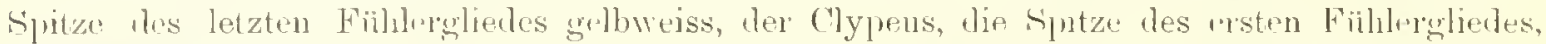

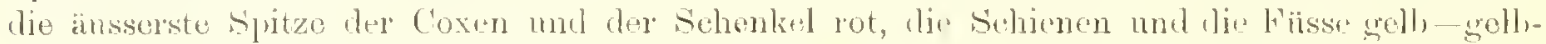
braun, die Unterseite, das Rostrmu und die übriçen T'eile der Fïhler Mrannschwarz.

ber liopt ist klein und verhiiltnismïssig wenig zugespitzt vorgezogen, etwas kiurzen als der Halsschild, die Angen sind ziemlich klein und nüissig vorspringend. Din Stim ist. (boim of) fast doppelt breitor als der Durchmesser des Auges, nach vorne schwach abfallend. I'ie Augen siml von uben gesuben rundlich eifömig, ron ler Seite gesthen bis zu Ḱchle sich erstreckend, der Torlerrand seicht ansgesehweift. l)as Rostrum erstreckt sich last bis zum vorletzten Ventralsegmente, das erste Glied ist dentlich länger als der Kopl', etwa um 1/4 kürzer als das zweite, dieses nur wenig kürzer als das dritte. bie Fühler sind gleich am Vordurande der Augen eingrelenkt, fein halb anliegend lwhart, das erste Glied dentlich länger als die Jänge des lioptes, etwa $1 \frac{1}{3}$ länger als die Breite der stim mit den Augen, das zweite zu Spitze lamm verdickt, otwa doppelt länger, dïnner als das schwach

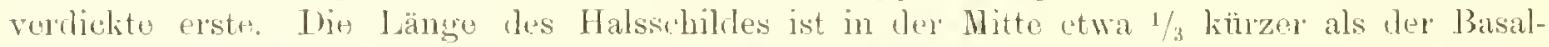

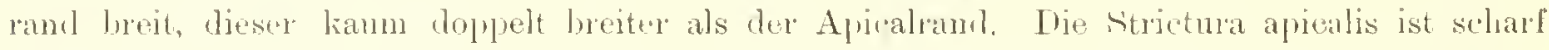
ahgesetzt, die Calli sind riemlich convex, weit nath hinton sich rerstreekem und von einander durch eine sehr feine längsturche getrent. Jie Seiten sind vor Aon rorspingenden llinterecken kaum merkbar ausgeschweitt und ron hier nath vorne fast gerallinig verengt. Der Basalrand ist kräftig ansgeschweift. Lhe Henielytren sind beim beteudend länger als der Hinterkörper, der Cunens ist dentlinh, länger als an Torederancle breit. - L Long. $5 \mathrm{~mm}$.

Fine durch die eigentimlielu Farbe, dureh den kleinen Kopt u. s. w: mit ter folgenden am nïehsten verwanclte Art.

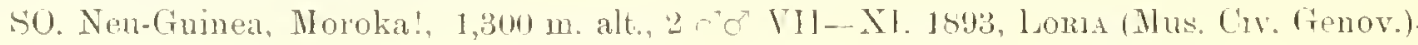

\section{Fulvius unicolor $n$. sp'}

Gestreckt, ziemlich olüzent. branschwarz, lie Beine ein wenigh heller, die Aussenecko Jens Corimms sehmal getbweiss.

Der Kopf ist grestreckt nnd schnal, weng zngespitzt, cbenso lang wie dir Halssehild, die Augen unässig gross, wenig vorspringend. I) Ste tirn ist hinter den Augen quler gelurelit,

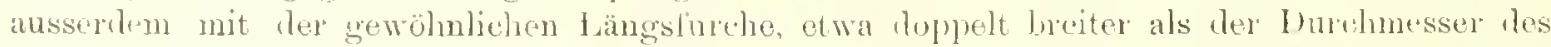
Aluges (c), nach vorme selur wenig alifallend. bie Angen sind von olven gesehen eifömig,

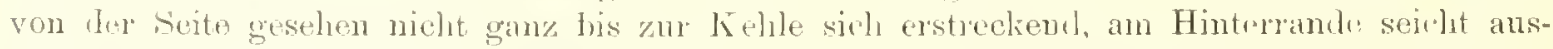

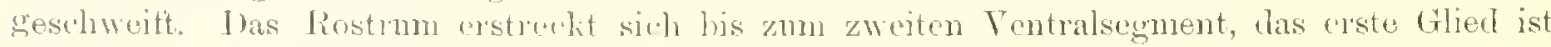
ntwas kürzer als der Kopt', las zweite etwa doppelt länger als das erste. Die Fiuhler sincl 
glench am Vorderrandw des Koptes cingelenkt, das erste Glied ist gestreckt, kaum verdickt,

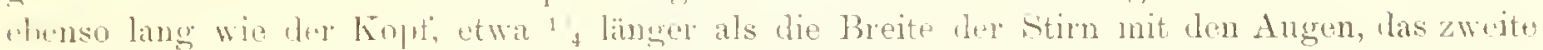

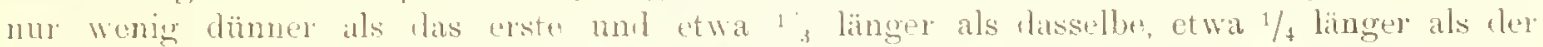
Basalrand des Halssehihles (die ïhrigen (tlieder mutilliert). J)ie länge des Halsschildes in dor Mitte ist etwa ${ }_{1}$ kitrzer als der Basalrand, diesen etwa dopjelt breiter als der Torder-

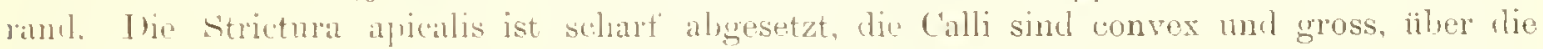

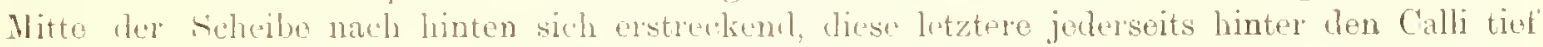

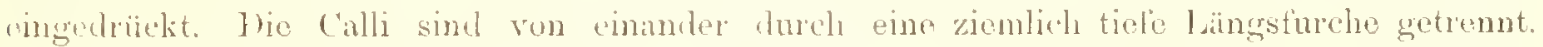
Die llinterecken sind rorsplingend und nith hinten vorgezogen, die seiten vor denselben

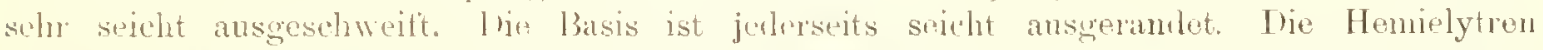
erstrecken sich bein "weit äber die spitze des llinterkïrpers. Der cuneus ist tontlich

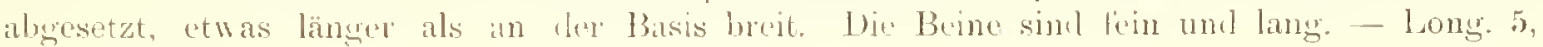
lat. 1.5 mmen.

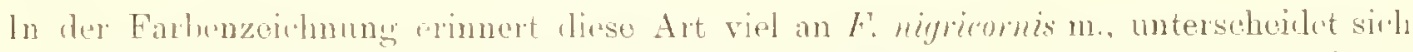

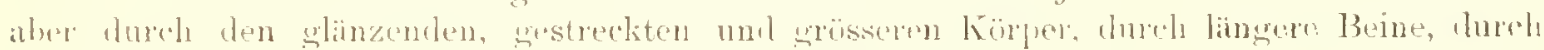

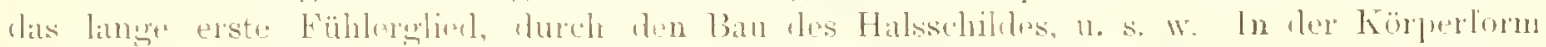

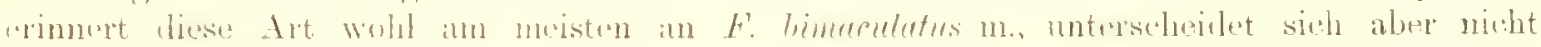

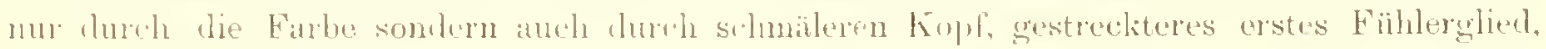
slureh getwöbtre ratli u. s. w.

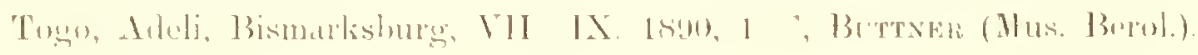

\section{Fulvius nigricornis 11.8 .}

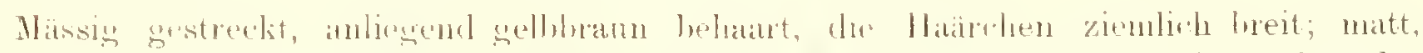

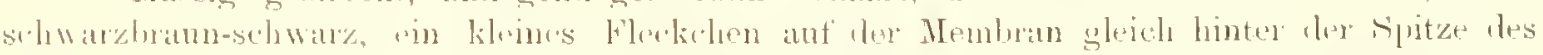

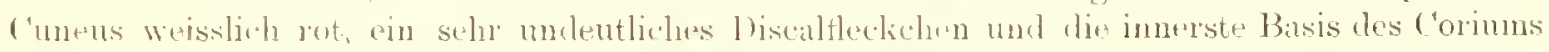
umlentlieh hell durelisehimmernel, alie äusserste spize des zweiten Fïhlerglindes, dis Rostrum

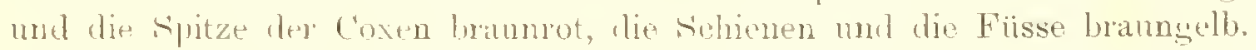

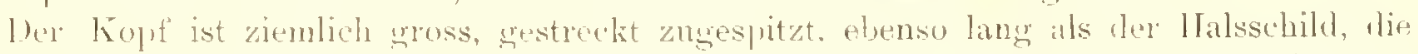

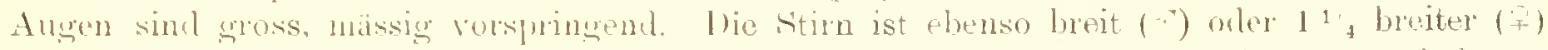

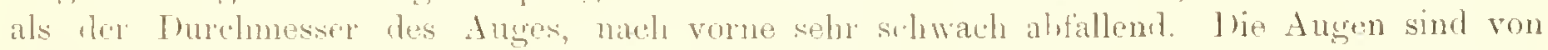

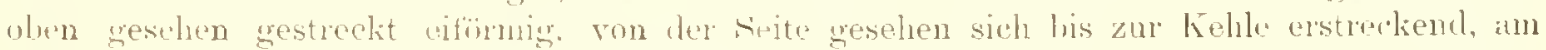

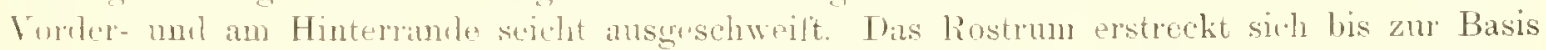

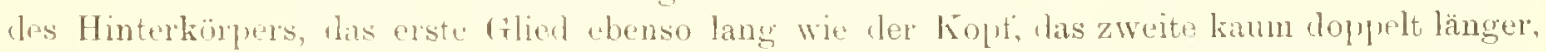

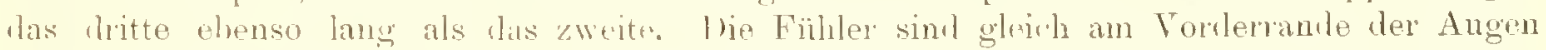
eingelenkt, fein anliegend behatrt, die zwi letzten filierler aussertem mit einzelnen langen, abstehenden Härehen besetzt. Das orste Cilien ist $1 / 3$ kïrzer als die lünge dos Kopfes, etwa su hreit wie die Stim mit den Augen. das zweite etwas mehr als doppelt länger als das erste, nur ein wenig länger als der Basulraml des Halssehildes, zm S'Hitze haum merkbar verdickit, viel sehmailer als dis rerdickte erste. Der Halsschild ist in der Mitte kaum 1/2 Mal kiirzer als an der Basis breit, ant der letztguannten Stelle doppelt breiter als an Vorder-

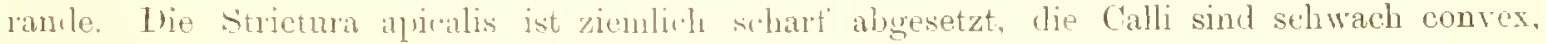
nach hinten sich weit erstreckend, von einander turch eine feine Längsturehe getrennt. Die Seiten sind uleich vor den vorsmingmen Iinterecken seicht, aber deutlich ansgeschweit, nach vorne nur sthwath scrunlet. lie Henielytren sincl etwal länger als ler Hinterkörper, bein $r^{*}$ nur wenig linger als bein .... leer c'uneus ist dentlich, kitirzer als an der Basis breit.

- Long. 2.9-3.1 $112 m$.

Ni:o 4 . 
lst wohl an nächsten wit $F$. hrevicomis Reut. verwandt, von diesem, sowje auch von len anderen mit liesen verwalten Arten durch die Farbe zu unterschiden.

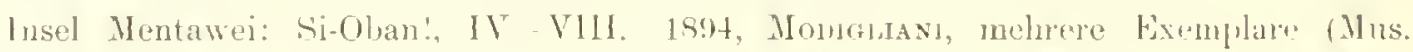

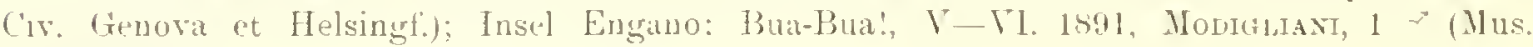
(iv. (ienov.),

\section{Fulvius variegatus 11 . s]'}

Gestrecket, matt, weitliulig mit kumen mol broiten. dicht anliegenden, schwach schuppentönigen, hellen Häärchen besetzt, Kopl, Halssclibl, Sichildchen und die [nterseite Iraun- schwarzbran, ein Längstrich in der Nitte des Kopfos, das sich auf dem Clypeus etwas erweitert, und zwei kïrzere jederseits hinter den Augen, auf dem Halsschilde jedrerseits oin Längsstrich und in der Mitte ein kurzer. hinten und zuweilen auch vorne melr oder weniger abgehrochener sowie auch die Hinterecken sehmal, die drei letzten Fühlerylieder, das Rostrum, die Spitz: der Coxen, die T'ibien und Tarsen rötlich grelb, das erste Fülılergliod zur Spitze mehr oder weniger ausgedelunt und die Spritze der Schenkel rotbraun, die Basis des crstgenannten und die abrigen Teile der letzteren braun-braunscluwarz. Die Hemielytren hell schnutrig gelb, die Spitze des Clarus breit und ein ausgedelnter Fleck an der inneren Apicalecko des Coriums rauchbraun, ein läingsfleckchen am Aussenrande etwas vor der äusseren Apjealecke rotbraun-braun, der Cuneus lraun-schwarz, die Mcmbran schwach rauchigr verdunkelt, mit dunkleren Venen, ein ganz kljines Querfleckehen dicht hinter der Cunealspitze weisslich.

Ler Kopf ist zienlich gross, zugespitzt, etwas länger als der Halsschild, die Augen sind gross und vorspringend. Jie Stirn ist ebenso breit (c) orler etwas breiter ( $)$ als der Lurchmesser res Auges, sehr schwach abfallend. Die Augren sind von oben resehen vestreukt eiförmigr, von der Seite geselıen bis zu der Kelıle sich erstreckencl, sowolıl am Vorder- wie anch am Hinterrande seicht. ausueschweift. Das Rostrum erstreckt sich etwa bis zur Mitte des llinterkörpers, das ersto Glied erreicht nu den Hinterand des Auges, das zweite ist etwa 1\% länger als das erste, das dritte Glied ist nur sehr wanig länger, clas vierte ebenso lang wio das zweite. Jie Fühler sind yleich an Vorderande der Augen eingelenkt, kurz anliegend beharot, das erste Ctlied ist etwa ${ }^{1 / 4}$ kiarzer als die lange des Kopfes, fast eluenso viel kirres als die Breite der Stirn mit den Augen. 1)as zweite Glied ist mehr wio doppelt linger als das erste, zur Spitze sehr schwach verdiclit, schmäler als das mässig verdiekte urste, etwa ${ }^{1} 3\left(f^{*}\right)$ orler $1 / \neq$ (änger als der llalsschild an Basalrande breit. Die Länge les Halssulildes in ler Mitte int un die Hälfte libur als der Basalrand breit. der letztgenannte fast doprelt breiter als ror Vorderand. Lie Strictura apicalis ist scharf abgesetzt, die Calli sint fast flach, naw hinten siel etwas ïber die Halsschildsmitte erstreckend, von einanler

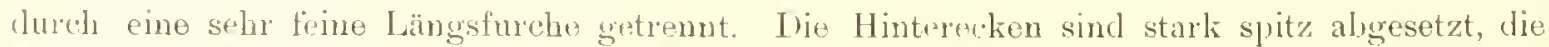
Seiten sind nach vorne fast gradlinig verengt. Tie Hemielytren sind beim c' bedentend länger, beim + ebenso lang als der Hinturoörper. der Cuneus ist doutlich, etwas läner als an l+'l Basis breit. - L Long. '2.5-; $111 \mathrm{n}$.

Tiese kileine Ant wejcht ziemlich viel von den anderen Arten der Gattung ab uml biliet wahscheinlich eino besondere Unterguttung. Besonders hervorzuheben ist die Farbe thes Koples und des Halssetrildes.

Nen-funea: Simlang, Huon-frolf!. 1898, Broú: Stenlinsort, Astrolabe Bai!. 1897. Buzo; Insel llelacs!, 1901, Bızó (Mus. Nat. Hung. et Helsingf.), Astrolabe-trebirge, II. 1893. Ighibirei, VII-VIl1. Is!o, Lorla (Mus. Civ. Genov.). 


\section{Fulvius brunneiceps n. spl.}

Gestrerkt, matt, fein unl selı kurz, weitlänfig anliegenu hehaart, schwarzbramn, der

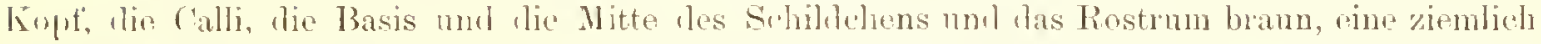
schmale, etwas undentich begrenzte, ien Aussenrand nicht treichende schmale Querbinde vor der Nitte des Coriums und die Basaluälfte des Cuneus, sowie anch die Spitze des Clavus grolbich weiss, die Spitze her ('oxen divo ülrigen Teile der Beine sind mutilliert) und das spritzendrittel des zweiter Füllererliedles weisslich.

Der Kopl ist mässig gross mni gestreckt zugespitzt, etwas kürzel als der Halsschild, (lie Angen sind mässig gross und vorspringeml. Thie Stirn ist etwa $1{ }^{\prime} / 3$ hreiter als der

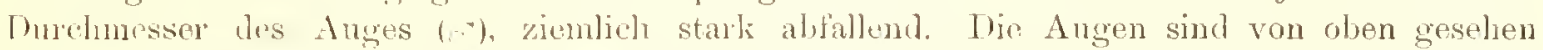

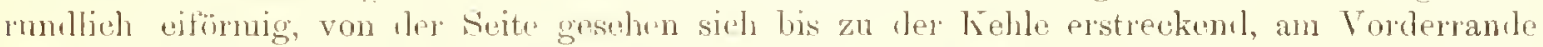
seicht ansgreschweift. Das Rostrum erstreckt sich bis zur Mitte des Hintertiorpers, das erste

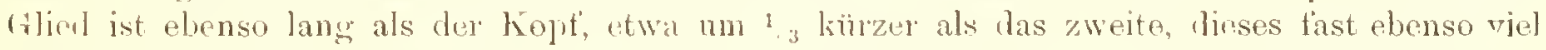
kiïrer als das dritte. Die Fïhler sind gleich am Vorflerrande der Augen eingelenkt, kurz hall, anliegend behaart, has erste Glierd unbedentend kiurzer als die Länge des Kopfes, fast ehenso lang als tho Broite her Stim mit hen Augen. Tas zweite Glied ist nieht voll doppelt länger als das erste, ebenso lang als ler Basalrand des Halsschildes, zur Spitze verlickt und hier nu wenig submäler als las ziemlich schwach verdickte ersto, las dritte ist um die Hälfte kürzer, has vierte elenso lang als das zweite. Die Länge lles Halsschilles in der Mitte ist. nm die Hälfte kürzer als die Breits des Basalrandes, dieser etwa ropjelt Ineiter als der Apicalınd. Die Strictura aprialis ist schart abgesetst, die Calli sind ziemlich stark convex, nach linten zu bis zur. Mitte vorgezogen. von einander lurel eine tiefe lüngsfurche getrennt. bie seiten sind ror den vorspringrnden Hinterecken seicht anseschweift, nach vorne in einer sciohten kundung verengt. Wer Basalrand ist jederseits selur seicht ausgeschweift. Ibie Hemielytren sincl beim viel länger als der Hinterköryer, ler Cunens ist dentlich, länger als an cler Basis breit. - Long. 3.\& mum.

Ist sehr nahe vorwant mit $F$. qundristllutus Stal, unterseheidet sich aber hurch die

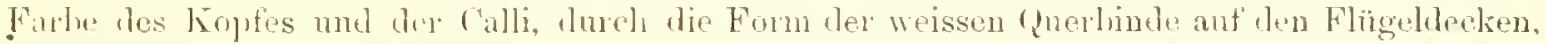

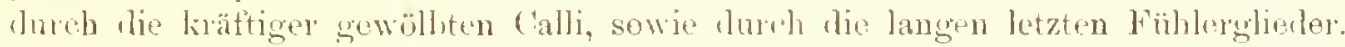

Siul-Amerika: Paragnay, Alto Parana, Prerto Bertoni!; Brasilien, Bella-Vista!, ^. VlI.

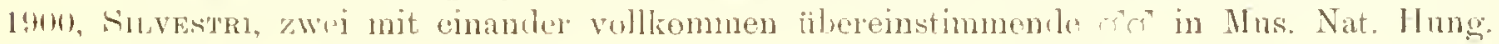

\section{Fulviıs submaculatus n. sp.}

Wenig gestreckt, Kopl" und Ialsschild selr schwach glinzend, die Henielytren matt,

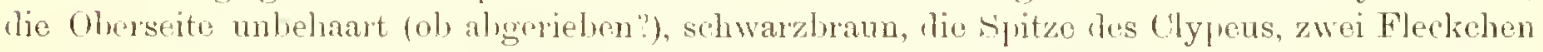
an der Basis mo die Spitzo des Schildehens, ein sehr kleines Feckehen an ler Basis der Hemielytren unt die Spitze des Clavus braungelb, ein kleines Basalfleckehen auf dem Cuneus gellweiss, die Beine hraun, die Sirhenliel in der Mitte breit rotgell, das Rostrum rotgelb, die Fïhler einfarbig braunseluwarz.

Der Kopf ist ziemlich gross mul gestreckt zugespitzt, chenso lang als der Halsschite, dir: Augen sind mässig gross, vorspringent. Thie Stirn ist in ler Witte seicht der länge nach eingredrückt, etwas breiter als der Durehnesser des Auges (千), zicmlich stark al,fallend. Die Augen sind von oben gesehen imnllich eiförmig, von lor Seite gesehen sich bis zu der

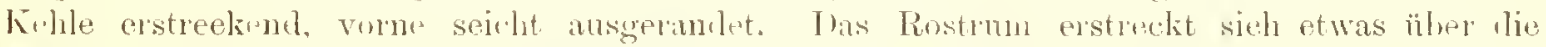
Mitte des Hinterküpers, das rste Glied ist thenso lang als der Kopl, das gweite etwa 11/3 $N: 04$ 
längrer als clas erste, etwa ebenso viel kürzer als das dritte. Die Fiühler sind dicht am Yorderrende der Augen eingrenlent, knz und halb anlierend beliart, las erste Glied ein wenig kiirzer als the Breite der. Stim mit len Augen, das zweite Glied ist nicht voll doppelt lianger als das erste, etwa $1 / 4$ kïrzer als der Basalrand des Halsschihles, zur. Spitze etwats verdickt,

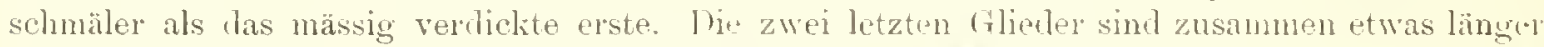

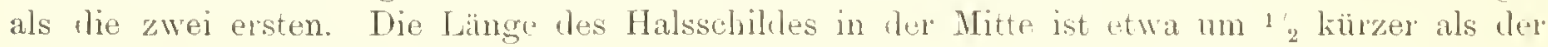
Basalrand. The Strictura apioalis ist schart abgesetzt, die Galli erstrecken sich nach hinten über die Witte der Scheibe und sind stark convex. Die Seiten sind vor den vorspingenden Hintereeken ziemlich ausureschweift, zur Spitze nur seicht germnelet. Der Basalrand ist massign ansgeschweift. Die Hemielytren orstrecken sich beim + ziemlich übor die Spitze des Hinterkörpers, der Cuneus ist deutlich, etwa so lang als an der Basis breit. - Long. 2.9, lat. $1 \mathrm{~mm}$.

Erinnert in der Förperform und dureh die Farbe der Fühler stark an F'. prollidns m., unterscheidet sich aber dureh ganz andere Farbe, durel die langen letzten Fühlerglieder, durch andere Form des Halsschildes, Jurch die stärlier convexen Calli u. s. w. Ton allen bekannton nearktischen und neotropischen Arten ist sie sehr abweichent.

West-Indien, Insul Guarleloupe!, 光 + (U. S. Nat. Mus.).

\section{Fulvius lunulatus thiles:}

Fulvius lemelatus Uhler, Proc. Zool. Sur. London, 1494, 192, 2. -... id. Retut. Ent. Tilskr., 1s95, 147, 9.

Mässig gestreckt, Kopf, Halsschild, Schildchen, der Aussenrand der Hemielytren schnal, dio Membran und die Unterseite glänzent, die dibrigen 'T'ile des Hemielytren matt, die Oberseite unbehart, schwarz, die Hemielytren flunkelbrann, eine gleichlıeite, qner nach vorne gerichtete Querlimle, die Basalhälfte des Cuneus und das Supitzendrittel des zweiten Fihlergliedes weiss, das Embolium, oine kurze Strecke vol den Cunens ausgenommen, sehmal gillweiss das erste unt die ülnigen Teile des zweiten Fïlnlerglierles und die lieine grelbrot, die letzten Fühlerglieder und das Rostrum yelbrot, das er'ste Glied dunkler, die Unterseite schwarz.

Der Kopf ist missig gross, ziemlich geneigt, vorne nur wenigr vorgezugen und zirmlich knrz, hreit zugespitzt, ebenso lang als der Halssehik, die Anuen sind ziemlich wross und vorspringend. The Stim ist etwa $1^{1 / 4}$ breiter als der Jurchmesser des Auges ( ), nach rorne

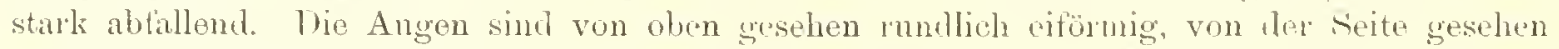
sich bis zum Kehle erstreckeml, vorne nicht ansgerandet. Das kostrum erstreckt sich bis

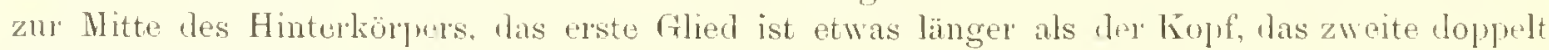
länger als das erste, etwas länger als das dritte. Die. Fühler sind gleich am Vorlerrande des Kopteng eingelenlit, das erste Glied etwas kinrzer als die Länge les Kopfes, etwa $1 / 4$ kïrzel als die Breite der Stirn mit den Angen, un the llälfte liủrzer als las zwrite, das stwa elsenso lang als des Basalrand des Halsschilfes ist und zur Spitze nur sohwach elwejtert elselueint, sthmäler als tas mässig verdickte erste. Die Länge des Halssuhilles in der Mittr ist nicht voll doppelt kürzer als the Breite tes Basalrandes, dieser doppelt lreitur als der Apieatrum. Dir. Strietura apicalis ist scharf abgesetzt. die Caili sind sehr stark ronvex, wodn wh der Hals-

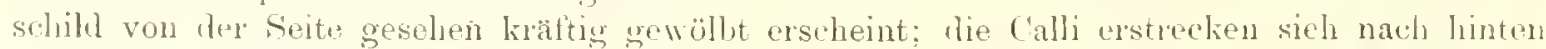
fast lis zum Basalrande und sind von einanler dureh eine ziemlich hreite Mittelfurele

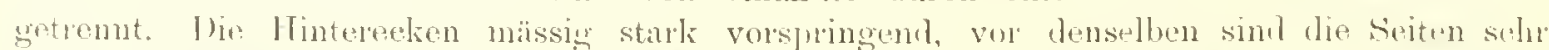

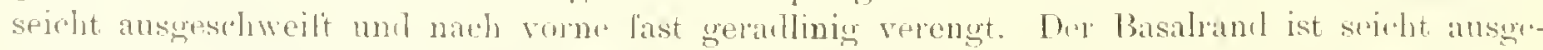

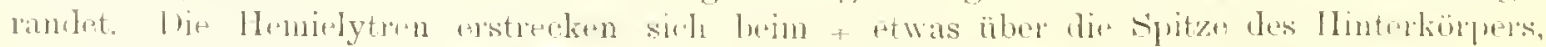

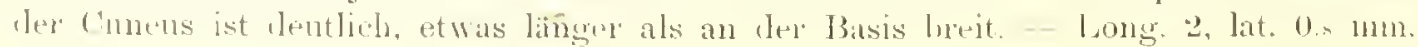


Diess. die kleinste bis jutzt bekannte Ajt der. Gattung weicht viel von den anderen ah. Besonthrs anflallend ist ler wänzenle Kürper, der ziemlich breit zugrespitzte greneigte Kont und lie grossen, stark gewölbten Calli. In ler Farbenzeichnung erinnert diese Art zirmlich an rinigen neotropischen, wio bisbistillutus stal u. a., andïallend ist aber die von dem iilsrigen kiirper abweichendo Grunlfutbe der Hemielytren.

las txemplin stimmt gut mit Thuen's beschreihung überein und ist wahrscheinlich lie: 'Tryo seiner Art.

West-Indien, Jnsel Grenala, firand Ftang! (Windward side), 1900 Fuss ï. d. M., 19. IX. 1491, H. H]. SMlтh, 1 + (U. S. Nat. Mas.).

Fulvius simillimus 11. sp.

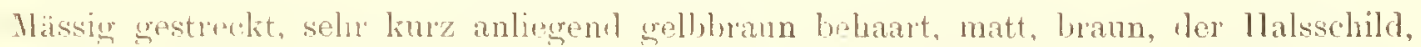
das schildchen, der ('lavus, die Ansseneeke les Coriums uul der Conens brannschwar, ein Längsstrich aut der Stim, anf dem Halsschild: ein schmaler fängsstrich in der Mlitte der Basis, dor nath vorne bis zn den Calli sich erstreckt, diese letztere, die äussurste splitze lles

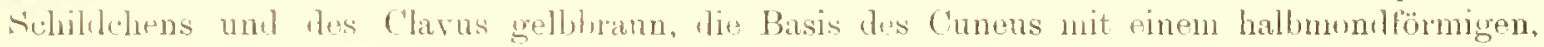
weisson Fleck, die Membran raurhig bramsehwarz, lie Boine, las Rostrum und die Fühler branngelb, die Coxen mul die Basis ter Sehenliet getb.

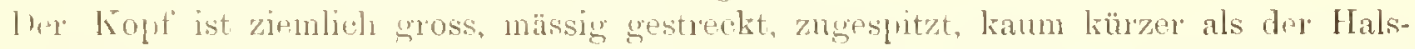
schild, die Angrn sind gross und vorspringend, die stirn ist etwa mm ${ }^{1 / 4}$ breiter als der Inrohmesser des Auges ( $)$, wenig ahtallend. Thit Augen sind von olnen gesehen rundlich eiförmig, ron der Seite geselen sich bis zur Kelle erstreckencl, an Hinterrande seicht ansgeschweift. Tas Rostrum arstreckt sich otwas über die Hintereoxen, das erste Glied ist ebenso lang wie der Kopt, liast un elie llälfte kiuzer als das zweite. Die Fïhler sind gleich am Turdrrante der Angen pingelenkt, kntz anliegend behaart, das erste Glieel kiurzer als die lainge des Koples, etwa $1 / 4$ kïrzer als dit Breite der Stim mit den Aagen. Das zweite Glied ist diek, nur unbedeutend dimner als das erste und etwa doppelt länger als dasselbe, zur Sitze schwah verdickt, bein "etwa ${ }^{1 / 5}$ kïrzer als der Basalrant des Halsschildes. Das dritte Glied ist seln foin, kurz. Die Länge des Halsschilies in der Mitte ist nicht voll um die Jälfte kürzer als der Basalrand, dieser etwa doppelt breiter als dur Apicalrand. Die Strietura apualis ist scharf abgesetzt, die Calli sind schwach convex, nach binten bis zur. Mitte ter Scheibe sich erstreckend, von einander durch eine line Längslurche getrennt. Ilie llinterecken sind zugespitzt, die seiten sehr sejcht ansgeschweift. Der Basalrand ist juderseits sehr seicht ansuess bweift. Die Homielytren überschreiten beim ziemlich den Hinterkin'per.

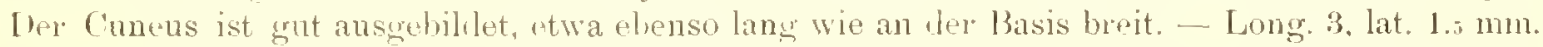

Steht dem $F$. firems l list. sehr nahe, mnterseheilet sich aber durch andere Farbo des Halssehildes, lurd einfarbiges Corium, durch andere Farbe w. Schenkel und der Fühler, sowie dureh das dickert zweite Fühlerylied.

Bolivia: Cochabamba!, 1 ơ (Mlus. Paris).

Trichofulvius n. gen.

Ther Körper ist wie bei den Fulvins-Arten gestreckt, matt, der Hinterkörler glïnzend.

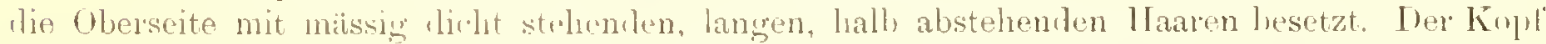
ist riemlich vertinal, mit abfallenler Stim, missig vorgrongen, zngespitzt, die Zügel drutlith. bie Angen rrstrecken sich nicht bis zor lieble. Dje Fühler sind gleich am Vorderrande der 
Angen eingelenkt, das erste Glied ist kurz und dick, die Kopfspitze kanm überragend, das zweite Glied ist lang und dünn, $1^{2}{ }_{3}$ länger als tas erste. Die zwei letzten Glieder sind nur wenig dünner als das zweite. Das exste Rostralylied rreicht den Hinterrand des Kopfes. Der Halsschild ist mässig gewöllot, die Hintereclien sind etwas abgerundet und nicht vorspringend, die Strictura apicalis ist scharf, die Calli erstrectsen sich nach binten nur bis zur Nitte der Scheibe. Die Ifemielytren siml bein bedentend länger als dær IInterliörper uni haben den Cunens gut ausgebildet. Das letzte Dorsalsegment trägt bein " jederseits ein kleines, nach hinten grerade gestrecktes Zähnchen. Die Beine sind mutillirt.

Steht obne Zweifel der Gattung Fulvius sehr nahe, unterscheidet sich aber durels dio lange Beharung der Oberseite, durch den verticalen Kopt, durch den Bau ler Fühler, sowie durch die Geschlechtsauszeichnung des $\sigma^{*}$ - Von sowohl lihmofulving Rent. wie Ceratofulvius Reut. sofort zu unterscheiden durch die am Vorderrande der Angen emgelenkten Fïhler.

Typus: Tr. fusciatus n. sp.

Trichofulvius iasciatus n. spr.

(Fig. 10-12 a.).

Grangelb, ziendich dicht mit braunen, runden Fleckchen bestreut, die auf dim Vorderkopte, vorne und an den Seiten des Halsschilhes mehr oder weniger zusanmentliessen, das Selildchen brann, lie Spitze und tie Basis jederseits braungell,. Das basale Drittel des Clarus, eine breite Querbinde etwa in der Mitte der Hemielytren, die anch las a ricale Drittel des Clavus eimnimmt, und die apicale Innenecke des Coriuns bram, hie und da fon der Grundtarbe durchbrochen, die hellen Querhinten weitlänfig mit rundin klemen Pinnktehen bestrent, der Conens einfarbig braun, hie Membran rauchfarhig braunsehwarz, gleich hinter der Cuneus-Spitze etwas heller. Die Unterseite einfarbig schwarz. Die Fühler gell, anf drm ersten Fühlergliedo die Basalbällte und die Spitze schmal und die Spitze des zweiten Ciliedes braun. Das Rostrum braungelb. die Apicalbälfte der hinteren Coxen gelbweiss (die ührigen Teile der Boine fehlen).

Der Kopt ist ebenso lang als der Halsschild, die Augen sind von oben geselien rundlieh. mässig gross, vorspringend, von der Seite gesehen nicht die Kehle erreichend, bein or ist ihr J) urchmesser um die Hälfte kürzer als die Broite dor Stim. l'as erste Fühlerglied ist ${ }^{\prime \prime}$ kürzer als die Breite der Stirn mit den Augren. Das zweite Glied ist 1/4 länger als der Basalrand des Halsschildes. Das dritte Glied ist nu ${ }^{1}$ kürzer als las zweite, doppelt länger als las vierte. Die Behaarung der Fühler ist selı kurz, anliegend, anf der Innenseite des ersten Gliedes zwei lïngere Hanre. Jas Rostrum erstreckt sich etwas ïber die Basis des Hintorliörpers, das erste filied ist verdickt, etwas kïrzer als das zweite, das dritte etwa ebenso lang als das vierte, etwas länger als das zweite. Die Calli les Halsschildes sinu flach, von eimander durch eino selur seichte Furehe gretrennt. Die Seiten des Halssehilkes sind vor den Hintereken kann inerkbar ausgesthweift, nach vorne fast geradlinig verengt. Iie luinge Ier Scheibe in der Nitte ist etwa $1 / 3$ kiüzer als die Breite des Basalrandes, dieser nitht voll Toprelt breiter als der Apicalrand. Tre Basis ist kaum merkbar ansgess hweift. Der Cuneus ist etwa so lang als breit. - Long. $2.2 \mathrm{~mm}$., lat. $1 \mathrm{~mm}$.

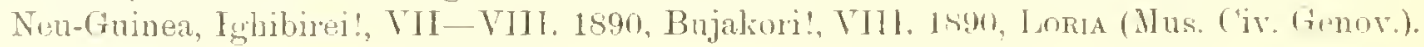




\section{Verbreitungstabelle der bekannten Cylaparien.}

Modigliania n. gren. romrolis n. sp. elonguteren. sp.

\section{Rhinocylapus $n$, sren.} simplimirollis n. sp. Ins Mrntawei: Si-chan. smmatrums n. sp. Sumatra: I jangayas. rentargulus n. sp. Borneo: Sarawak.

Rhinomiris Kink. viemins Walk. camelus n. sp. intrimatius n. S]'.

Rhinomiridius n. gुen. aethioprieus n. sp.

Cylapus Say.

tennieornis siay. famularis Stal. stellatus Dist. Alfr. oce.: Ferando-Po;
Franz. Conso; Camerun.

Ins. Mentawes: Siloban, sipura.

Simmatra: Si-Rambé

Pulo Laut (sec. Kirk.); C'arin Cheba!, Ihutan: Ma1.ia Bazti!, Perlong!.

Ins. Nentawei: Si-Oban. Sipora, Sereinu.

Tonkin: Tuyen-guan.

U. S. Alner.

Mexico.

Guatemala: San Juan. ('ubilcuitz. maryinieollis Dist. Panana: Vulc. Chirinui. Bugalua.

cretieus list. Panana: Bugaha.

cerlereus Iist.

stygits list.

strintus Reut.

politus n s!r. nohilis n. sp. schönheri Stål. mulilus Dist. muyosus Dist. seutelluris n. sp. cluciromis n. sp. pieatus Dist.

Brasilia: Mimas (terais!, s. Catarina!;

Peru: Pachitea!. Brasilia: sita Catarina. Venezuela: Caracas. Brasilia: Rio Janeiro. Panama: ("hiringi. Guatemala: Senaliu. Eruador: Bucay. Peru: Sicuani. Panama: Bugraba.

\section{Vannins Dist.}

mbrovittutus Dist. Guatemala: Las Mercedes, Cerro Zunil; Panana: Chiriqui.

anmulicomis n. sp. Marlagasear: Ikongo. Grevis n. sp. N. Guinea: Simbang. crassicomis n. sp. Bolivia.

Vanniopsis n. žen. ruteserens n. sp. 


\section{Verbreitungstabelle der bekannten Fulviarien.}

Fulvidius n. gen.

punctatus n. sp.

('alin Chelsí.

Cylapofulvius n. gen.

punctatus n. 11.

yriseseens n. sp.

Neu-fruinea: Astrolabe Bai.

" , Noroka.

Bironiella n. gुen.

metallescens n. sp.

Peritropis Ulıler.

juvamians n. spl.

similis $\mathrm{n}$. $\mathrm{sp}$.

Java: Pengatengan.

Ins. Lingano: Bua-Bua, Malaconni.

saldacformis Uhler. Amer. Jor:. Penns!, Texas!, Guatemala: Livingston!, Tres Aguas!.

lewisi Dist. Ceylon.

unnulicornis n. sp. Nen-Guinea: Simbang. Astrolabe Bai, Kapakapa. lugubris n. sp. Malacea: Singapore.

Euchilofulvius n. gen.

tibialis n. sp.

Ins. Mentawei: Si-Oluan.

\section{Fulvius Stål.}

pullitues n. spr. brevicarnis Reut.

dimidiatus n. sp. flesticomis n. spl. subuitens $\mathrm{n}$. sp.

Nen-Guinea: Simbang. Ind. or.: Bhamo in Birna; Afr. oce.: Senegal; Congo, Libreville!; Gallia: Rouen!; Ind. oce.: Ins. St. Thomé, Ribeira Pal. ma!; Cuba: Cayamas!; Ins. Martinique!. Venezuela.

Ind. or.: Pulo-Penang.

Sunatra: si-Rambé.

Neu-Guinea: Bujakoni; Irs- ox:yrarmoiles Reut. Caucasus: Derbent, kilisa. bethopol; C'rin: Gursut': Graecia: Aetolia!; Valachia: Conana; Illyria: Domanovic; Gallia: Lyon!; Italia.

bifonestrutus n. s]). Lns. Mentawei: Sipora. bimuculutus n. sp. Neu-Guinea: Moroka. uniculor n. sp. Afr.: Togo.

nigricomis n. sp. Ins. Mentawei: Si-Oban; Ins. Engano: Bua-Bua. diveifer Reut. Ins. Pemba.

rariegatus ns. sp. Neu-Guinea: Simbang; Astrolabe Bai; Ins. Delacs; Ighibirei.

mrunneus Prov. Camada; Colorarto; Massiauhusetts; Baltimore; California mer; Washington DC!

stilletipemes Stal Brasilia.

hevelemenni Reut. An. bor.: Marylanit; Falls Ch. Ta..

quatristillatus Stal. Brasilia: Rio Janeiro; Petropolis!; S:ta Catarina!; Bolivia: - Prov. Sara! Cocharamba!; Venezuela: Corozal; Paraguay: Rio Monday!.

bredlini Rout. Brasilia: San Fransesco. hibirei; Fl. Paumomu; Astrolabe Bai; Ins. NJentawei: Sipora; Ins. Engano: Malaconni. bishistillutus sital. Brasilia: Rio Janeiro!; Blumenau!; Guatemala: Cacao!; Costa-Rica: San Carlos!; Grenada!; Guadeloupe!; Panama? $\quad(=$ (ulhomaculatus Dist.).

brumeiceps n. sp. Paraguay: Alto Parana; Brasilia: Bella-Vista.

dulius Rent. utratus Dist.

Venezuela: Colonia Towar. Guatemala; Ins. Grenada; Amer. bor.

sulmuculutus n. sp. Ins. Guadeloupe. fuscuns 1)ist. Guatemala; Panama. simillimus n. sl. Bolivia. 
unthororvaldes Stil. Mexico; (thatemalal; Panama.

lumulutus Uliler. Ins. Grenada.

Rhinofulvius Reut. ${ }^{2}$

allifions Rent." ) Arabia mer.: Aden?
Ceratofulvius lient. ${ }^{3}$ )

claricomis Reut. $\left.{ }^{*}\right)$ Australia: Victora.

Trichofulvius n. gen.

fusciatus n. sp. Neu-Guinea: Ighibirei.

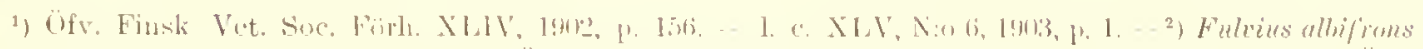

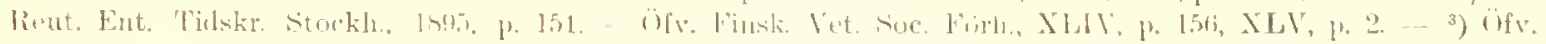

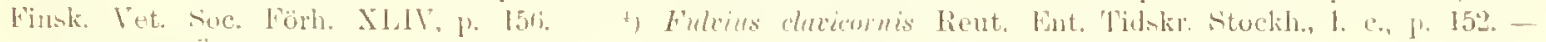

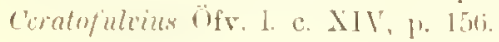

\section{Allgemeine Bemerkung.}

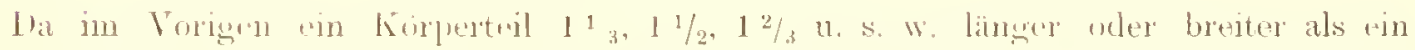

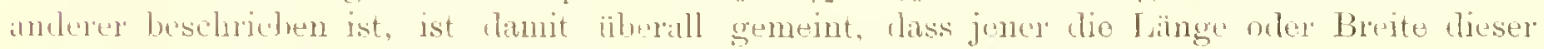

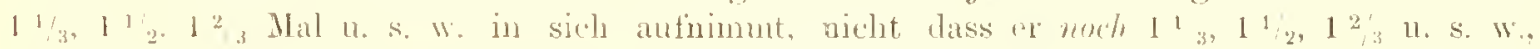

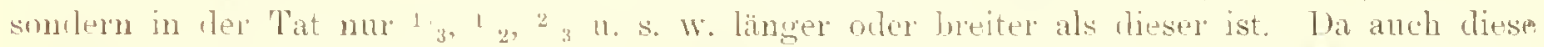
letøter: Bezuchnungsweise melunals angewemlet worken ist, finde ich, um Missdentungen zu rermeiden, nötig den Lesirn hiraut ansilrïckich aufmerlisam zu mitchen. 


\section{Tafelerklärung.}

1-1 a. Marligliuniu cunealis n. gen. et. sp.

2-2a. Rhinocylupus simplicicollis n. zuen. et sp.

3-3a. Khinomividius acthiopicus n. gen. et sp.

1-1 a. cylapas clavicomis n. sp.

5-ba. Timmiopsis rufescens n. gen. et sy.

6. Fulvillus punctatus n. gen. ot sp.

7-7 a. Cylupofulvims punctutus n. wen. ot su.

8-s a. Enchilofibloms tibialis n. gen, et sy.

9. Futvine pallihlus n. sp).

10-10 a. Trichofulvius firsciutus n. gon. ot sp. 

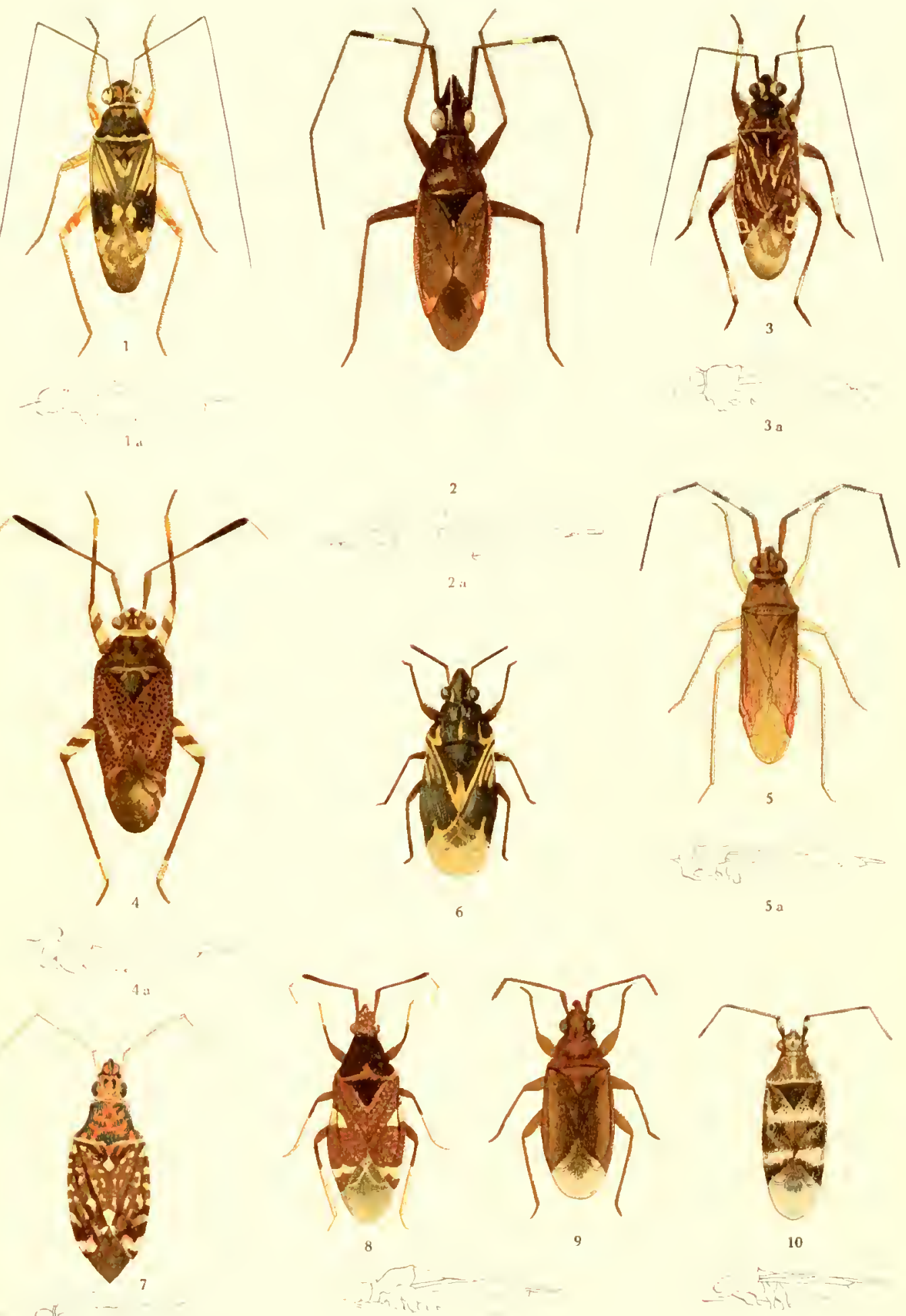

$10 \mathrm{a}$ 





\section{$=$}

AYLORD BROS. Ine.

Syracuse, N. Y.

Stochton, Cslif. 
SMITHSONIAN INSTITUTION LIBRARIES 